DOI:10.5465/amd.2019.0190

\title{
Constructing safety: Reconciling Error Prevention and Error Management in Oil \& Gas and Petrochemicals Operations
}

\author{
Charles Cowley \\ Cranfield University \\ College Road, Cranfield MK43 0AL, Bedfordshire \\ United Kingdom \\ Tel: $+44(0) 1234751122$ \\ Fax: +44 (0)1234 751806 \\ charles.cowley@cranfield.ac.uk \\ charlescowley51@gmail.com \\ David Denyer \\ Cranfield University \\ david.denyer@cranfield.ac.uk \\ Elmar Kutsch \\ Cranfield University \\ elmar.kutsch@Cranfield.ac.uk \\ Kim Turnbull James \\ Cranfield University \\ k.james@cranfield.ac.uk
}

\section{Acknowledgement}

The authors are grateful for the sponsorship of the Energy Institute who gave financial support and practical help in gaining access to carry out the fieldwork.

There is also a SUPPLEMENT to this article containing additional supporting information, accessible online in the Additional Materials section. 


\title{
CONSTRUCTING SAFETY: RECONCILING ERROR PREVENTION AND ERROR MANAGEMENT IN OIL \& GAS AND PETROCHEMICALS OPERATIONS
}

\begin{abstract}
On the basis of a qualitative study of three different operational oil and gas and petrochemical sites, in the Middle East, Asia-Pacific and Europe, we examine how actors construe error prevention and error management and how they reconcile these approaches in their everyday practice. Our repertory grid data reveal that actors recognise the importance of error prevention, but also appreciate that emergent and unexpected issues require error management in order to trap, address or mitigate problems in the making. Errors are also regarded to play an important role in adaptation, innovation and learning. However, our interview data and analysis of incident investigation reports reflect a narrower range of factors and indicates a strongly institutionalised predisposition towards error prevention. There are practical implications for the management of process safety and for incident analysis, which may be overlooking the importance of error management, and also for individuals at the sharp end who may be coping with the gap between what they believe is important in terms of process safety and what they bring to the surface, share and document.
\end{abstract}

Keywords: errors, error prevention, error management, safety, process safety, paradox

(There is also a SUPPLEMENT to this article containing additional supporting information, accessible online in the Additional Materials section.)

\section{INTRODUCTION}

Actions undertaken in organizations are error-prone. Most errors are prevented before potential effects materialise, others are managed to mitigate loss, but some result in negative consequences. Drawing on a growing body of research on errors in organizations (Van Dyck et al., 2005; Frese and Zapf, 1994; Goodman et al., 2011; Hofmann and Frese, 2011; Lei, Naveh and Novikov, 2016; Reason, 1990; Zapf, Prumper and Frese, 1992), we define action errors as "unintended deviations from plans, goals, or adequate feedback processing, as well as incorrect actions resulting from lack of knowledge" (Frese and Keith, 2015: 689). Action errors differ from violations, which are intentional deviations from goals, plans, and standards, whereas action errors are unintended (Frese and Keith, 2015). Error research distinguishes between error prevention and error management (Frese and Keith, 2015; Hofmann and Frese, 2011). 
The error prevention (EP) perspective is underpinned by a belief that errors are harmful and damaging and must be eliminated at all costs (Frese and Keith, 2015). Whereas the error management (EM) perspective assumes that it is neither possible nor desirable to eradicate action errors in organizations because they play an important role in adaptation, innovation and learning (Hofmann and Frese, 2011). Despite a growing body of literature on errors (Goodman et al., 2011; Hofmann and Frese, 2011; Lei, Naveh and Novikov, 2016), there are theoretical and practical limitations.

Firstly, much of the existing 'errors' literature has been conceptual or positivist in approach (Lei, Naveh and Novikov, 2016). Few existing studies pay attention to how actors perceive EP and EM. Positivist errors research typically regards EP and EM as something more or less determined and given, which can be conceptually represented by a set of variables causally related to each other (Abbott, 2001). Interpretative (Burrell and Morgan, 1979) and qualitative (Johnson et al., 2006) studies are required to explore how actors construe EP and EM and how various meanings interact and lead to both actions and organizational outcomes. This is important because, from an interpretative paradigm (Burrell and Morgan, 1979), meaning is constitutive of organizational phenomena (Sandberg and Alvesson, 2020). Without understanding the meaning of EP and EM, we cannot recognize and observe EP and EM in practice. To address these issues, our first research question is: how do actors construe EP and EM in their attempts to avert and mitigate adverse organizational consequences?

Secondly, some errors scholars have argued that EP and EM can occur concurrently (Goodman et al., 2011; Hofmann and Frese, 2011; Lei, Naveh and Novikov, 2016) and that integration and balance of EP and EM is necessary and desirable (Vogus and Sutcliffe, 2007). For example, in their analysis of the Air France 447 disaster, Oliver, Calvard and Potočnik (2017) 
propose that organizations adopt "strategies that allow controls to be designed into systems while also developing and maintaining the disturbance-handling capabilities of those who operate them". The work on high reliability organizations highlights the need for the ability to integrate, balance and shift between prevention and adaptation (Weick and Sutcliffe, 2006). Despite calls for the integration of the high-reliability concept and error management theory (Frese and Keith, 2015), as noted above, the specific ways to achieve such an integration and balance of EP and EM in real organizational settings remains under-explored (Goodman et al., 2011). This motivates our second research question: how do actors enact, reconcile and integrate EP and EM approaches in their attempts to avert and mitigate adverse organizational consequences?

Thirdly, the performance of EP and EM and their possible integration is shaped by context. EP dominates in some contexts and in others EM prevails, but existing theory does not fully explain this variability. When people act, they "bring events, structures, constraints, and opportunities that were not there before they took action into existence and set them in motion" (Weick, 1988: 306). The results in our third question: how do particular contexts shape EP and EM?

To address our research questions, in what follows we review the research literature on error prevention and error management and then present three qualitative data sets obtained from the operational sharp end of three separate oil and gas and petrochemical sites in a single multinational company. Data were obtained using Repertory Grid interviews (Kelly, 1955), semistructured interviews and incident investigation reports. Finally, we discuss how the findings address our research question and the implications for theory and practice.

\section{Error Prevention and Error Management}

The error prevention (EP) perspective is underpinned by a belief that errors are negative and must be contained and prevented at all costs (Hofmann and Frese, 2011). From this perspective, there 
is zero-tolerance of errors (Frese and Keith, 2015) because their effects quickly escalate and ramify (Weick, Sutcliffe and Obstfeld, 1999), propagate (Reason, 1997), and cascade into component and system failure (Perrow, 1984). The ultimate goal of EP is the creation of 'fail-safe' system designs for 'error free' performance (Goodman et al., 2011) by means of employing multiple-defensive layers, including engineered safeguards, procedures and other administrative controls (Reason, 1990, 2000).

A primary goal of EP is to reduce human error (Goodman et al., 2011) and eradicate error precursors - conditions that provoke error. Human error can arise from individuals' unfamiliarity with the task, lack of knowledge or 'unsafe' attitudes. To prevent errors it is important to more or less "control" the behavior of organizational participants by ensuring compliance with norms, rules, and procedures (Carroll, 1998), so that deviations from organizationally-specified goals and standards (Hofmann and Frese, 2011) are eliminated. EP also focuses on removing error precursors in the work environment, such as distractions, ineffective layout, poor access, confusing displays or signage, or situations where speed overrules quality (Lei, Naveh and Novikov, 2016) and also from task demands such as competing priorities, high workload, time pressure (Reason, Parker and Lawton, 1998).

In contrast to EP, the EM perspective assumes that it is neither possible nor desirable to eradicate errors in organizations. EM assumes that unexpected threats will emerge that cannot be planned for and prevented, so there will always be a need to improvise and recombine knowledge and resources to cure or catch and correct problems in the making (Reason, 1990). EM is required for swift reaction to surprises (Edmondson, Bohmer and Pisano, 2001; Staw, Sandelands and Dutton, 1981), flexible responses to novel events (Hofmann and Frese, 2011), adjusting positively and bouncing back from challenging conditions and learning from errors (Hofmann and Frese, 
2011; Lei, Naveh and Novikov, 2016). The idea that EM is required in order to enable rapid, flexible response (Lei, Naveh and Novikov, 2016) is evident in the literatures on high reliability organizations (La Porte, 1996; Roberts, 1990; Weick, Sutcliffe and Obstfeld, 1999) and resilience engineering (Hollnagel, Woods and Leveson, 2006). This literature suggests that EM requires flexibility and adaptive practices in service of making 'things go right' (Hollnagel, 2014).

The EM perspective holds that humans are understood to provide a positive contribution towards organizational resilience (Hollnagel, Woods and Leveson, 2006) by addressing design flaws (Rasmussen, 1997) and 'seeing and fixing', responding to and containing problems (Sutcliffe and Vogus, 2003), without knowing in advance what one will be called to act upon (Wildavsky, 1988). Error management practices emphasize 'situation awareness' (Endsley, 1999), 'expert improvisation' (Hale and Borys, 2013; Hollnagel, 2014; Leveson, 2011; Rego and Garau, 2007), vigilance and attentiveness (Weick, Sutcliffe and Obstfeld, 1999), mindful organising (Weick and Sutcliffe, 2006), dispersion of decision making (Roberts, Stout and Halpern, 1994), deference to expertise (Weick and Sutcliffe, 2006), organizational evolution to circumstances (Rochlin, La Porte and Roberts, 1987), variety to map the uncertainty (Roberts, 1990), and bricolage (Sutcliffe and Vogus, 2003; Weick, Sutcliffe and Obstfeld, 1999). The primary goal of these practices is "the primary intention of promoting the welfare of the organization or one of its stakeholders" (Morrison, 2006: 6).

EM not only helps to mitigate potential negative organizational consequences or damage control but it also enhances positive effects, such as learning and innovation (Frese and Keith, 2015). Innovation and change necessarily generate errors while trying to discover successes (Edmondson and Lei, 2014; Hofmann and Frese, 2011). Organizations can maximise the learning from accidents, incidents and near misses (Leveson et al., 2009) when they treat errors as windows 
that reveal the status and health of the system (Weick and Sutcliffe, 2001) and can contribute to the process of collective mindfulness (Weick, Sutcliffe and Obstfeld, 1999). Learning from errors is said to be enhanced when people are reluctant to simplify explanations (Weick and Sutcliffe, 2001) and have the ability to create new categories, openness to new information, and awareness of more than one perspective (Langer, 1989).

\section{Methods}

Our study design was guided by our concern for capturing actors lived experiences of EP and EM. We recognised that the EP and EM labels were unlikely to be used by practitioners. We needed complementary methods with would reveal the perceptions, constructs, meaning making, and practices that our research question requires. We used three established research methods for uncovering these. First, we used Repertory Grid Technique (Kelly, 1955) to ascertain how actors conceptualise the practices that contribute to the prevention and mitigation of adverse incidents. Second, we used semi-structured interviews to examine the practices that support or impede process safety. Third, we drew on official documented reports to ascertain organisationally sanctioned accounts of the practices and conditions that contribute to incidents. The three datasets helped us to examine different types of incident (actual, near miss and potential) in three different oil and gas and petrochemical sites within a single multinational company.

\section{Selection of cases}

Access to the oil and gas and petrochemical sites in the multinational company was facilitated by both the project funder and a key contact in the host organization. The lead researcher in the project team had spent over 30 years working in the oil and gas and petrochemical industry (but had not worked at any of the sites included in this study). The oil and gas and petrochemical industry is an example of a hierarchical, rule-based industry that has traditionally had a focus on 'process safety' with a strong emphasis on error prevention and that has only in recent years acknowledged the 
need for error management (Baker et al., 2007; Flin, Wilkinson and Agnew, 2014; HSE PSLG, 2009).

In discussion with the key contact and global and regional managers we selected three operational sites with varying records of success in avoiding major incidents like fires, explosions or toxic releases: Site A, a large recently-constructed petrochemicals complex in the Middle East, which was in transition from project-based to operations-based, had recently suffered a number of process safety incidents, including some fatalities; Site B, a rapidly-expanding oil and gas onshore operation in the Asia-Pacific region with a large number of geographically dispersed wells and production units feeding an export facility, was chosen as informants felt there would be opportunities for learning since it had suffered a number of fires, explosions and well blowouts and also some near misses and potential incidents that could have had very serious consequences; and Site C, an offshore oil and gas operation in Europe, had recently won the company's award for process safety performance and had been in operation for over 20 years with no major process safety incidents in recent years. A more detailed description of the fieldwork sites is provided in the SUPPLEMENT to this article. The research design enabled a cross-site comparison of EM and EP.

\section{Three sources of data}

We interviewed a total of 73 respondents using Repertory Grid Technique and the semi-structured method. A manager at each site nominated by the main contact in the host company helped to identify suitable interviewees. Our focus was people working at the 'sharp end'; operator/technicians, shift supervisors, engineers and managers directly involved in plant operations and maintenance. Some interviewees worked in the design, construction and renovation of the sites and some for contractors. The interviewee sample obtained is shown in Table 1. 
Insert Table 1 about here

Due to interviewee time constraint or unavailability of incident information, some interviews were unable to include the Repertory Grid (of the total 73 interviews, 55 included a Repertory Grid). However, Pareto analyses (Goffin and Koners, 2011; Micheli et al., 2012) indicate high confidence that data saturation was achieved (see Figure SUP-3 in the SUPPLEMENT). A third source of data comprised 194 reports and documents obtained from the three sites, relating to 117 incidents. $81 \%$ of the incidents discussed by interviewees had a corresponding incident report. It was not possible to ascertain whether the remaining $19 \%$ of incidents mentioned by respondents had not been investigated by the organisation or the reports had not been archived.

Data Set 1: Repertory Grids. Repertory Grid Technique was chosen for this research because it is considered a powerful and adaptable tool that can "help respondents articulate their views on complex topics without interviewer bias" (Goffin, 2002: 199). A Repertory Grid interview explores how the respondent makes sense of a particular topic, by eliciting "just those constructs which the person uses in making sense of that particular realm of discourse - that particular slice of their experience" (Jankowicz, 2004: 12).

The technique is based on Kelly's (1955) Personal Construct Theory, which holds that people make sense of the world by observing and construing meaning from experiences, and that their own individual meaning of such a 'personal construct' is made clear by comparing it with its opposite, or 'pole'. For example, a person may construe a situation as "normal operation" and describe the opposite 'pole' as "situation never seen before". This latter, the 'pole', helps explicate the person's intended specific meaning of the construct. Thus, the technique uncovers the ways 
the person constructs their experience in a way that would not emerge so clearly in interviews which often do not explore both the ways things are and how they are not.

The interviews proceeded by asking the interviewee to compare three examples ("triads") that relate to the topic of interest and to think of ways they may be similar to or different from each other. A number of different triads were selected in turn by the interviewer from a set of examples ("elements") agreed between the interviewer and the participant as being relevant to the topic.

We asked each participant to come to the interview prepared to discuss two examples, with which they were personally familiar, of each of three types of incidents: "actual incidents" with real consequences, "near misses" and "potential incidents". Our assumption was that EP and EM practices might vary by event type. To help participants prepare, we sent them a pre-interview briefing note that included industry established definitions of the three different incident types. The incident type definitions and a more detailed description of the Repertory Grid interview technique are provided in the SUPPLEMENT.

The process elicited a number of constructs that together represent the respondent's repertoire of ideas they consider important about a specific topic (Jankowicz, 2004). Finally, the respondent was asked to rate each incident on the scale from construct to pole (from 4 to 1 ) according to the extent that the construct applied to the incident. This resulted in a matrix - the repertory grid (Figure 1). The horizontal axis of the grid is formed of the agreed set of elements (i.e., the 6 incidents), the vertical axis is formed of the list of constructs that have emerged in the interview, and the matrix cells contain the participant's ratings of each element along the constructpole scale. The grid was analysed to extract meaning relating to the individual interviewee's understanding, and when put together with other peoples' grids, patterns of common understanding of a group of people can be determined (Tan and Hunter, 2002). 
Insert Figure 1 about here

The repertory grid that we obtained from each interview summarised the participant's personal views about the unfolding of the incidents, in the form of a set of personal constructs, together with ratings indicating how much the participant considered each construct applied to each incident. We collated the repertory grids from the 55 interviews into a spreadsheet, together with explanatory quotes extracted from the interview transcripts to obtain fuller descriptions of the meaning of each construct.

Analysis of Repertory Grid data. To help control for potential researcher bias in the analysis of the data, a one-day data workshop was run with two pairs of researchers working independently. Each pair comprised one experienced academic faculty member and a “knowledgeable practitioner" as suggested by Miles and Huberman (1994: 38). To prepare for the workshop, two identical sets of cards were produced, printed with the wording of the construct and its pole, an explanatory quote and the construct reference number and the site.

Following a similar process to Goffin and Koners (2011), the two pairs worked in separate rooms to code the constructs, sorting them into categories that each team established and defined independently. After the workshop, the two sets of categories were compared in a "reliability matrix". An extract from the final reliability matrix is given in Figure SUP-2 in the SUPPLEMENT.

The initial comparison of the two teams' categorisation yielded a commonality ratio (Goffin et al., 2012) of only $40 \%$. The majority of the inconsistency was due to definitional clarity issues (Jankowicz, 2004). In most cases the two research teams agreed on the meaning of constructs but had assigned different labels. A second round of re-categorisation improved the 
commonality ratio to $85 \%$ which exceeded the suggested $80 \%$ criterion (Miles and Huberman, 1994).

This data validation and first step of analysis sorted the 135 individual constructs into a total of 17 categories. These categories and their definitions are shown in Table 2, together with descriptions of the construct - pole scales indicating the sense of the construct used by participants. We derived these by analysing the descriptive phrases extracted from the interview transcripts and converting them into 'word clouds' to facilitate the wording of each definition and construct - pole scale description. Also included in Table 2 are example illustrative quotes from the interviews, which we used to help further interpret and classify each of the 17 construct categories under the headings of EP, EM and Context. We further divided both EP and EM groups into either 'management practices' that are typically enacted by managers and 'working practices' enacted at the operational working level, typically by operator/technicians.

\section{Insert Table 2 about here}

Our rationale for classifying the construct categories as EP or EM was derived from our understanding of the literature. To help us classify, we summarised our understanding of the two paradigms in Table SUP - 5. From this understanding of the two paradigms, we classed the construct categories that were largely concerned with eradication of error precursors as EP, those largely concerned with detection, coping with and learning from errors we classed as EM and those that related to contextual factors, we classed as 'Context'.

Classifying some construct categories as EP or EM in this manner was relatively straightforward: 'Risk Assessment' 'Equipment Design' 'Competence', 'Procedures', 'Supervision' and Compliance', were easily classified as EP because they were directly concerned 
with eradication of error precursors. However, classifying some other construct categories demanded more thought. For example, we determined the construct category 'Escalation to Hierarchy' as meaning that problems were referred up the hierarchy for resolution, in contrast to the 'HRO' characteristic of 'deference to expertise', so we interpreted this as fitting within the EP paradigm. In a similar manner, the construct categories of 'Incident Investigation and Analysis' 'Detection' 'Mitigation' and 'Organizational Learning' were interpreted as aligning with the EM paradigm. The construct category 'Emergency Response' was understood as meaning action taken to mitigate ('whatever is necessary...') rather than the planning stage, so that too aligned with the EM paradigm.

The remaining constructs were more challenging to classify as EP or EM and required more detailed analysis including independent coding, inter-coder reliability checks and reference to the existing literature (see Table SUP-5). For example, 'Vigilance' could be classified as EP since it could be understood as contributing to Compliance, but working closely with the interview extracts we concluded that it is a contributor to situation awareness and Sensemaking, so was classified as EM. Following a similar approach, the construct category 'Communication' was understood from the interview extracts as the informal 'non-technical skill' that includes "Speaking up at meetings and...Listening" and "Being assertive ... Skills for the exchange (transmission and reception) of information, ideas and feelings, by verbal (spoken, written) or nonverbal methods" (Flin, Wilkinson and Agnew, 2014: 10-14) which aligns with the EM paradigm. Similarly, again by examining the interview quotes, 'Checking Challenge and Follow-up' was interpreted in the sense of "intervention by a second person" (Frese and Keith, 2015: 666) so was classified as EM. Finally, 'Work Pressure' was classed as neither EP nor EM but as a contextual factor or error precursor, as defined earlier. 
Sorting the data into the 17 categories of construct gives a broad description of how participants think about the events discussed in the interviews, and clearly some categories seem more important because they occurred more frequently. However, a high frequency "can also indicate that a construct was obvious, and therefore readily mentioned" (Goffin, Lemke and Szwejczewski, 2006: 200). Relying on frequency alone could thus give a misleading result. So, in Repertory Grid analysis another measure of importance is often used, alongside frequency: the variability of the construct ratings given by participants. If a construct has a wide variability of element ratings compared with those of other constructs within a grid, this strong differentiation between the elements and can be taken as a measure of its high importance to the interviewee, (Kelly, 1955; Rogers and Ryals, 2007). Using a combination of both frequency and variability thus gives a more realistic assessment of the relative importance of constructs to the participants.

As commonly used by others (Goffin, Lemke and Szwejczewski, 2006; Lemke, Clark and Wilson, 2011) the measures we used for frequency and variability of each construct category were 'percentage unique frequency' (\%UF) and 'average normalised variability' (ANV). The \%UF represents the proportion of interviewees with an individual construct within that category; 'unique' meaning that if more than one of a participant's constructs were in a category, only one was counted. The ANV measures the relative variability of the ratings of a particular construct compared with the overall variability of all the ratings in a particular interviewee's grid, normalised for the different numbers of constructs in the set of grids and finally averaged over all the occurrences of constructs in a category.

To calculate the ANV of a construct category we first calculated the variability of the ratings of each individual construct within that category, as the 'percentage Total Sum of Squares' (\%TSS) of the construct within its grid. This is "the percentage of the total Sum of Squares 
computed for the entire grid... reported for each construct" (Grice, 2002: 340). This calculation was done using the specialist repertory grid software Idiogrid (Grice, 2002). We then normalised this value for the different numbers of constructs in the whole set of grids and finally averaged it over all the occurrences of constructs in the category.

Again following the approach used by others (Goffin, Lemke and Szwejczewski, 2006; Raja et al., 2013) we then determined the constructs of particular importance to the participants ('key constructs') by establishing criteria for both \%UF and ANV. Goffin et al (2006: 200). They note that "The frequency count necessary for identifying important constructs is left open for interpretation in the repertory grid literature" and they chose criteria that selected only those constructs in the top 50 percentile of each of the two measures, \%UF and ANV, i.e., those at or above the median. We adopting a similar approach, selecting as 'key constructs' only those whose values of \%UF and ANV were both in the 'top half' of the set of construct categories under consideration.

Our analysis considered three such sets: first, to gain an overall view, the complete set of all the Repertory Grids, second, seeking patterns that may provide insight, we analysed the grids by incident type ('actual', 'near miss' and 'potential incident', which were the 'elements' in the Repertory Grids) and third, again seeking patterns that may reveal differences linked with context, we compared and contrasted the different sets of grids obtained at the three sites A, B and C. Since the data sets were different in each site, the 'key' criteria were also different.

To determine those categories of construct of most importance to the whole participant population without differentiating between incident types or between sites, we established our 'key' criteria as a \%UF value of at least 10 and an ANV value of at least 38, these figures being the median values of each measure for the complete data set. For the analysis based on incident 
types, the grid data was separated out for each incident type in turn. Each of these incident-typespecific data sets comprised all participants, so the same \%UF key criterion applied, but the ANV values were re-calculated for each reduced grid, so a type-specific ANV key criterion was also necessary. For the site-based analysis, only the grids from each site were used, so site-specific key criteria for both \%UF and ANV were recalculated. The results of applying these key criteria to determine the construct categories of most importance to the participants, in overall terms and analysed by incident type and by site, are given in Table 3, marked as $\mathrm{Y}$ in the Key column, and highlighted.

Insert Table 3 about here

Data Set 2 - Semi-structured interviews. The semi-structured interviews commenced with a series of open-ended questions designed to elicit information about the practices used to avoid, trap or mitigate errors and their consequences. Relevant follow-up questions were used to build a deeper understanding of the interviewees' views about the dynamics of preventing and managing error.

Analysis of Semi-Structured interview data. We started analysing the interview transcripts by analysing a sample of the interviews to create an initial coding template (Miles and Huberman, 1994) and then as the analysis continued, using NVivo 12 software and following a process described by Walsh and Bartunek (2011) we developed the template coding model, iteratively comparing segments of the interviews with it. In this way, we created from the interview transcripts a list of 63 first-order codes, 44 being factors that were either supporting EP and EM processes and 19 that were impeding them. The relative frequency of mention by interviewees are shown on the left-hand side of Table 4, analysed into supporting or impeding, and by site, A, B or C. 
Continuing with the Walsh and Bartunek (2011) process we then pursued a cycle of abductive and retroductive reasoning, informed by the existing literature on EP and EM and also by comparing the data with the findings of the Repertory Grid interviews.

We grouped the first-order factors into 19 second-order theoretical categories. These are in the right-hand side columns of Table 4, which show the average proportion of interviewees mentioning a constituent factor within a category, allowing direct comparison of the frequency of mention at each site. We ranked these figures in a similar way as was done in the Repertory Grid study, and chose the categories in the 'top half' of this ranking as being of most interest. These are shown highlighted.

Insert Table 4 about here

The classification of the 19 theoretical categories as EP or EM followed the same rationale and method that we used for the Repertory Grid constructs. We examined the coded segments of interview transcripts to guide us in this, comparing them with the EP and EM paradigms described earlier. Examples of these illustrative interview quotes are given in Table 5 (this is an extract: the complete table is in the SUPPLEMENT as Table SUP-3). Those concerned with systematic elimination of error precursors we classed as EP and those concerned with detecting, mitigating and learning from errors we classed as EM. The further distinction between those practices enacted at the management level and those at the operational working level was made by examining the wording of the constituent first order codes to identify who was involved in enacting the particular practices.

Insert Table 5 about here 
An example of the distinction between 'supporting' and 'impeding' first-order actors is seen in how risk management was discussed by participants: As Table 4 shows, there were 5 interviews at site $\mathrm{C}$ that mentioned the 'supporting' factor of 'Processes for risk management' and only one that mentioned the associated 'impeding' factor of 'Cumbersome risk bureaucracy'. These factors were both put into the theoretical category of 'Risk Management' which was classified as EP. In another example, at site A there were 6 interviews that mentioned the supporting factor of 'Clarifying expectations and responsibilities' and 7 that mentioned the associated 'impeding' factor of 'Authoritarian over-directing'. Both of these factors were put into the theoretical category of 'Planning and Resourcing' and classified as EP.

There is some overlap between the 17 categories of Repertory Grid constructs and the 19 theoretical categories that emerged from the Semi-Structured interviews, but also some differences. This is to be expected since the focus of the Repertory Grid study was on comparing the three different types of incident, with the analysis done in an essentially grounded process; the guiding topic of Semi-Structured study was organizational practices, and although the analysis was partially informed by the results of the Repertory Grid study, the initial template was developed in a grounded manner.

We took two steps to verify the trustworthiness of our findings. First, we asked a researcher who was not familiar with our initial findings to code two of the interview transcripts as a means to assess interrater reliability. Overall, the agreement rate was $80 \%$ percent, which is deemed acceptable (Miles and Huberman, 1994). We also checked systematically for data saturation by examining the cumulative number of codes identified from each interview. This procedure revealed that the last nine interviews yielded no new codes (see Figure SUP-4 in the SUPPLEMENT) 
Data Set 3 - Incident Documents. 194 documents relating to 117 incidents were obtained from the three sites, mainly 'Incident Reports' containing basic descriptions of the incident and more detailed 'Incident Investigation Reports' containing findings about causes and recommendations for avoiding future incidents.

Analysis of Incident Documents data. Following a similar process as used for the analysis of the semi-structured interviews (Walsh and Bartunek, 2011), we starting by analysing a sample of the incident documents to create an initial coding template using NVivo, and as we progressed through the large number of documents we refined the template into two lists: 'Causal Factors' and 'Recommendations'. The relative frequency of mention in the documents was measured as unique frequency per incident, since some incidents were described in more than one document, and some documents repeated the same factor. These numbers were then averaged to give the proportion of each incident type per site. The two lists are shown in Tables $6 \mathrm{a}$ and $6 \mathrm{~b}$

Insert Tables $6 \mathrm{a}$ and $6 \mathrm{~b}$ about here

Using the same approach as for both the Repertory Grid data and the semi-structured interview data, we were able to group the Causal Factors and Recommendations abductively into 12 second-order theoretical categories, whose relative frequency of mention was a simple sum of the unique frequencies of their constituent factors. A Pareto analysis gave some confidence that theoretical saturation was achieved (see Figure SUP-5 in the SUPPLEMENT). Check coding was done by an independent researcher; inter-coder reliability of $80 \%$ was achieved, which is deemed acceptable (Miles and Huberman, 1994).

Both the sets of Causal Factors and Recommendations were also classified as EP or EM, following the same rationale and method as before, examining the coded segments of incident 
documents and comparing them with the EP and EM paradigms, and also distinguishing between management and working practices within both EP and EM. Examples of these illustrative quotes from the incident documents are given in Table $7 \mathrm{a}$ and $7 \mathrm{~b}$ (these are extracts - the full tables are in Table SUP-4a and Table SUP-4b in the SUPPLEMENT.)

Insert Tables $7 \mathrm{a}$ and $7 \mathrm{~b}$ about here

The way we classified Recommendations as EP or EM should be noted: Whilst any learning from an investigation could be inferred as EM since EM implies a learning process, in this study we have instead assessed the Recommendations according to the objective of the recommendation - whether it is to reinforce EP or improve EM. For example, the objective of a recommendation such as 'Improve procedures or other tech. documents' is to reinforce the existing procedures, which are by nature EP. So this recommendation would be classed as EP. The reasoning here was that whilst recommendations from incident investigations are of course learning opportunities and on the surface might be all be classified as EM, many of the recommendations called for reinforcement of EP and not for adaptations or a rethinking of how different processes and operations could be in future Therefore, recommendations were analysed as either EP or EM depending on the underlying issue they are addressing.

The summary results of the Incident Documents study (Tables 6a and 6b) show an overwhelming preference to identify EP issues rather than EM. This is addressed further in the Discussion. To identify the most frequently occurring theoretical categories of Causal Factors and Recommendations we performed a ranking of the normalised unique frequencies, and chose the categories in the 'top half' of this ranking, similarly to the other studies. These are highlighted in Tables $6 \mathrm{a}$ and $6 \mathrm{~b}$. 
There is some overlap between the Repertory Grid constructs, the theoretical categories from the Semi-Structured interviews and the two sets of Causal Factors and Recommendations that emerged from the Incident Documents study. A comparison of the most important results ('top half' of the ranking) of all three studies was made and is summarised in Table 8 (See Discussion)

\section{Findings}

Repertory Grids The findings of the Repertory Grid interviews help to explain how actors conceptualise the practices that contribute to the avoidance and mitigation of adverse consequences and those that they perceive to cause accidents. The construct definitions and results are presented in Table 2.

Overall View of EP and EM. The left-hand columns of Table 3 show the 17 construct categories that emerged as important from the overall analysis of the Repertory Grids from all three sites (as described in the Methods section). Firstly, it can be seen that they divide clearly into EP, EM and one contextual category of 'Work Pressure' and that the number in EP and EM is fairly evenly balanced at 7 and 9 respectively, with slightly more in EM than EP. Secondly slightly more EM construct categories (4 compared with 2 for EP) were determined to be 'key', that is, of particular importance to the interviewees. This gives an indication that, overall, the interviewees construed both EM and EP approaches as important, with a slight preference for EM.

Differences between Incident Types. The middle group of columns in Table 3 show the results of analysing the repertory grid data separately for each incident type, actual, near miss and potential incident. The aim was to examine whether or not actors used different constructs to differentiate these three event types. We were surprised by the similarity in how people construed the three incident types: 'Compliance' (EP), 'Incident Investigation and Analysis' (EM) and 'Work Pressure' (Context) were 'key' construct categories for all incident types. However, some 
differences can be seen: 'Detection' and 'Sensemaking' (both EM) only appear as 'key' for Potential Incidents, while 'Escalation to Hierarchy' (EP) appears as 'key' only for (which are similar types of incident, the difference often being just luck). This is unsurprising as the identification of Potential Incidents is dependent on 'Detection' and 'Sensemaking', and when Actual Incidents and Near Misses do occur, it is expected that they would be reported up the organization's hierarchy.

Differences between Sites. The right-hand group of columns in Table 3 show the results of analysing the repertory grid data separately for each site, A, B and C, to examine whether actors at the different sites construed the relative importance of EP and EM in different ways. The balance between EP and EM constructs was quite different for each site. Out of 7 constructs determined as 'Key' for Site A, only 3 were EM, while for Site B, 5 out 9 key constructs were EM. Finally, it is striking that for Site C, all 6 out of 6 key constructs were EM. The context of 'work pressure' can also be seen as 'Key' for only Sites A and B and not Site C. The apparent importance of EM practices for the Site $\mathrm{C}$ respondents is particularly notable, since Site $\mathrm{C}$ was recognised by key informants within the company as having had the best safety outcomes.

Comparing across sites raises the possibility of a confound between differences between sites and types of interviewee. We analysed the coded extracts from the interviews and found any differences between the coded categories were not attributable to level in the organization. This is likely because although the interviewees were at different levels of hierarchy, they were all working very close to the sharp end of operations, maintenance and engineering.

Comparing these two different analyses, a correspondence is seen between the EM approach both with the better outcome of Potential Incidents and also with the better safety outcomes of Site C, while the EP approach can be seen to be more closely associated both with 
Sites A and B and also with both Near Miss and Actual Incidents. A possible interpretation is that the EM approach is more successful in detecting system weaknesses (Potential Incidents) before they can incubate into Actual of Near Miss incidents.

A possible explanation for the small number of constructs appearing in the Repertory Grids for Site $\mathrm{C}$ is that people on this site were focussing on what they perceived as the most important ideas. That all these constructs were of an EM nature may support this view; the EP aspects of procedures, compliance, competence and risk assessment perhaps being taken for granted. An analogy could be that of a sports coach focussing on a small number of aspects to improve, rather than giving a complete description of everything that someone would need to perform well and are already doing.

Semi-Structured Interviews The semi-structured interviews help to explain how actors reconcile EP and EM in their everyday practice. Illustrative quotes from the interviews are given in Table SUP-3 in the SUPPLEMENT and the results are summarised in Table 4.

Respondents from both Site A and B reported organizational constraints such as inadequate resourcing, unclear responsibilities and change fatigue. Site B interviews made numerous mentions of production pressure. A Site B Engineer noted "Everybody wants now, tomorrow, day after, very short-term and medium-term focused." Site C was reported to have a more open, trusting culture with a lower threshold for expressing views and reporting issues. By contrast, Site A interviewees made frequent mention of blame culture as illustrated by a Site A Supervisor "if I say like this, then there will be a lot of finger pointing, then we end up missing actually what caused this one".

At Site $\mathrm{C}$ there was a greater emphasis on both EP and EM than at the other two sites. Around a third of interviewees at Site $\mathrm{C}$ reported EP practices of planning and resourcing and a 
norm of compliance as 'supporting' factors and a quarter similarly mentioned technical competence. In stark contrast, planning and resourcing and procedures were mentioned as 'impeding' factors by a third and a quarter of respondents respectively at Site A. As one respondent at Site C noted "I think it's very experienced personnel in the control room. The operators, I think they know the hazards very good'.

Site $\mathrm{C}$ respondents made many more mentions of 'supporting' EM practices than those at the other sites, for example over a third at Site $\mathrm{C}$ mentioned encouraging improvement, compared with a fifth at Sites A and B. Also at Site C a third of respondents mentioned the contextual condition of structure and maturity as supportive, while both Sites A and B mentioning this as 'impeding'.

At Site A, respondents described cumbersome risk management processes. A manager at Site A commented, "if I look at the incidents, it's not that we didn't spot the hazard and we didn't put a whole bunch of controls on it but we may have actually overloaded the work crew". Interviewees at Site B indicated similar factors impeding effective EP: “...we're a long way from where we need to be. The procedures that we've got in the business are one task fits all..." (Site B supervisor).

A significant difference across the sites was in relation to the EM practices of mindful compliance and questioning, strong response to a weak signal, and teamworking to solve problems. These factors together were mentioned by almost half of the respondents at Site $\mathrm{C}$ but only $10 \%$ and $8 \%$ respectively at Sites $\mathrm{A}$ and $\mathrm{B}$. Site $\mathrm{C}$ interviewees also reported building situation awareness, building capacity for improvisation, supporting risk awareness but these factors were barely mentioned at the other two sites. A Site C manager commented "We have quite 
a lot of potential incidents, and I think that's a good thing, because potential incidents tell me as a leader that we actually notice it".

We observed how EP and EM practices were successfully entwined, particularly at Site C, where EM was being clearly viewed as a collaborative approach. The modification of a procedure to suit actual working conditions was always discussed. There was a network of 'technical authorities' for specific subjects who were routinely consulted by operations and maintenance staff, often informally by phone or video link, with decisions frequently being agreed there and then, and sometimes requiring technical studies. Work started with the EP practices of using effective procedures with technical competence and a norm of compliance. During the work, EM practices of mindful compliance and questioning and supporting risk awareness were also followed. Whenever a system weakness was identified, this triggered EM practices of strong response to a weak signal, building situation awareness and teamworking to solve problems, resulting in a technical solution, supported by the EM practice of deferring to expertise. Finally, the technical solution was implemented, and the (EP) procedure was modified.

The management practices found to be most associated with this effective entanglement of the two approaches were sensemaking/sensegiving, engaging \& supporting workers, supporting formal networks and supporting informal networking. Contextual conditions were also important. At Site $\mathrm{C}$ the low threshold and accessible leaders were seen as providing a supportive environment in which the interplay of these practices could flourish.

In terms of practices, sensemaking and challenging assumptions were mentioned by around a third of interviewees at sites A and B but, interestingly, was mentioned by fewer participants (20\%) at Site C. A Site B manager indicated this may be because leaders in sites B and A needed to help people understand process safety hazards in their work because "they had never 
experienced anything any different and they've never been educated around process safety risks...". A very significant difference between the three sites was enabling rule-following AND competent improvisation, which was mentioned by almost half the respondents (48\%) at Site C but only 5\% at Site A. A manager at Site C commented "You're complying but then you are professional enough to know when you have to deviate and then it's smarter to deviate than actually just following the rule. I think that's part of the organization knows that...”.

Improvisation is of course a contentious issue in the context of process safety incidents, in a sector that puts a premium of rule adherence. However, the improvisation process observed at Site C, described above, was collaborative, deliberately involving the requisite expertise (formally empowered in the form of nominated 'technical authorities') to decide how to deviate safely in a particular situation. Competence to improvise is thus understood as organizational competence, also relying on individual mindful questioning, to avoid 'mispliance' (Reason, Parker and Lawton, 1998: 295).

Incident Documents The analysis of the incident documents helps to explain how actors' personal experiences of EP and EM compare with formal accounts published in incident reports. Illustrative quotes extracted from the incident documents are given in Tables SUP-4a and SUP-4b in the SUPPLEMENT (extracts from these are given in Tables $7 \mathrm{a}$ and $7 \mathrm{~b}$ ). The summary results of coding the documents are shown in Table $6 \mathrm{a}$ (Causal Factors) and Table $6 \mathrm{~b}$ (Recommendations). The left-hand side of Tables $6 \mathrm{a}$ and $6 \mathrm{~b}$ lists first order Causal Factors and Recommendations identified in the documents, analysed by type of incident and by site. These are then grouped on the right-hand side of these tables into the second-order 'Theoretical Categories'. The relative frequency of mention of these categories is shown by the 'Totals for Theoretical Categories' 
figures, which are the totals of the normalised unique frequencies of the constituent codes of each category, analysed by incident type and site.

The results show that the causal factors identified and the recommendations made in these formal documented reports overwhelmingly reflect the EP approach, which contrasts with the importance given by the interviewees to the interplay of EP with EM. This bias towards EP is borne out by the quotes from the incident documents. For example, 'Inadequate Procedures' was a very frequent causal factor identified in incident documents at both Site A: 'Method statement and JSA (Job Safety Analysis) lacking appropriate work method detail and associated hazard controls' and Site B: 'The Work Instruction assigned to the job added limited value and more importantly did not relate the critical components of the work scope', and many recommendations were to improve procedures: 'add new step in maintenance procedure: to stroke test valves in the field after installation to confirm actuator is moving freely' (Site A report) and 'New procedure to facilitate the depressurizing of the Piping ex. the discharge XV's to fin fan rack' (Site B report).

Production pressure occurred as a frequent causal factor in reports from all three sites in statements such as 'Time pressure resulted in Area 1 mech supervisor executing the work himself instead of searching for different support personnel' (Site A report) 'more focussed with production / cost saving initiatives than asset integrity. Concern was explicitly voiced that these fires are continually occurring' (Site B report) and 'Operator stressed to complete job within the night shift and stressed by weather conditions (heavy rains, papers wet), which caused the decision to break the isolation plan' (Site C report). These extracts from the incident documents emphasise the overall major EP focus in the incident documents, both on causal factors and recommendations.

A similar, though slightly different, pattern is seen for the recommendations (Table 6b): although only minor variation in the proportion of EM recommendations is seen across incident 
types, across the sites there are more differences: At Site A less than a fifth of recommendations were EM, Site B just over $10 \%$, while almost a third of the recommendations made at Site C were EM in nature. For example: 'To avoid future similar incidents Projects /Asset to share practices between Platform and Onshore plant and possibly agree one leading practice' and 'Giving a problem statement, a solution or an action will probably not shift your belief. Giving you insights and understanding on what caused the problem will' (both quotes from Site C reports). The Site $\mathrm{C}$ reports made proportionally many more recommendations than either Site A or Site B in the categories of 'Organizational Learning' (between 3 and 5 times as many), 'Compliance' (between 2 and 5 times as many) and 'Planning \& Resourcing' (between 2 and 3 times as many). These cross-site comparisons are interesting because of Site C's better perceived safety performance.

\section{Discussion and contributions}

A comparison of the findings from the three studies is presented in Table 8, which enables us to compare and contrast three key aspect of our data: a) the three incident types, b) the three data sets and c) the three sites.

Insert Table 8 about here

Comparing and contrasting the three incident types Our initial assumption was that potential incidents might emphasise error prevention and near misses could emphasise error management practices that were taken to stop a hazard from leading to significant consequences. However, Table 8 shows that there is little difference between how respondents construe event types. Actual incidents are, in the oil \& gas and petrochemicals industry, typically recorded, reported to government safety regulators and investigated to find system weaknesses that can be corrected in an attempt to avoid recurrence of such an incident. Because by definition no 
consequences result from potential incident and near misses and few regulators demand reporting of near miss incidents, their identification is more problematic than Actual Incidents (Phimister et al., 2003; Van Der Schaaf and Kanse, 2004). Thus although they may be observed by people working in operations or maintenance, they are more easily ignored or covered-up (Lawton and Parker, 2002) so may not be identified within an organization's incident management processes, or there may be a lack of 'organizational commitment to ensure that such lessons are remembered' (Hopkins, 2010: 62).

Many organizations operating high hazard technology in developed countries do recognise the potential value of near misses for learning about system weaknesses and therefore have internal management processes that encourage or even demand that Near Miss incidents are reported internally and investigated, although they may not be implemented as rigorously as for Actual Incident. Potential Incidents also have the potential for revealing 'latent conditions' and 'active failures' (Reason, 1990, 2016, 1997). The fact that respondents provided important insights about EP and EM when discussing all three events types, suggests that there are opportunities for organizations to learn about errors by examining potential incidents and near misses as well as actual incidents.

Comparing and contrasting the three data sets Table 8 shows the construct categories that emerged from the Repertory Grid analysis determined as the most important ('Key') by participants, below that the most frequent factors that emerged from the analysis of the semistructured interviews, and below that, the most frequent factors that emerged from the analysis of the incident documents analysis. There is some overlap between the 17 categories of Repertory Grid constructs and the 19 theoretical categories that emerged from the Semi-Structured interviews, but also some differences. These differences are to be expected since we intentionally 
treated them as separate datasets and later compared and contrasted the findings. The rationale was to ascertain whether or not there were differences between how individuals construe events and organisationally approved accounts in the form of official documents. The focus of the Repertory Grid study was on comparing the three different types of incident, with the analysis done in an abductive process; the guiding topic of Semi-Structured study was management practices associated with EP and EM, and although the analysis was partially informed by the results of the Repertory Grid study, the initial template was also developed in an abductive manner, and this approach was repeated for the analysis of the incident reports.

Table 8 portrays the distribution of the key factors that emerged from the three studies. The Table shows that the repertory grid technique identified 'hidden' meaning, or a 'deeper' meaning than is directly shared in the interviews or documented in the incident reports. The repertory grid interviews show that participants hold a broad array of constructs about both EP and EM, which they regard as important, but during the interviews, respondents discussed a much narrower range of EP practices that support process safety. The analysis of incident reports shows an even narrower range of constructs and are heavily skewed toward EP.

The 'causes' and recommendations resulting from the incident investigations were almost exclusively EP in nature (rather than EM) perhaps reflecting the more 'acceptable' discourse of prevention and the traditional 'rule-following' and 'command and control' paradigm prevalent in high hazard industries. Incident investigations often suffer from 'hindsight bias' (Dekker, 2011) and focus on finding and fixing problems "rather than to challenge deep assumptions with rigorous and systemic thinking..." (Carroll, 2002: 124). This is particularly so since recommendations emanating from incident reports are shaped by current institutionalised industry guidance. The absence of EM from incident reporting may sometimes even be deliberate, since 'organizational 
learning is a political process shaped by the interpretations and interests of competing stakeholders...' who may seek to reinforce the existence of EP to 'protect themselves from scapegoating by producing their own event narratives' (Buchanan and Denyer, 2013: 213).

Comparing and contrasting the three sites Acknowledging the potential existence of other unobserved site differences, a cross-site comparison does enable us to make some tentative observations about the influence of context on EP and EM and the effect on organizational outcomes: First, for Sites A and B, many more EM practices are seen as important in the Rep Grid study than in either the Semi-Structured interviews or the Incident Documents studies. Second, for Site A, there are no EM management practices seen as 'key' in any of the studies. We suggest that organizational contextual conditions provide possibilities for some actors to discuss EM and the integration with EP but constrain others. Actors are subject to normative pressures and cognitive constraints to embrace practices regarded as appropriate or legitimate (Greenwood, Suddaby and Hinings, 2002; Suddaby and Greenwood, 2005, Scott, 1994: 74). The oil and gas sector is naturally highly procedural with a strong focus on conformity and compliance, increasing the likelihood that actors will frame discourses to resonate with established interests and values.

We suggest that responding to the organization's expectations narrows the range of constructs people choose to discuss, creating a gap between what people believe is important in terms of process safety and what they are willing bring to the surface, share and document. This was the case at Site A and to some extent Site B, where there appears to be a stronger organizational emphasis on EP. Only at Site C did respondents feel able to discuss the virtues of EM, such as expert improvisation, problem solving, change and learning. At Site $\mathrm{C}$, we find that the perceived confidence, consistency and control afforded by established and effective EP. At Site C, respondents reported leadership, a supportive environment and a strong learning orientation as key 
elements that stimulated reflection and productive dialogue about the interplay of EP and EM, which in practice required time and encouragement to develop.

Our study is not without limitations. Whilst an interpretative and fine-grained research approach to studying errors - such as studying a single multi-national organization - is important for developing new theory, we recognize the limitations of such an approach. Although we consider that the characteristics of the three sites were described sufficiently to differentiate them, the descriptions are inevitably incomplete and other information about process safety practices, outcomes and culture at the three sites would add to this picture. We also recognise that categorisation of constructs, practices and other factors as either EP or EM can be challenging and open to interpretation. To overcome this we independently coded the data and performed an assessment of inter-coder reliability. We have explained our rationale in the analysis sections for each of the three data sets, but accept that other interpretations are possible.

Although we guarded against bias, as in any qualitative research, that concern remains. Specifically, for the Repertory Grid study, we acknowledge that limitations include some missing data points in some repertory grids, some doubtful distinction between the types of event by some interviewees, the small average number of constructs that were obtained per interview, and that the imbalance across sites of number and type of interviewees. Although we claim no statistical significance or correlation for the differences so analysed, some clear associations have been suggested between the process safety outcomes of the sites and both the broad theoretical dimensions that emerged from the analysis and some of the first and second-order codes that were obtained from the interview data. But the causal direction and mechanisms underlying these associations is not well understood; the greater focus on EM at site C may have led to the better 
outcomes, or such outcomes may allow more opportunity to focus on EM compared with the other sites where the occurrence of major indents may be forced to focus on EP.

Caution should of course be exercised in interpreting the generalizability of these associations. Yet this opens the possibility for some compelling research opportunities when we think about the integration of EP and EM and organizational outcomes. Further empirical analysis, involving larger samples and quantitative methods to examine the relationship between error prevention and management and safety outcomes would be a fruitful direction for future research. Qualitative Comparative Analysis (Fiss, 2007; Ragin, 1987) is another obvious next step to build on our exploratory work with other new studies to examine the configuration of EP and EM variables and their interrelationships and how these affect organizational outcomes. Recognising that Repertory Grid technique is not in common use in organizational research, the novel use in this study to compare event types offers a flexible, focused and highly contextualized abductive process with much potential value to researchers in management and organization studies. Other high hazard industries such as rail, nuclear power and commercial aviation also combine a traditional highly procedural approach with error management (Cacciabue, 2005; Helmreich, 2000; IAEA, 2013) allowing some potential for comparisons and avenues for future research.

\section{Conclusions}

This study addresses three interrelated questions that address theoretical and practical challenges apparent in the literature on errors in organisations. Firstly, the study reveals how actors construe $\mathrm{EP}$ and EM in their attempts to avert and mitigate adverse organizational consequences. As we have shown in this paper, much of the existing 'errors' literature refers primarily to antecedents or errors and error coping strategies (Lei, Naveh and Novikov, 2016) with sparse attention to how actors perceive EP and EM and how they can be integrated. 
Existing errors research is conceptual or tries to explain EP and EM by examining regularities among variables. Our empirical investigation of the interplay of EP and EM is interpretative (Burrell and Morgan, 1979) and qualitative in character (Johnson et al., 2006). The study has enabled an exploration of the underlying meanings behind EP and EM practices from the respondent's 'point of view'. We suggest that the repertory grid technique helped participants to become aware of their implicit constructs, which included EM constructs, yet in discussing incidents during the semi-structured interviews respondents tended to focus on EP, perhaps in an attempt to convey what they would like others to think they do. Thus, our study reveals an important mismatch between the error constructs that people think are important and the practices that they are willing to share and document. The importance actors ascribe to the value of EM challenges traditional, institutionalized views and the singular preoccupation with EP in many organizations.

Secondly, our study reveals how actors enact, reconcile and integrate EP and EM approaches in their attempts to avert and mitigate adverse organizational consequences. The errors literature tends to emphasize EP, which our findings suggest underplays the importance of EM in achieving organizational outcomes such as process safety. The findings from this study support previous work (Hofmann and Frese, 2011; Lei, Naveh and Novikov, 2016; Frese and Keith, 2015) suggesting that EP is a more 'natural' response than EM only and therefore there is seldom an organizational choice between EP or EM but typically a choice between EP alone or the combination of EP and EM. Drawing on the work on tensions and paradox in organizational settings (Clegg, da Cunha and e Cunha, 2002; Lewis, 2000; Lewis and Smith, 2014; Milosevic, Bass and Combs, 2018; Smith and Lewis, 2012; Zhang et al., 2015) our overall conclusion is that EP and EM should not be regarded as separate opposites (Lewis and Smith, 2014) with an 
'either/or' choice that is related to context, but are fundamentally interdependent—contradictory but also mutually enabling.

Our study has implications for the management of process safety and incident investigation processes, which may be overlooking the importance of EM to process safety, and also for individuals at the sharp end who may be coping with the gap between what they believe is important in terms of process safety and their willingness to bring to the surface, share and document EM. Managers should learn to expect both errors and unexpected situations and see these as opportunities to enact EM rather than as an indication of poor EP. Organisations need to encourage reflection and productive dialogue about the role and value of EM. Our finding that anxiety about EM may create defensive responses, highlighting the need for psychological safety to help people feel both comfortable with and responsible for discussing and enacting EM (Edmondson and Lei, 2014).

Thirdly, in examining errors in three different oil and gas and petrochemicals sites the research shows how particular contextual conditions can shape EP and EM. There are practical implications for organisations which may be overlooking the importance of EM to process safety. While organisations within these industries primarily engage in relatively prescriptive and routine activity, they can also suddenly encounter novel, unprecedented challenges. In contexts requiring rapid adaptation, existing systems, procedures and routines can unravel, disrupting the organization. Destabilizing conditions require flexibility and improvised behaviors (Cornelissen, Mantere and Vaara, 2014; Weick, 1988; Weick, Sutcliffe and Obstfeld, 1999; Weick and Sutcliffe, 2007) and more fluid approaches to collective action (Uhl-Bien, Marion and McKelvey, 2007). It is therefore unsurprising that in the repertory grid data respondents acknowledged the importance of supplementing rigid EP with more fluid EM. However, a loss of stability may stimulate anxiety 
and create defensive responses that can impede the required response and adaptation. We believe that respondents' reluctance to bring to the surface, share and document EM, despite acknowledging its importance in the repertory grids, reveal a deeply held, institutionalised belief that EM may result in a loss of control and instability, also generating anxiety and producing defensive responses. In order for the organizational discourse to widen to include more EM practices there needs to be clear expectations that EM work is acceptable, authorised and valued.

\section{REFERENCES}

Abbott, A. (2001) Time Matters: on Theory and Method. Chicago: University of Chicago Press. Baker, J., Leveson, N., Bowman, F. and Priest, S. (2007) The report of the BP US refineries independent safety review panel.

Buchanan, D.A. and Denyer, D. (2013) 'Researching Tomorrow's Crisis: Methodological Innovations and Wider Implications', International Journal of Management Reviews, 15(2), pp. 205-224.

Burrell, G. and Morgan, G. (1979) Sociological Paradigms and Organisational Analysis. London: Routledge.

Cacciabue, P.C. (2005) 'Human error risk management methodology for safety audit of a large railway organisation', Applied Ergonomics, 36(6 SPEC. ISS.), pp. 709-718.

Carroll, J.S. (1998) 'Organizational Learning Activities in High-hazard Industries: The Logics Underlying Self-Analysis’, The Journal of Management Studies, 35(6), p. 699.

Carroll, J.S. (2002) 'Learning from Experience in High Hazard Organizations', Research in Organizational Behavior, 24, pp. 87-137.

Clegg, S.R., da Cunha, J.V. and e Cunha, M.P. (2002) 'Management Paradoxes: A Relational View', Human Relations, 55(5), pp. 483-503.

Cornelissen, J.P., Mantere, S. and Vaara, E. (2014) 'The contraction of meaning: The combined effect of communication, emotions, and materiality on sensemaking in the stockwell shooting', Journal of Management Studies, 51(5), pp. 699-736.

Dekker, S. (2011) 'The criminalization of human error in aviation and healthcare: A review', Safety Science, 49(2) Elsevier Ltd, pp. 121-127.

Van Dyck, C., Baer, M., Frese, M. and Sonnentag, S. (2005) 'Organizational error management culture and its impact on performance: A two-study replication', Journal of Applied Psychology, 90(6), pp. 1228-1240.

Edmondson, A.C., Bohmer, R. and Pisano, G. (2001) 'Speeding Up Team Learning.', Harvard Business Review, 79(9)

Edmondson, A.C. and Lei, Z. (2014) 'Psychological Safety: The History, Renaissance, and Future of an Interpersonal Construct', Annual Review of Organizational Psychology and Organizational Behavior, 1(1), pp. 23-43.

Endsley, M.R. (1999) 'Situation Awareness and Human Error : Designing to Support Human Performance', High Consequence Systems Surety Conference. 
Fiss, P.C. (2007) 'A Set-Theoretic Approach to Organizational Configurations', Academy of Management Review, 32(4), pp. 1180-1198.

Flin, R., Wilkinson, J. and Agnew, C. (2014) Crew Resource Management for Well Operations teams - Report No. 501.

Frese, M. and Keith, N. (2015) 'Action Errors, Error Management, and Learning in Organizations', Annual Review of Psychology, 66(1), pp. 661-687.

Frese, M. and Zapf, D. (1994) 'Action as the core of work psychology: A German approach', in Triandis, H. C., Dunnette, M. D. and Hough, L. M. (eds.) Handbook of Industrial and Organizational Psychology. Consulting Psychologists Press, pp. 271-340.

Goffin, K. (2002) 'Repertory Grid Technique', in Partington, D. (ed.) Essential Skills for Management Research. Sage Publications.

Goffin, K. and Koners, U. (2011) 'Tacit knowledge, lessons learnt, and new product development', Journal of Product Innovation Management, 28(2), pp. 300-318.

Goffin, K., Lemke, F. and Szwejczewski, M. (2006) 'An exploratory study of "close" suppliermanufacturer relationships', Journal of Operations Management, 24(2), pp. 189-209.

Goffin, K., Raja, J.Z., Claes, B., Szwejczewski, M. and Martinez, V. (2012) 'Rigor in qualitative supply chain management research', International Journal of Physical Distribution \& Logistics Management, 42(8/9), pp. 804-827.

Goodman, P.S., Ramanujam, R., Carroll, J.S., Edmondson, A.C., Hofmann, D.A. and Sutcliffe, K.M. (2011) 'Organizational errors: Directions for future research', Research in Organizational Behavior, 31, pp. 151-176.

Greenwood, R., Suddaby, R. and Hinings, C.R. (2002) 'Theorizing change: The role of professional associations in the transformation of institutionalized fields', Academy of Management Journal, 45(1), pp. 58-80.

Grice, J.W. (2002) 'Idiogrid: Software for the management and analysis of repertory grids', Behavior Research Methods, Instruments, and Computers, 34(3), pp. 338-341.

Hale, A. and Borys, D. (2013) 'Working to rule or working safely? Part 2: The management of safety rules and procedures', Safety Science, 55, pp. 222-231.

Helmreich, R.L. (2000) 'On error management: Lessons from aviation', British Medical Journal, 320(7237), pp. 781-785.

Hofmann, D.A. and Frese, M. (2011) Errors in Organizations. New York: Routledge/Taylor \& Francis Group.

Hollnagel, E. (2014) Safety-I and Safety-II. Aldershot: Ashgate Publishing Limited.

Hollnagel, E., Woods, D.D. and Leveson, N. (2006) Resilience Engineering: Concepts and Precepts. Aldershot: Ashgate Publishing Limited.

Hopkins, A. (2010) Failure to Learn. Sydney: CCH Australis Ltd. HSE PSLG (2009) Safety and environmental standards for fuel storage sites.

IAEA (2013) Managing Human Performance to Improve Nuclear Facility Operation.

Jankowicz, D. (2004) The Easy Guide to Repertory Grids. Chichester: Wiley.

Johnson, P., Buehring, A., Cassell, C. and Symon, G. (2006) 'Evaluating qualitative management research: Towards a contingent criteriology', International Journal of Management Reviews, 8(3), pp. 131-156.

Kelly, G. (1955) The psychology of personal constructs. Vol. 1. A theory of personality. Vol. 2. Clinical diagnosis and psychotherapy. Oxford: Norton.

Langer, E. (1989) Mindfulness. Cambridge, M: Da Capo Press. 
Lawton, R. and Parker, D. (2002) 'Barriers to incident reporting', Quality and Safety in Health Care, 11(1), p. 7.

Lei, Z., Naveh, E. and Novikov, Z. (2016) 'Errors in Organizations: An Integrative Review via Level of Analysis, Temporal Dynamism, and Priority Lenses', Journal of Management, 42(5), pp. 1315-1343.

Lemke, F., Clark, M. and Wilson, H. (2011) 'Customer Experience Quality: An exploration in business and consumer contexts using repertory grid technique', Journal of the Academy of Marketing Science, 39, pp. 846-869.

Leveson, N. (2011) Engineering a Safer World - Systems Thinking Applied to Safety. Cambridge, Massachusetts: The MIT Press.

Leveson, N., Dulac, N., Marais, K. and Carroll, J. (2009) 'Moving Beyond Normal Accidents and High Reliability Organizations: A Systems Approach to Safety in Complex Systems', Organization Studies, 30(2-3), pp. 227-249.

Lewis, M. (2000) 'Exploring Paradox: Toward a More Comprehensive Guide', Academy of Management Review, 25(41)

Lewis, M.W. and Smith, W.K. (2014) 'Paradox as a Metatheoretical Perspective: Sharpening the Focus and Widening the Scope', The Journal of Applied Behavioral Science, 50(2), pp. 127149.

Micheli, P., Jaina, J., Goffin, K., Lemke, F. and Verganti, R. (2012) 'Perceptions of industrial design: The "means" and the "ends", Journal of Product Innovation Management, 29(5), pp. 687-704.

Miles and Huberman (1994) Qualitative Data Analysis.2nd Editio. Thousand Oaks, CA: Sage Publications.

Milosevic, I., Bass, A.E. and Combs, G.M. (2018) 'The Paradox of Knowledge Creation in a High-Reliability Organization: A Case Study', Journal of Management, 44(3), pp. 11741201.

Morrison, E.W. (2006) 'Doing the job well: An investigation of pro-social rule breaking', Journal of Management, 32(1), pp. 5-28.

Oliver, N., Calvard, T. and Potočnik, K. (2017) 'Cognition, Technology, and Organizational Limits: Lessons from the Air France 447 Disaster’, Organization Science, 28(4), pp. 729 743.

Perrow, C. (1984) Normal Accidents: Living with High-Risk Technologies. Basic Books.

Phimister, J.R., Oktem, U., Kleindorfer, P.R. and Kunreuther, H. (2003) 'Near-miss incident management in the chemical process industry', Risk Analysis, 23(3), pp. 445-459.

La Porte, T.R. (1996) 'High Reliability Organizations: Unlikely, Demanding and At Risk.', Journal of Contingencies \& Crisis Management, 4(2), pp. 60-71.

Ragin, C.C. (1987) The Comparative Method. Oakland California: UCAL Press.

Raja, J.Z., Bourne, D., Goffin, K., Çakkol, M. and Martinez, V. (2013) 'Achieving customer satisfaction through integrated products and services: An exploratory study', Journal of Product Innovation Management, 30(6), pp. 1128-1144.

Rasmussen, J. (1997) 'Risk management in a dynamic society - A modelling problem', Safety Science, 27(2-3), pp. 183-213.

Reason, J. (1990) Human Error. Cambridge: Cambridge University Press.

Reason, J. (2000) 'Safety paradoxes and safety culture', Injury Control and Safety Promotion, , pp. 3-15.

Reason, J. (2016) Organizational Accidents Revisited. Farnham: Ashgate Publishing Limited. 
Reason, J., Parker, D. and Lawton, R. (1998) 'Organizational controls and safety: The varieties of rule-related behaviour.', Journal of Occupational and Organizational Psychology, 71(4), pp. 289-304.

Reason, J.T. (1997) Managing the risks of organizational accidents. Farnham: Ashgate.

Rego, L. and Garau, R. (2007) 'Stepping into the Void', Center for Creative Leadership.

Roberts, K.H. (1990) 'Some Characteristics of One Type of High Reliability Organization', Organization Science, 1(2), pp. 160-176.

Roberts, K.H., Stout, S.K. and Halpern, J.J. (1994) 'Decision Dynamics in Two High Reliability Military Organizations', Management Science, 40, pp. 614-624.

Rochlin, G., La Porte, T. and Roberts, K. (1987) 'The self-designing high-reliability organization: Aircraft carrier flight operations at sea', Naval War College Review, 40(4), p. 97.

Rogers, B. and Ryals, L. (2007) 'Using the repertory grid to access the underlying realities in key account relationships', International Journal of Market Research, 49(5), pp. 595-612.

Sandberg, J. and Alvesson, M. (2020) 'Meanings of Theory: Clarifying Theory through Typification', Journal of Management Studies

Van Der Schaaf, T. and Kanse, L. (2004) 'Biases in incident reporting databases: An empirical study in the chemical process industry', Safety Science, 42(1), pp. 57-67.

Scott, R.W. (1994) 'Institutions and Organizations: toward a Theoretical Synthesis', in Scott, W. R. and Meyer, J. W. (eds.) Institutional Environments and Organizations: Structural Complexity and Individualism. Thousand Oaks, CA: Sage Publications.

Smith, W.K. and Lewis, M.W. (2012) 'Leadership Skills for Managing Paradoxes', Industrial and Organizational Psychology, 5(2), pp. 227-231.

Staw, B., Sandelands, L. and Dutton, J. (1981) 'Threat-Rigidity Effects in Organizational Behavior: A Multilevel Approach', Administrative science quarterlySQ, (December)

Suddaby, R. and Greenwood, R. (2005) 'Rhetorical Strategies of Legitimacy', Administrative Science Quarterly, 50(March)

Sutcliffe, K.M. and Vogus, T.J. (2003) 'Organizing for resilience', Positive Organizational Scholarship: Foundations of a New Discipline, (October), pp. 94-110.

Tan, F.B. and Hunter, M.G. (2002) 'The Repertory Grid Technique: A Method for the Study of Cognition in Information Systems', MIS Quarterly, 26(1), pp. 39-57.

Uhl-Bien, M., Marion, R. and McKelvey, B. (2007) 'Complexity Leadership Theory: Shifting leadership from the industrial age to the knowledge era', The Leadership Quarterly, 18, pp. 298-318.

Vogus, T.J. and Sutcliffe, K.M. (2007) 'The Safety Organizing Scale’, Medical Care, 45(1), pp. 46-54.

Walsh, I.J. and Bartunek, J.M. (2011) 'Cheating the fates: Organizational foundings in the wake of demise', Academy of Management Journal, 54(5), pp. 1017-1044.

Weick, E. (1988) 'Enacted Sensemaking in Crisis Situations', Journal of Management Studies, 25(4)

Weick, K.E. and Sutcliffe, K.M. (2006) 'Mindfulness and the Quality of Organizational Attention', Organization Science, 17(4), pp. 514-524.

Weick, K.E. and Sutcliffe, K.M. (2001) Managing the unexpected: assuring high performance in an age of complexity. Jossey-Bass.

Weick, K.E. and Sutcliffe, K.M. (2007) Managing the unexpected: assuring high performance in an age of complexity. 2nd edn. San Francisco: Jossey-Bass. 
Weick, K.E., Sutcliffe, K.M. and Obstfeld, D. (1999) 'Organizing for High Reliability: Processes of Collective Mindfulness', in Research in Organizational Behavior, Volume 21. Stanford Jai Press, pp. 81-123.

Wildavsky, A. (1988) Searching for Safety. New Brunswick: Transaction Books.

Zapf, D., Prumper, J. and Frese, M. (1992) 'Errors in Working with Office Computers: A First Validation of a Taxonomy for Observed Errors in a Field Setting', International Journal of Human-Computer Interaction, 4(4), pp. 311-339.

Zhang, Y., Waldman, D.A., Lan Han, Y. and Bei Li, X. (2015) 'Paradoxical Leader Behavior in People Management: Antecedents and Consequences', Academy of Management Journal, 58(2), pp. 538-566.

Figure 1 Example Repertory Grid, showing Construct Categories

\begin{tabular}{|c|c|c|c|c|c|c|c|c|c|}
\hline \multirow[b]{2}{*}{ REF } & \multirow[b]{2}{*}{$\begin{array}{l}\text { CONSTRUCT } \\
\text { CATEGORY }\end{array}$} & \multirow[b]{2}{*}{ CONSTRUCT } & \multicolumn{6}{|c|}{ Elements } & \multirow[b]{2}{*}{ POLE } \\
\hline & & & $\mathbf{a}$ & b & c & d & e & $\mathbf{f}$ & \\
\hline & & & \multicolumn{2}{|c|}{ Actual } & \multicolumn{2}{|c|}{ Near-miss } & \multicolumn{2}{|c|}{ Potential } & \\
\hline 2.q.1 & SENSEMAKING & $\begin{array}{l}\text { process safety barriers understood } \\
\text { and good reporting of failures }\end{array}$ & 4 & 3 & 1 & 2 & 3 & 1 & $\begin{array}{l}\text { poor understanding of PS barriers } \\
\text { and poor reporting }\end{array}$ \\
\hline 2.q.2 & MITIGATION & reaction of isolate and make safe & 4 & 1 & 1 & 1 & 1 & 1 & $\begin{array}{l}\text { reaction of immediate fix and return } \\
\text { to service }\end{array}$ \\
\hline $2 . q .3$ & DETECTION & $\begin{array}{l}\text { proactive systematic identification } \\
\text { of barrier weaknesses }\end{array}$ & 4 & 4 & 2 & 1 & 3 & 3 & $\begin{array}{l}\text { reactive identification due to loss of } \\
\text { primary containment }\end{array}$ \\
\hline 2.q.4 & $\begin{array}{l}\text { EMERGENCY } \\
\text { RESPONSE }\end{array}$ & $\begin{array}{l}\text { organisational reaction of } \\
\text { independent deep investigation }\end{array}$ & 4 & 1 & 4 & 1 & 3 & 2 & local shallow investigation \\
\hline 2.9 .5 & DETECTION & engineered instrument detection & 1 & 1 & 3 & 4 & 4 & 4 & procedural human detection \\
\hline 2.q.6 & $\begin{array}{l}\text { RISK } \\
\text { ASSESSMENT }\end{array}$ & correct risk perception of hazard & 4 & 1 & 1 & 1 & 4 & 1 & low risk perception \\
\hline
\end{tabular}

Table 1 Populations sampled

\begin{tabular}{|l|l|c|c|c|c|c|c|}
\hline Job Type & Organizational level & \multicolumn{3}{|c|}{ Rep Grid Interviews } & \multicolumn{3}{|c|}{ Semi-structured Interviews } \\
\hline SITE & & A & B & C & A & B & C \\
\hline \multirow{4}{*}{ Ops/Maintenance } & Contractor & 7 & 0 & 0 & 8 & 0 & \\
\cline { 2 - 9 } & Operator/Technician & 3 & 1 & 0 & 4 & 0 & 1 \\
\cline { 2 - 9 } & Supervisor or Engineer & 3 & 13 & 1 & 2 & 17 & 6 \\
\cline { 2 - 9 } & Ops/Maint. Manager & 3 & 13 & 8 & 4 & 12 & 11 \\
\hline \multirow{5}{*}{ Design/Construction } & Contractor & 0 & 0 & 0 & 0 & 0 & 1 \\
\cline { 2 - 9 } & Operator/Technician & 0 & 1 & 0 & 0 & & \\
\cline { 2 - 9 } & Supervisor or Engineer & 0 & 0 & 0 & 0 & 2 & 0 \\
\cline { 2 - 8 } & Engineering Manager & 1 & 1 & 0 & 3 & & 2 \\
\cline { 2 - 8 } & Totals & $\mathbf{1 7}$ & $\mathbf{2 9}$ & $\mathbf{9}$ & $\mathbf{2 1}$ & $\mathbf{3 1}$ & $\mathbf{2 1}$ \\
\hline
\end{tabular}


Table 2 - Construct Categories from Repertory Grid Interviews

\begin{tabular}{|c|c|c|c|c|c|}
\hline \multirow{2}{*}{$\begin{array}{l}\text { Construct } \\
\text { Category }\end{array}$} & \multirow{2}{*}{$\begin{array}{c}\text { Illustrative Quotes from Rep Grid } \\
\text { interviews }\end{array}$} & \multirow{2}{*}{$\begin{array}{c}\text { Definition } \\
\text { (Element of EP / EM Strategy) }\end{array}$} & \multicolumn{2}{|c|}{ Construct - Pole Scale } & \multirow{2}{*}{$\begin{array}{l}\text { EP / EM } \\
\text { Category. }\end{array}$} \\
\hline & & & $\begin{array}{l}\text { Sense of } \\
\text { Construct }\end{array}$ & Sense of Pole & \\
\hline Risk Assessment & $\begin{array}{l}\text { So we knew we understood the risk. It was } \\
\text { just about how do you manage that risk }\end{array}$ & $\begin{array}{l}\text { Analysis of hazards and risks, } \\
\text { determining their probability and } \\
\text { consequences and considering how } \\
\text { they might cascade into component } \\
\text { and system failure. }\end{array}$ & $\begin{array}{l}\text { Proactive risk- } \\
\text { based } \\
\text { understanding of } \\
\text { hazards and } \\
\text { controls } \\
\end{array}$ & $\begin{array}{l}\text { Lack of } \\
\text { understanding - } \\
\text { missed opportunity } \\
\text { for mitigation }\end{array}$ & \multirow{6}{*}{$\begin{array}{l}\text { EP ORG. } \\
\text { PRACTICES }\end{array}$} \\
\hline $\begin{array}{l}\text { Equipment } \\
\text { Design }\end{array}$ & $\begin{array}{l}\text { No engineering controls over over-fill of } \\
\text { diesel tanks - manual operation }\end{array}$ & $\begin{array}{l}\text { Use of 'fail-safe' and ergonomic } \\
\text { equipment and system designs and } \\
\text { employing multiple-defensive } \\
\text { layers, including engineered } \\
\text { safeguards and controls, } \\
\text { maintenance and inspection. }\end{array}$ & $\begin{array}{l}\text { Lack of } \\
\text { engineering } \\
\text { controls; tolerance } \\
\text { of manual } \\
\text { operation }\end{array}$ & $\begin{array}{l}\text { Poor design; } \\
\text { unclear information }\end{array}$ & \\
\hline Competence & $\begin{array}{l}\text { They wouldn't have the same hydrocarbon } \\
\text { experience... that whole importance of } \\
\text { isolation etc is not so imbued and } \\
\text { inculcated... }\end{array}$ & $\begin{array}{l}\text { Assuring the requisite skill, } \\
\text { knowledge and experience to do } \\
\text { the job safely and effectively }\end{array}$ & $\begin{array}{l}\text { Trained, } \\
\text { experienced } \\
\text { competent people }\end{array}$ & $\begin{array}{l}\text { Untrained, } \\
\text { inexperienced } \\
\text { people, lacking in } \\
\text { competence }\end{array}$ & \\
\hline Procedures & $\begin{array}{l}\text { Operating procedures. Most of those being } \\
\text { in the control room, are control room } \\
\text { procedures. So there are a few field tasks in } \\
\text { there as well, so talking about the ones we } \\
\text { use most of the time...We've probably got } \\
\text { ten to twelve that we use regularly }\end{array}$ & $\begin{array}{l}\text { Formal work procedures and } \\
\text { administrative controls. }\end{array}$ & $\begin{array}{l}\text { Existence of } \\
\text { effective } \\
\text { procedures }\end{array}$ & $\begin{array}{l}\text { Lack of or } \\
\text { ineffective } \\
\text { procedures }\end{array}$ & \\
\hline Supervision & $\begin{array}{l}\text { We are always communicating with our } \\
\text { PTLs [Production Team Leaders] on some } \\
\text { grey areas, like am I even supposed to do } \\
\text { this? Then our supervisor will give us what } \\
\text { is supposed to be done. }\end{array}$ & $\begin{array}{l}\text { Those in authority and hierarchical } \\
\text { positions taking responsibility for } \\
\text { the work of others, issuing } \\
\text { instructions, and monitoring their } \\
\text { actions. }\end{array}$ & $\begin{array}{l}\text { Effective } \\
\text { supervision }\end{array}$ & Poor supervision & \\
\hline $\begin{array}{l}\text { Escalation to } \\
\text { Hierarchy }\end{array}$ & $\begin{array}{l}\text { We all say, as long as your line manager } \\
\text { approves, then it's good. So we understand } \\
\text { nothing bad happens.... With these two } \\
\text { cases, people talked to their line manager } \\
\text { and still things got screwed up. }\end{array}$ & $\begin{array}{l}\text { Escalation to those in authority and } \\
\text { hierarchical positions for making } \\
\text { key decisions. }\end{array}$ & $\begin{array}{l}\text { Reliance on } \\
\text { supervisor or line } \\
\text { manager approval }\end{array}$ & $\begin{array}{l}\text { Deference to } \\
\text { experts and } \\
\text { technical people } \\
\text { involved }\end{array}$ & \\
\hline
\end{tabular}




\begin{tabular}{|c|c|c|c|c|c|}
\hline \multirow{2}{*}{$\begin{array}{l}\text { Construct } \\
\text { Category }\end{array}$} & \multirow{2}{*}{$\begin{array}{l}\text { Illustrative Quotes from Rep Grid } \\
\text { interviews }\end{array}$} & \multirow{2}{*}{$\begin{array}{c}\text { Definition } \\
\text { (Element of EP / EM Strategy) }\end{array}$} & \multicolumn{2}{|c|}{ Construct - Pole Scale } & \multirow{2}{*}{$\begin{array}{l}\text { EP / EM } \\
\text { Category. }\end{array}$} \\
\hline & & & $\begin{array}{c}\text { Sense of } \\
\text { Construct }\end{array}$ & Sense of Pole & \\
\hline Compliance & $\begin{array}{l}\text { So I think for this one, the panel operator } \\
\text { followed the correct procedure. Actually } \\
\text { this guy, I think he did a good job. }\end{array}$ & $\begin{array}{l}\text { Ensuring compliance with } \\
\text { organizationally specified or } \\
\text { industry standards, norms, rules, } \\
\text { and procedures. }\end{array}$ & $\begin{array}{l}\text { Compliance with } \\
\text { organizationally } \\
\text { specified / industry } \\
\text { standards }\end{array}$ & $\begin{array}{l}\text { Non-compliance } \\
\text { with } \\
\text { organizationally } \\
\text { specified / industry } \\
\text { standards }\end{array}$ & $\begin{array}{c}\text { EP } \\
\text { WORKING } \\
\text { PRACTICES }\end{array}$ \\
\hline $\begin{array}{l}\text { Emergency } \\
\text { Response }\end{array}$ & $\begin{array}{l}\text { This one was a full-on emergency, so it got } \\
\text { all the response whatever you need... }\end{array}$ & $\begin{array}{l}\text { The immediate action of mitigation } \\
\text { of an unexpected event or } \\
\text { dangerous situation }\end{array}$ & $\begin{array}{l}\text { Emergency } \\
\text { response handled } \\
\text { by specialist } \\
\text { Emergency } \\
\text { Response Team }\end{array}$ & $\begin{array}{l}\text { Emergency } \\
\text { handled by } \\
\text { operators on site - } \\
\text { no specialist } \\
\text { Emergency } \\
\text { Response Team } \\
\end{array}$ & \multirow{3}{*}{$\begin{array}{c}\text { EM } \\
\text { ORG. } \\
\text { PRACTICES }\end{array}$} \\
\hline $\begin{array}{l}\text { Incident } \\
\text { Investigation } \\
\text { and Analysis }\end{array}$ & $\begin{array}{l}\text { Response was to involve an independent } \\
\text { person coming in to investigate }\end{array}$ & $\begin{array}{l}\text { Investigation and analysis of } \\
\text { negative incidents to learn and } \\
\text { prevent repetition }\end{array}$ & $\begin{array}{l}\text { Timely, rigorous } \\
\text { investigation and } \\
\text { analysis to learn } \\
\text { and prevent } \\
\text { repetition }\end{array}$ & $\begin{array}{l}\text { Ineffective } \\
\text { investigation and } \\
\text { analysis of } \\
\text { incidents }\end{array}$ & \\
\hline $\begin{array}{l}\text { Organizational } \\
\text { Learning }\end{array}$ & $\begin{array}{l}\text { Good learning: we've gone round put big } \\
\text { stickers on the valves to clarify tagging }\end{array}$ & $\begin{array}{l}\text { Acquisition, dissemination, and } \\
\text { implementation of knowledge or } \\
\text { skills through experience, post- } \\
\text { incident }\end{array}$ & $\begin{array}{l}\text { Effective learning } \\
\text { from experience } \\
\text { throughout the } \\
\text { organisation }\end{array}$ & $\begin{array}{l}\text { lack of or } \\
\text { misunderstanding } \\
\text { of incidents - } \\
\text { ineffective learning }\end{array}$ & \\
\hline Detection & $\begin{array}{l}\text { The isolation authority identified it 'cos it } \\
\text { had conflicting information attached }\end{array}$ & $\begin{array}{l}\text { Noticing signals, hazards, risks or } \\
\text { signs of an impending incident }\end{array}$ & $\begin{array}{l}\text { Noticing hazards as } \\
\text { an incident unfolds }\end{array}$ & $\begin{array}{l}\text { Failure to notice } \\
\text { hazards as an } \\
\text { incident unfolds }\end{array}$ & \\
\hline Vigilance & $\begin{array}{l}\text { We have very few actual incidents. We have } \\
\text { quite a lot of potential incidents, and I think } \\
\text { that's a good thing, because potential } \\
\text { incidents tells me as a leader that we } \\
\text { actually notice it [laughs]. And is aware } \\
\text { that, hey, here it could actually have } \\
\text { happened something, but it didn't, we } \\
\text { stopped it before it did, but we reported so } \\
\text { we can learn... }\end{array}$ & $\begin{array}{l}\text { Being alert to and mindful of } \\
\text { potential vulnerabilities and } \\
\text { potential problems }\end{array}$ & $\begin{array}{l}\text { Purposefully } \\
\text { looking for } \\
\text { vulnerabilities and } \\
\text { potential problems }\end{array}$ & $\begin{array}{l}\text { Overlooking } \\
\text { vulnerabilities and } \\
\text { potential problems }\end{array}$ & $\begin{array}{c}\text { EM } \\
\text { WORKING } \\
\text { PRACTICES }\end{array}$ \\
\hline
\end{tabular}




\begin{tabular}{|c|c|c|c|c|c|}
\hline \multirow{2}{*}{$\begin{array}{l}\text { Construct } \\
\text { Category }\end{array}$} & \multirow{2}{*}{$\begin{array}{c}\text { Illustrative Quotes from Rep Grid } \\
\text { interviews }\end{array}$} & \multirow{2}{*}{$\begin{array}{c}\text { Definition } \\
\text { (Element of EP / EM Strategy) }\end{array}$} & \multicolumn{2}{|c|}{ Construct - Pole Scale } & \multirow{2}{*}{$\begin{array}{l}\text { EP / EM } \\
\text { Category. }\end{array}$} \\
\hline & & & $\begin{array}{c}\text { Sense of } \\
\text { Construct }\end{array}$ & Sense of Pole & \\
\hline Sensemaking & $\begin{array}{l}\text { People will actually say, "Oh, we're not } \\
\text { certain about this anymore." Actually, } \\
\text { actively go out and seek that confirmation } \\
\text { rather than just blindly going ahead } \\
\text { because that's what the procedure says. }\end{array}$ & $\begin{array}{l}\text { Interpreting present conditions and } \\
\text { developing situational awareness of } \\
\text { plant and potential risks }\end{array}$ & $\begin{array}{l}\text { Situational } \\
\text { awareness and } \\
\text { understanding of } \\
\text { plant conditions } \\
\text { and potential risks }\end{array}$ & $\begin{array}{l}\text { Ineffective } \\
\text { recognition or } \\
\text { interpretation of } \\
\text { plant conditions } \\
\text { and potential risk }\end{array}$ & \\
\hline Communication & $\begin{array}{l}\text { We talk to each other so we know, "What } \\
\text { are you going to do today?" And in the } \\
\text { mechanical often needs help from us to } \\
\text { work together }\end{array}$ & $\begin{array}{l}\text { The interpersonal verbal and non- } \\
\text { verbal exchange and processing of } \\
\text { information relating to plant safety }\end{array}$ & $\begin{array}{l}\text { Effective } \\
\text { communication }\end{array}$ & $\begin{array}{l}\text { Poor } \\
\text { communication }\end{array}$ & \multirow{3}{*}{$\begin{array}{l}\text { EM } \\
\text { WORKING } \\
\text { PRACTICES }\end{array}$} \\
\hline $\begin{array}{l}\text { Checking } \\
\text { Challenge and } \\
\text { Follow-up }\end{array}$ & $\begin{array}{l}\text { So if he wouldn't have personally } \\
\text { intervened to do that situation, the line-up } \\
\text { was identical to the other incident we had, } \\
\text { we could have had a backflow.. So the } \\
\text { potential incident backflow, by intervention } \\
\text { of the operator we actually prevented that }\end{array}$ & $\begin{array}{l}\text { Intervention to challenge or } \\
\text { question the potential impact of a } \\
\text { decision, work method or situation, } \\
\text { including follow-up checking }\end{array}$ & Effective challenge & $\begin{array}{l}\text { Ineffective or no } \\
\text { challenge }\end{array}$ & \\
\hline Mitigation & $\begin{array}{l}\text { They completely stopped the job on site and } \\
\text { dealt with it... }\end{array}$ & $\begin{array}{l}\text { Individual or collective actions to } \\
\text { reduce the consequences of } \\
\text { incidents, including unplanned } \\
\text { actions }\end{array}$ & $\begin{array}{l}\text { Job stopped, } \\
\text { problem dealt with } \\
\text { and secured }\end{array}$ & $\begin{array}{l}\text { No or ineffective } \\
\text { action taken to } \\
\text { reduce the } \\
\text { consequences of } \\
\text { incidents }\end{array}$ & \\
\hline Work Pressure & $\begin{array}{l}\text { These two we had the 'hang on we're just } \\
\text { trying to get Train } 1 \text { running... keep } \\
\text { charging ahead. Nothing really stopped we } \\
\text { didn't shut down... rush rush... }\end{array}$ & $\begin{array}{l}\text { Tension or pressure on people } \\
\text { created by competing priorities, } \\
\text { time, productivity drivers and } \\
\text { targets, leading to shortcuts instead } \\
\text { of considered action }\end{array}$ & $\begin{array}{l}\text { Production and } \\
\text { schedule pressure } \\
\text { from line; rush and } \\
\text { stress }\end{array}$ & $\begin{array}{l}\text { No pressure or rush } \\
\text { from line; relaxed } \\
\text { environment }\end{array}$ & CONTEXT \\
\hline
\end{tabular}


Table 3 - Summary Results of Repertory Grid Analysis

\begin{tabular}{|c|c|c|c|c|c|c|c|c|c|c|c|c|c|c|c|c|c|c|c|c|}
\hline \multirow{3}{*}{ Construct } & \multirow{2}{*}{\multicolumn{3}{|c|}{ Overall }} & \multicolumn{7}{|c|}{ Incident Type } & \multicolumn{9}{|c|}{ Site } & \multirow{4}{*}{ EP / EM Category } \\
\hline & & & & \multirow{2}{*}{\begin{tabular}{c|} 
All \\
\%UF
\end{tabular}} & \multirow{2}{*}{\multicolumn{2}{|c|}{$\begin{array}{c}\text { AI } \\
\text { ANV KEY }\end{array}$}} & \multirow{2}{*}{\multicolumn{2}{|c|}{$\begin{array}{c}\text { NM } \\
\text { ANV KEY }\end{array}$}} & \multirow{2}{*}{\multicolumn{2}{|c|}{$\begin{array}{c}\text { PI } \\
\text { ANV KEY } \\
\end{array}$}} & \multicolumn{3}{|c|}{$\mathbf{A}$} & \multicolumn{3}{|c|}{ B } & \multicolumn{3}{|c|}{$\mathrm{C}$} & \\
\hline & $\%$ UF & ANV & KEY & & & & & & & & $\% \mathrm{UF}$ & ANV & KEY & $\%$ UF & ANV & KEY & $\%$ UF & ANV & KEY & \\
\hline Criteria for 'Key' & $\geq 10$ & $\geq 38$ & & $\geq 10$ & $\geq 33$ & & $\geq 26$ & & $\geq 28$ & & $\geq 13$ & $\geq 29$ & & $\geq 8$ & $\geq 38$ & & $\geq 11$ & $\geq 35$ & & \\
\hline Risk Assessment & 10 & 39 & $\mathrm{Y}$ & 10 & 47 & $\mathrm{Y}$ & 16 & & 33 & $\mathrm{Y}$ & 19 & 34 & $\mathrm{Y}$ & 8 & 41 & $\mathrm{Y}$ & 0 & 0 & & \\
\hline Equipment Design & 8 & 32 & & 8 & 8 & & 19 & & 33 & & 19 & 25 & & 4 & 38 & & 0 & 40 & & \\
\hline Competence & 8 & 26 & & 8 & 26 & & 48 & & 4 & & 13 & 22 & & 8 & 30 & & 0 & 0 & & $\begin{array}{l}\text { EP } \\
\text { EPZATION }\end{array}$ \\
\hline Procedures & 20 & 37 & & 20 & 12 & & 26 & Y & 31 & Y & 38 & 35 & Y & 15 & 32 & Y & 0 & 0 & & PRACTICES \\
\hline Supervision & 4 & 51 & & 4 & 19 & & 0 & & 0 & & 13 & 45 & Y & 0 & 0 & & 0 & 0 & & \\
\hline Escalation to Hierarchy & 10 & 32 & & 10 & 44 & $\mathrm{Y}$ & 39 & Y & 22 & & 19 & 25 & & 8 & 36 & Y & 0 & 0 & & \\
\hline Compliance & 18 & 38 & $\mathrm{Y}$ & 18 & 35 & $\mathrm{Y}$ & 43 & Y & 52 & $\mathrm{Y}$ & 19 & 35 & $\mathrm{Y}$ & 23 & 38 & Y & 0 & 0 & & $\begin{array}{l}\text { EP WORKING } \\
\text { PRACTICES } \\
\end{array}$ \\
\hline Emergency Response & 10 & 39 & $\mathrm{Y}$ & 10 & 5 & & 35 & $\mathrm{Y}$ & 7 & & 0 & 0 & & 15 & 40 & $\mathrm{Y}$ & 11 & 40 & Y & \\
\hline $\begin{array}{l}\text { Incident Investigation } \\
\text { and Analysis }\end{array}$ & 25 & 38 & $\mathrm{Y}$ & 25 & 49 & $\mathrm{Y}$ & 45 & $\mathrm{Y}$ & 32 & $\mathrm{Y}$ & 0 & 0 & & 42 & 39 & $\mathrm{Y}$ & 22 & 0 & & $\begin{array}{l}\text { EM } \\
\text { ORGANIZATION } \\
\text { PRACTICES }\end{array}$ \\
\hline Organizational Learning & 8 & 30 & & 8 & 25 & & 29 & & 6 & & 0 & 0 & & 4 & 50 & & 33 & 35 & Y & \\
\hline Detection & 37 & 39 & $\mathrm{Y}$ & 37 & 19 & & 22 & & 44 & $\mathrm{Y}$ & 13 & 33 & $\mathrm{Y}$ & 46 & 39 & $\mathrm{Y}$ & 56 & 48 & $\mathrm{Y}$ & \\
\hline Vigilance & 22 & 41 & $\mathrm{Y}$ & 22 & 33 & $\mathrm{Y}$ & 33 & Y & 24 & & 38 & 34 & Y & 4 & 50 & & 44 & 55 & Y & \\
\hline Sensemaking & 16 & 36 & & 16 & 20 & & 21 & & 38 & Y & 13 & 29 & $\mathrm{Y}$ & 19 & 37 & Y & 11 & 43 & Y & EM WO \\
\hline Communication & 6 & 32 & & 6 & 38 & & 13 & & 0 & & 19 & 28 & & 0 & 0 & & 0 & 0 & & CTICES \\
\hline $\begin{array}{l}\text { Checking Challenge and } \\
\text { Follow-up }\end{array}$ & 2 & 54 & & 2 & 68 & & 0 & & 0 & & 6 & 48 & & 0 & 0 & & 0 & 0 & & \\
\hline Mitigation & 8 & 42 & & 8 & 80 & & 18 & & 53 & & 0 & 0 & & 12 & 40 & Y & 11 & 60 & Y & \\
\hline Work Pressure & 12 & 43 & $\mathrm{Y}$ & 12 & 40 & $\mathrm{Y}$ & 46 & Y & 28 & $\mathrm{Y}$ & 25 & 37 & Y & 8 & 47 & Y & 0 & 0 & & CONTEXT \\
\hline
\end{tabular}


Table 4 - Summary Results of Coding of Semi-Structured Interviews

\begin{tabular}{|c|c|c|c|c|c|c|c|c|c|c|c|c|c|c|}
\hline \multicolumn{9}{|c|}{$\begin{array}{l}\text { First order factors - Evidence from interviews } \\
\text { No of interviews mentioning the factor at least once }\end{array}$} & \multicolumn{5}{|c|}{$\begin{array}{l}\text { Theoretical Categories } \\
\text { (Normalised Average \%) }\end{array}$} & \multirow[t]{3}{*}{$\begin{array}{c}\text { EP/EM } \\
\text { CATEGORY }\end{array}$} \\
\hline \multirow[b]{2}{*}{ SUPPORTING } & \multirow{2}{*}{\multicolumn{4}{|c|}{ SITE }} & \multirow[b]{2}{*}{ IMPEDING } & \multirow{2}{*}{\multicolumn{3}{|c|}{$\begin{array}{l}\text { SITE } \\
\text { A } \mathrm{B} \text { C }\end{array}$}} & \multirow{4}{*}{$\begin{array}{c}\text { Risk } \\
\text { Management } \\
\end{array}$} & \multirow{2}{*}{\multicolumn{3}{|c|}{\begin{tabular}{c|} 
SUPPORT \\
SITE
\end{tabular}}} & \multirow{2}{*}{\begin{tabular}{|c|} 
IMPEDING \\
SITE
\end{tabular}} & \\
\hline & & & & & & & & & & & & & & \\
\hline $\begin{array}{l}\text { Processes for risk management } \\
\text { Processes for situation awareness }\end{array}$ & $\begin{array}{l}1 \\
1\end{array}$ & $1 \quad 2$ & $\begin{array}{r}5 \\
3 \\
\end{array}$ & & Cumbersome risk bureaucracy & 2 & 2 & 1 & & 10 & 3 & 19 & $\begin{array}{lll}5 & 3 & 5\end{array}$ & \\
\hline Average & 2 & 21 & 4 & & & 1 & 1 & 1 & & & & & & \\
\hline $\begin{array}{l}\text { Clarifying expectations \& resps } \\
\text { Effective monitoring \& control } \\
\text { Effective planning and resourcing } \\
\text { Encouraging proactive work } \\
\text { Prioritising process safety }\end{array}$ & $\begin{array}{l}6 \\
5 \\
2 \\
1 \\
1 \\
5\end{array}$ & $\begin{array}{ll}6 & 7 \\
5 & 4 \\
2 & 6 \\
1 & 1 \\
5 & 8\end{array}$ & $\begin{array}{c}8 \\
4 \\
8 \\
4 \\
10\end{array}$ & & Authoritarian over-directing & 7 & & 1 & $\begin{array}{l}\text { Planning and } \\
\text { Resourcing }\end{array}$ & 19 & 16 & 33 & 33 & \\
\hline Average & 4 & $4 \quad 5$ & 7 & & & 7 & & 1 & & & & & & $\begin{array}{l}\text { ORG. } \\
\text { RACTICES }\end{array}$ \\
\hline Technical Competence & & & 5 & & Lack of tech competence & 1 & 2 & & Competence & & & 24 & $\begin{array}{lll}5 & 6 \\
\end{array}$ & \\
\hline Effective Procedures & & 2 & 3 & & Unclear procedures & 5 & 6 & & Procedures & & 6 & 14 & 2419 & \\
\hline $\begin{array}{l}\text { Embedding improved designs } \\
\text { Embedding improved procedures } \\
\text { Embedding improved competence }\end{array}$ & $\begin{array}{l}2 \\
2 \\
1\end{array}$ & 2 & $\begin{array}{l}2 \\
7\end{array}$ & & Ineff. embedding of improvements & 4 & 2 & 3 & $\begin{array}{l}\text { Embedding } \\
\text { Improvements }\end{array}$ & 10 & 6 & 14 & 19 & \\
\hline Average & 2 & 22 & 3 & & & 4 & 2 & 3 & & & & & & \\
\hline Norm of Compliance & & 1 & 9 & & Ineffective implementation & 3 & & & Compliance & & 3 & 43 & 14 & $\begin{array}{c}\text { EP } \\
\text { WORKING } \\
\text { PRACTICES } \\
\end{array}$ \\
\hline $\begin{array}{l}\text { Engaging \& supporting workers } \\
\text { Protecting people from politics } \\
\text { Removing difficult people } \\
\text { Supporting formal networks } \\
\text { Supporting informal networking }\end{array}$ & $\begin{array}{l}5 \\
1 \\
4 \\
6 \\
4\end{array}$ & $\begin{array}{ll}5 & 10 \\
1 & 4 \\
4 & \\
6 & 2 \\
4 & 2 \\
\end{array}$ & $\begin{array}{l}5 \\
3 \\
1 \\
4 \\
4\end{array}$ & & Ineff. engagement or support & 2 & & 1 & $\begin{array}{l}\text { Supporting } \\
\text { Individuals \& } \\
\text { Networks }\end{array}$ & 19 & 13 & 14 & 10 & \\
\hline Average & 4 & 4 & 3 & & & 2 & & 1 & & & & & & \\
\hline $\begin{array}{l}\text { Enabling rule-following AND } \\
\text { competent improvisation }\end{array}$ & 1 & 8 & 10 & & & & & & $\begin{array}{l}\text { Enabling } \\
\text { Ambidexterity }\end{array}$ & 5 & 26 & 48 & & EM \\
\hline Average & 1 & 8 & 10 & & & & & & & & & & & \\
\hline $\begin{array}{l}\text { Demonstrating passion for safety } \\
\text { Encouraging new ideas }\end{array}$ & 1 & $\begin{array}{ll}1 & 3 \\
6 & 9\end{array}$ & $\begin{array}{c}6 \\
10\end{array}$ & & & & & & Encouraging & 19 & 19 & 38 & & $\begin{array}{c}\text { ORG. } \\
\text { PRACTICES }\end{array}$ \\
\hline Average & 4 & 46 & 8 & & & & & & & & & & & \\
\hline $\begin{array}{l}\text { Encouraging diverse skills \& views } \\
\text { Encouraging effective teamwork }\end{array}$ & $\begin{array}{l}5 \\
3\end{array}$ & $\begin{array}{ll}5 & 2 \\
3 & 3\end{array}$ & $\begin{array}{l}2 \\
9\end{array}$ & & Ineffective support of diversity & 3 & & & Encouraging & 19 & 10 & 29 & 14 & \\
\hline Average & 4 & 43 & 6 & & & 3 & & & & & & & & \\
\hline $\begin{array}{l}\text { Encouraging leadership at all levels } \\
\text { Influencing within peer group }\end{array}$ & 2 & $\overline{2}$ & & & & & & & Emergent & 5 & 3 & 24 & & \\
\hline Average & 1 & 1 & 5 & & & & & & & & & & & \\
\hline $\begin{array}{l}\text { Sensemaking } \\
\text { Challenging assumptions }\end{array}$ & $\begin{array}{l}9 \\
5\end{array}$ & $\begin{array}{ll}9 & 19 \\
5 & 4\end{array}$ & $\begin{array}{l}8 \\
1\end{array}$ & & Giving mixed messages & 1 & & 3 & Sensemaking \& & 33 & 39 & 24 & 14 & \\
\hline Average & 7 & $7 \quad 12$ & 25 & & & 1 & & 3 & & & & & & \\
\hline $\begin{array}{l}\text { Identifying \& reporting PIs } \\
\text { Reporting \& analysing NMs \& AIs }\end{array}$ & 5 & 56 & $\begin{array}{l}5 \\
1\end{array}$ & & & & & & Preoccupation & 14 & 10 & 14 & & \\
\hline Average & 3 & 3 & 3 & & & & & & & & & & & \\
\hline $\begin{array}{l}\text { Mindful compliance \& questioning } \\
\text { Strong response to a weak signal } \\
\text { > Reviewing \& analysing PIs } \\
\text { Teamworking to solve problems }\end{array}$ & $\begin{array}{l}1 \\
3\end{array}$ & $\begin{array}{ll}1 \\
3 \\
2\end{array}$ & $\begin{array}{l}5 \\
4 \\
4 \\
7\end{array}$ & & Acting with complacency & 3 & & & $\begin{array}{l}\text { Reluctance to } \\
\text { Simplify }\end{array}$ & 10 & 10 & 48 & 14 & EM \\
\hline Average & 2 & 3 & 10 & & & 3 & & & & & & & & WORKING \\
\hline Building situation awareness & 1 & 1 & 4 & & & & & & Sensitivity to & 5 & 3 & & & PRACTICES \\
\hline Average & 1 & 1 & 4 & & & & & & Operations & 5 & 3 & & & \\
\hline $\begin{array}{l}\text { Building capacity for improvisation } \\
\text { Supporting risk awareness }\end{array}$ & 1 & 1 & 8 & & Improvising without risk awareness & 2 & 1 & 1 & Commitment to & 2 & 5 & 19 & $\begin{array}{lll}10 & 3 & 5\end{array}$ & \\
\hline Average & 1 & 2 & 4 & & & 2 & 1 & 1 & & & & & & \\
\hline $\begin{array}{l}\text { Countering deference to hierarchy } \\
\text { Deferring to expertise } \\
\text { Delegating decision-making }\end{array}$ & 1 & $\begin{array}{l}2 \\
6 \\
\end{array}$ & $\begin{array}{l}2 \\
3 \\
2 \\
\end{array}$ & & & & & & $\begin{array}{l}\text { Deference to } \\
\text { Expertise }\end{array}$ & $\mathbf{0}$ & 10 & & & \\
\hline Average & 0 & 3 & 2 & & & & & & & & & & & \\
\hline $\begin{array}{l}\text { Just culture } \\
\text { Reporting culture } \\
\text { 'Stop' culture } \\
\text { Open culture - trust \& low threshold }\end{array}$ & $\begin{array}{l}1 \\
3\end{array}$ & $\begin{array}{ll}1 & 2 \\
3 & 2\end{array}$ & $\begin{array}{l}1 \\
2 \\
3 \\
7\end{array}$ & & $\begin{array}{l}\text { Blame culture } \\
\text { Ineffective learning processes } \\
\text { Production pressure } \\
\text { Ineffective mgt of stress or fatigue }\end{array}$ & $\begin{array}{l}5 \\
1 \\
3 \\
1\end{array}$ & $\begin{array}{l}3 \\
1 \\
8\end{array}$ & $\begin{array}{l}1 \\
1 \\
4\end{array}$ & Culture & 10 & 3 & 14 & $\left|\begin{array}{lll}14 & 10 & 10\end{array}\right|$ & \\
\hline Average & 2 & 1 & 3 & & & 3 & 3 & 2 & & & & & & \\
\hline Accessible leaders - flat structure & & & 6 & & $\begin{array}{l}\text { Inadequate resourcing } \\
\text { Unclear responsibilities } \\
\text { Ineff. transition Proj to Ops } \\
\text { Too much change too quickly } \\
\end{array}$ & $\begin{array}{l}3 \\
3 \\
4\end{array}$ & $\begin{array}{l}5 \\
5 \\
5 \\
7 \\
\end{array}$ & $\begin{array}{l}1 \\
1 \\
1\end{array}$ & $\begin{array}{l}\text { Structure \& } \\
\text { Maturity }\end{array}$ & & & 29 & $1419 \quad 5$ & CONTEXT \\
\hline Average & & & 6 & 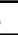 & & 3 & 6 & 1 & & & & & & \\
\hline
\end{tabular}


Table 5 EXTRACT from Table SUP-3 Illustrative Quotes and Categorisation of Factors from Semi-Structured Interviews

\begin{tabular}{|c|c|c|c|}
\hline Theor. Cat. & Site & Illustrative Quote from Semi-Structured Interviews & EP / EM Cat. \\
\hline \multirow{3}{*}{$\begin{array}{l}\text { Embedding } \\
\text { improvements }\end{array}$} & $\mathbf{A}$ & $\begin{array}{l}\text { So very interactive session, about two hours, we do it every quarter on a couple of processes. And that gives two } \\
\text { ways. That gives them the way of our assurance on how healthy we are in execution, but it also gives the } \\
\text { opportunity to feedback what we think can be better in the procedures. }\end{array}$ & \multirow{3}{*}{$\begin{array}{l}\text { EP } \\
\text { Organization } \\
\text { Practices }\end{array}$} \\
\hline & B & $\begin{array}{l}\text { I think the way that I do it is I engage the technicians in doing all of the red lining and reviewing of } \\
\text { procedures... typically use night shift. To walk and red line the procedures. Is this currently what we do? }\end{array}$ & \\
\hline & $\mathbf{C}$ & $\begin{array}{l}\text { They have found several errors between the control room master P\&ID and on the site. They have then now } \\
\text { suggested to actually elevate this as a bigger project...I know that when they raise that to their leadership, they } \\
\text { will get support of doing that. }\end{array}$ & \\
\hline \multirow{3}{*}{ Compliance } & $\mathbf{A}$ & $\begin{array}{l}\text { But always the issue is the implementation. For example, when you see the documentation, and the rules and } \\
\text { procedures, everything is there, but who is going to implement it. So the leaders are giving the coaching, } \\
\text { showing the way, the direction, the guidance, everything, but always the problem is with the implementation. }\end{array}$ & \multirow{3}{*}{$\begin{array}{l}\text { EP } \\
\text { Working } \\
\text { Practices }\end{array}$} \\
\hline & B & $\begin{array}{l}\text { If you feel the procedure is not working, the procedure is not letting you to get to the desired objective, stop it, } \\
\text { come to us. That is the expectation we have given. }\end{array}$ & \\
\hline & $\mathbf{C}$ & $\begin{array}{l}\text { We have a tendency to write too many procedures and not respect the craftsmanship...I think this is a very nice } \\
\text { balance because I don't expect people to follow procedure if they certainly see that the procedure is wrong. I will } \\
\text { not challenge them a lot on the way they will do the task but I will challenge them to document the difference }\end{array}$ & \\
\hline \multirow{3}{*}{$\begin{array}{l}\text { Supporting } \\
\text { individuals \& } \\
\text { networks }\end{array}$} & $\mathbf{A}$ & $\begin{array}{l}\text { I've seen that at A just by giving the right steer, the right expectations to guys. Don't distract them with all kind } \\
\text { of other shit, just let the guys focus on what they need to deliver and need to do and give them the few of the right } \\
\text { tools and steers to them, makes a hell of a difference. }\end{array}$ & \multirow{3}{*}{$\begin{array}{l}\text { EM } \\
\text { Organization } \\
\text { Practices }\end{array}$} \\
\hline & B & $\begin{array}{l}\text { I think we've got potentially some strengthening of network and networks... Yes, that's where I'd like to see this } \\
\text { get to but where we're at the moment is probably reliant on ...communications and networks at the field manager } \\
\text { / superintendent level. }\end{array}$ & \\
\hline & $\mathbf{C}$ & $\begin{array}{l}\text { If you've got a problem, you know who to contact to talk about that problem. It's not that you go outside and } \\
\text { shout to the moon. [laughter] You know who to contact ... you know who they are, most of them. }\end{array}$ & \\
\hline
\end{tabular}


Table 6a - Summary Results of Coding of Causal Factors in Incident Documents

Incident Documents Coding

1st Order Codes

Unique Frequency of Codes

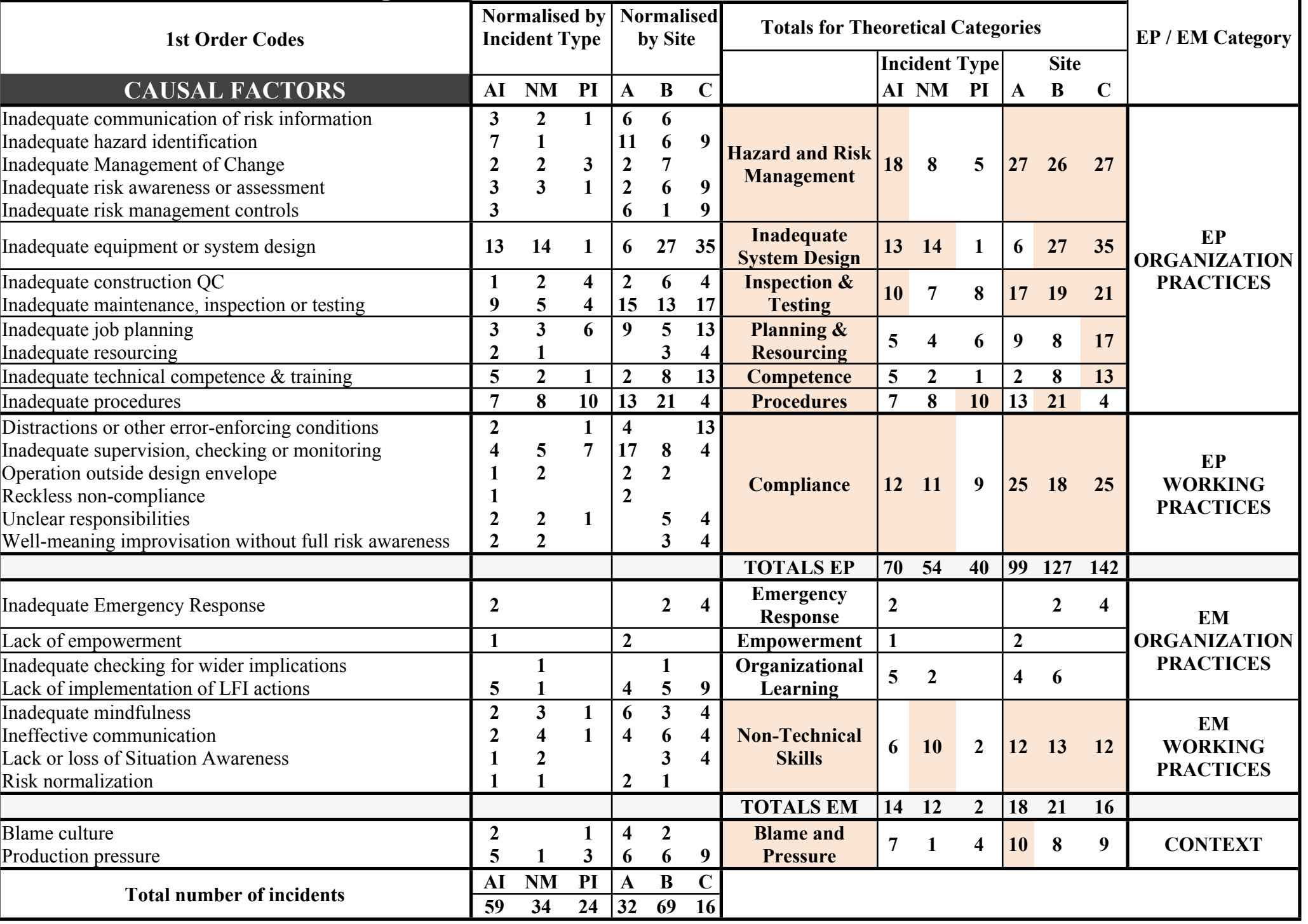


Table 6b - Summary Results of Coding of Recommendations in Incident Documents

\begin{tabular}{|c|c|c|c|c|c|c|c|c|c|c|c|c|c|c|}
\hline \multirow{4}{*}{\begin{tabular}{|c|} 
Incident Documents Coding \\
1st Order Codes \\
RECOMMENDATIONS
\end{tabular}} & \multicolumn{13}{|c|}{ Unique Frequency of Codes } & \multirow{4}{*}{ EP / EM Category } \\
\hline & \multirow{2}{*}{\multicolumn{3}{|c|}{$\begin{array}{l}\text { Normalised by } \\
\text { Incident Type }\end{array}$}} & \multirow{2}{*}{\multicolumn{3}{|c|}{$\begin{array}{c}\text { Normalised } \\
\text { by Site }\end{array}$}} & \multicolumn{7}{|c|}{ Totals for Theoretical Categories } & \\
\hline & & & & & & & & Inci & dent & ype & & SITE & & \\
\hline & $\mathbf{A I}$ & $\mathbf{N M}$ & PI & $\mathbf{A}$ & B & $\mathbf{C}$ & & AI & NM & PI & $\mathbf{A}$ & B & $\mathbf{C}$ & \\
\hline $\begin{array}{l}\text { Improve communication of risk information } \\
\text { Improve hazard identification and risk assessment } \\
\text { Review risk management studies }\end{array}$ & $\begin{array}{l}4 \\
2 \\
3\end{array}$ & $\begin{array}{l}2 \\
1\end{array}$ & 7 & $\begin{array}{l}2 \\
2\end{array}$ & $\begin{array}{l}8 \\
4 \\
6\end{array}$ & $\begin{array}{c}13 \\
4\end{array}$ & $\begin{array}{l}\text { Hazard and Risk } \\
\text { Management }\end{array}$ & 9 & 3 & 8 & 4 & \multicolumn{2}{|c|}{1817} & \multirow{6}{*}{$\begin{array}{l}\text { EP } \\
\text { ORGANIZATION } \\
\text { PRACTICES }\end{array}$} \\
\hline $\begin{array}{l}\text { Improve equipment or system design } \\
\text { Review engineering design }\end{array}$ & $\begin{array}{l}8 \\
6\end{array}$ & $\begin{array}{l}10 \\
12\end{array}$ & $\begin{array}{l}4 \\
3\end{array}$ & $\begin{array}{l}9 \\
2\end{array}$ & $\begin{array}{l}19 \\
23\end{array}$ & $\begin{array}{c}17 \\
4\end{array}$ & $\begin{array}{l}\text { Equipment or } \\
\text { System Design }\end{array}$ & 14 & 22 & 7 & \multicolumn{2}{|c|}{$\begin{array}{lll}11 & 42 & 21 \\
\end{array}$} & 17 & \\
\hline Improve maintenance, inspection or testing & 9 & 3 & 6 & 15 & 12 & 13 & Inspection \& Testing & 9 & 3 & 6 & 15 & 12 & 13 & \\
\hline $\begin{array}{l}\text { Review or improve work planning } \\
\text { Review technical resources }\end{array}$ & $\begin{array}{l}\mathbf{5} \\
\mathbf{2}\end{array}$ & $\begin{array}{l}1 \\
1\end{array}$ & 3 & 9 & $\begin{array}{l}\mathbf{1} \\
\mathbf{3}\end{array}$ & $\begin{array}{c}26 \\
9\end{array}$ & $\begin{array}{l}\text { Planning \& } \\
\text { Resourcing }\end{array}$ & 7 & 2 & 3 & 9 & 4 & 35 & \\
\hline Improve technical competence $\&$ training & 5 & 6 & 9 & 6 & 16 & 9 & Competence & 5 & 6 & 9 & 6 & 16 & 9 & \\
\hline $\begin{array}{l}\text { Improve procedures or other tech documents } \\
\text { Review procedures or other tech documents }\end{array}$ & $\begin{array}{c}10 \\
5\end{array}$ & $\begin{array}{l}7 \\
5\end{array}$ & $\begin{array}{c}18 \\
1\end{array}$ & & $\begin{array}{c}23 \\
7\end{array}$ & $\begin{array}{ll}13 \\
13\end{array}$ & Procedures & 15 & 12 & 19 & 33 & 30 & 26 & \\
\hline $\begin{array}{l}\text { Clarify roles \& responsibilities } \\
\text { Improve supervision, checking or monitoring }\end{array}$ & $\begin{array}{l}3 \\
3\end{array}$ & $\begin{array}{l}2 \\
2\end{array}$ & $\begin{array}{l}9 \\
4\end{array}$ & $\begin{array}{l}4 \\
2\end{array}$ & & $\begin{array}{l}17 \\
13\end{array}$ & Compliance & 6 & 4 & 13 & 6 & 14 & 30 & $\begin{array}{c}\text { EP } \\
\text { WORKING } \\
\text { PRACTICES } \\
\end{array}$ \\
\hline & & & & & & & TOTALS EP & 65 & 52 & 65 & 84 & 136 & 151 & \\
\hline Emergency Response & 3 & & & & 4 & 9 & Emergency Response & 3 & & & & 4 & 9 & \\
\hline $\begin{array}{l}\text { Recognise or give appreciation of good work } \\
\text { Support people involved in incidents }\end{array}$ & 1 & & 1 & 2 & & 4 & $\begin{array}{l}\text { Recognition and } \\
\text { Support }\end{array}$ & 1 & & 1 & 2 & & 4 & \\
\hline $\begin{array}{l}\text { Explore wider learning implications } \\
\text { Improve implementing of learning into practice } \\
\text { Improve learning from Incidents communication } \\
\text { Improve routine learning from practice } \\
\text { Reflective incident review }\end{array}$ & $\begin{array}{l}3 \\
2 \\
2 \\
1 \\
2\end{array}$ & & $\begin{array}{l}\mathbf{3} \\
\mathbf{3} \\
\mathbf{1}\end{array}$ & $\begin{array}{l}6 \\
2\end{array}$ & $\begin{array}{l}\mathbf{9} \\
\mathbf{3} \\
\mathbf{3} \\
\mathbf{1}\end{array}$ & \begin{tabular}{c|}
13 \\
4 \\
9 \\
4 \\
22
\end{tabular} & $\begin{array}{l}\text { Organizational } \\
\text { Learning }\end{array}$ & 10 & 7 & 10 & 8 & 16 & 52 & $\begin{array}{l}\text { EM } \\
\text { ORGANIZATION } \\
\text { PRACTICES }\end{array}$ \\
\hline $\begin{array}{l}\text { Improve communication } \\
\text { Improve reflective mindfulness } \\
\text { improve teamwork } \\
\text { Undergo behavioural safety training }\end{array}$ & $\begin{array}{l}1 \\
1 \\
1 \\
1\end{array}$ & 1 & 1 & $\begin{array}{l}4 \\
2 \\
2\end{array}$ & $\begin{array}{l}1 \\
1\end{array}$ & 9 & Non-Technical Skills & 4 & 2 & 1 & 8 & 2 & 9 & $\begin{array}{l}\text { EM } \\
\text { WORKING } \\
\text { PRACTICES }\end{array}$ \\
\hline & & & & & & & TOTALS EM & 18 & 9 & 12 & 18 & 18 & 65 & \\
\hline $\begin{array}{l}\text { Decisive action for safety } \\
\text { Reinforce safety priority }\end{array}$ & 2 & 1 & $\begin{array}{l}1 \\
1\end{array}$ & 4 & $\begin{array}{l}1 \\
2\end{array}$ & 4 & Safety Messaging & 2 & 1 & 2 & 4 & 3 & 4 & CONTEXT \\
\hline & $\mathbf{A I}$ & $\overline{\text { NM }}$ & $\overline{\text { PI }}$ & A & $\mathbf{B}$ & $\mathbf{C}$ & & & & & & & & \\
\hline Total number of incidents & 59 & 34 & 24 & 32 & 69 & 16 & & & & & & & & \\
\hline
\end{tabular}


Table 7a - EXTRACT of Table SUP-4a Categorisation of Causal Factors from Incident Documents

\begin{tabular}{|c|c|c|c|}
\hline Theor. Cat. & Site & Illustrative Quote from Incident Documents - Causal Factors & $\begin{array}{l}\text { EP / EM } \\
\text { Category }\end{array}$ \\
\hline \multirow{3}{*}{ Compliance } & A & $\begin{array}{l}\text { Coordinator and System Owner left the work location and supervision of Operation Support personnel was left to } \\
\text { Area } 1 \text { mech execution lead }\end{array}$ & \multirow{3}{*}{$\begin{array}{c}\text { EP } \\
\text { WORKING } \\
\text { PRACTICES }\end{array}$} \\
\hline & B & The Isolation Authority did not cross-check with P\&ID to identify the correct vessel & \\
\hline & $\mathbf{C}$ & Several isolations plans set in the same area created confusion and conflicts & \\
\hline \multirow{3}{*}{$\begin{array}{l}\text { Organizational } \\
\text { Learning }\end{array}$} & A & $\begin{array}{l}\text { This was a repeat incident, the previous investigation of a small acid leak at the same location did not identify } \\
\text { the correct root cause, therefore the weak signal was not followed through. }\end{array}$ & \multirow{3}{*}{$\begin{array}{c}\text { EM } \\
\text { ORG. } \\
\text { PRACTICES }\end{array}$} \\
\hline & B & $\begin{array}{l}\text { Of significant concern is that as there has been at least three similar incidents have occurred at [Site B] in the } \\
\text { past five year, it is clear that with regard to this issue that organisation learning has not happened }\end{array}$ & \\
\hline & C & Knowledge of similar incidents was not sufficiently taken into account in planning process. & \\
\hline
\end{tabular}

Table 7b - EXTRACT of Table SUP-4b Illustrative Quotes and Categorisation of Recommendations from Incident Documents

\begin{tabular}{|c|c|c|c|}
\hline Theor. Cat. & Site & Illustrative Quote from Incident Documents - Recommendations & EP / EM Cat. \\
\hline \multirow{3}{*}{$\begin{array}{l}\text { Hazard and } \\
\text { Risk } \\
\text { Management }\end{array}$} & $\mathbf{A}$ & $\begin{array}{l}\text { Operations personnel involved in this incident to develop a safety briefing highlighting exactly what went } \\
\text { wrong and the potential consequences }\end{array}$ & \multirow{6}{*}{$\begin{array}{c}\text { EP } \\
\text { ORG. } \\
\text { PRACTICES }\end{array}$} \\
\hline & B & $\begin{array}{l}\text { Develop communication to staff to clarify use of electrical and non-intrinsically safe equipment inside the } \\
\text { plant. }\end{array}$ & \\
\hline & $\mathbf{C}$ & $\begin{array}{l}\text { Communicate to all relevant parties the incident learnings and how to work safely on live systems with } \\
\text { compression fittings. }\end{array}$ & \\
\hline \multirow{3}{*}{$\begin{array}{l}\text { Planning \& } \\
\text { Resourcing }\end{array}$} & A & Maintenance team to review current JHA with update to include hazard of xxx services & \\
\hline & B & Define well integrity work programme and establish whether resourcing levels are adequate & \\
\hline & $\mathbf{C}$ & The matrix for start-up should be reviewed & \\
\hline \multirow{3}{*}{$\begin{array}{l}\text { Non-Technical } \\
\text { Skills }\end{array}$} & $\mathbf{A}$ & $\begin{array}{l}\text { Any sudden change in Flow other than normal to be communicated by [Plant] PO to [Facilities] PO } \\
\text { (Panel Operators) }\end{array}$ & \multirow{3}{*}{$\begin{array}{c}\text { EM } \\
\text { WORKING } \\
\text { PRACTICES }\end{array}$} \\
\hline & B & staff to avoid (perception of) informal instruction and multiple accountable persons & \\
\hline & $\mathbf{C}$ & $\begin{array}{l}\text { To avoid future similar incidents Projects /Asset to share practices between Platform and Onshore plant } \\
\text { and possibly agree one leading practice }\end{array}$ & \\
\hline
\end{tabular}


Table 8 - Comparison of the Results of the 3 Studies: Rep Grid, Semi-Structured Interviews and Incident Documents

\begin{tabular}{|c|c|c|c|c|c|c|c|c|c|c|c|c|c|c|c|c|c|c|c|c|c|c|c|c|c|c|}
\hline \multirow{4}{*}{\multicolumn{2}{|c|}{$\begin{array}{c}\text { KEY } \\
\text { FACTORS }\end{array}$}} & STUDY & \multicolumn{7}{|c|}{ EP ORGANIZATION PRACTICES } & & $\begin{array}{c}\text { EP } \\
\text { WORK } \\
\text { WPR }\end{array}$ & \multicolumn{7}{|c|}{ EM ORGANIZATION PRACTICES } & \multicolumn{6}{|c|}{ EM WORKING PRACTICES } & \multicolumn{2}{|c|}{ CONTEXT } \\
\hline & & REP GRID & Risk Mgt & & & & & $\begin{array}{l}\text { Procedur } \\
\text { es }\end{array}$ & Superv. & $\begin{array}{c}\text { Escalatain } \\
\text { tierarchy }\end{array}$ & Comprece & \begin{tabular}{|c|} 
em. \\
esponse \\
\end{tabular} & 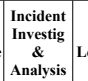 & \begin{tabular}{|c||} 
Oorg \\
Learning \\
\end{tabular} & & & & & & & Detection & vigilance & 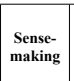 & Mitigation & $\begin{array}{c}\text { Work } \\
\text { Pressure }\end{array}$ & \\
\hline & & SEMI-STRUCT & & & & $\begin{array}{l}\begin{array}{l}\text { Plan \& } \\
\text { Resourc }\end{array} \\
\text { R }\end{array}$ & Compet. & $\begin{array}{c}\text { Procedur } \\
\text { es }\end{array}$ & & & Comprece & & & & 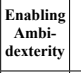 & \begin{tabular}{|l} 
Encour'g \\
Improvet
\end{tabular} & $\begin{array}{l}\text { Encourg } \\
\text { Teamuork }\end{array}$ & \begin{tabular}{|l}
$\begin{array}{l}\text { Emergent } \\
\text { Leautership }\end{array}$ \\
\end{tabular} & 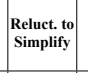 & & & & \begin{tabular}{|l|}
$\begin{array}{c}\text { Sense- } \\
\text { making }\end{array}$ \\
\end{tabular} & & & $\begin{array}{c}\text { Structure } \\
\text { Maturity } \\
\text { Matrity }\end{array}$ \\
\hline & & INCID. DOCS & Risk Mgt & \begin{tabular}{|l} 
Equipt \\
Design
\end{tabular} & 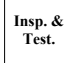 & $\begin{array}{l}\begin{array}{l}\text { Plan. \& } \\
\text { Resourc }\end{array} \\
\text { R }\end{array}$ & Compet & $\begin{array}{l}\text { Procedur } \\
\text { es }\end{array}$ & & & Compree & & & \begin{tabular}{|c|c|} 
Org \\
Learning
\end{tabular} & & & & & & $\begin{array}{l}\text { Non Tech } \\
\text { Skills } \\
\text { She }\end{array}$ & & & & & $\begin{array}{c}\text { Work } \\
\text { Pressure }\end{array}$ & \\
\hline \multirow{9}{*}{$\begin{array}{l}\text { INCID. } \\
\text { TYPE }\end{array}$} & & REP GRID & $\mathrm{Y}$ & & & & & & & $\mathrm{Y}$ & $\mathrm{Y}$ & & $\mathrm{Y}$ & & & & & & & & & $\mathrm{Y}$ & & & $\mathrm{Y}$ & \\
\hline & AI & SEMI-STRUCT & & & & & & & & & 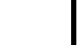 & & & & & & & & & & & & & & & \\
\hline & & INCID. DOCS & $\mathrm{Y}$ & $\mathrm{Y}$ & $\mathrm{Y}$ & & & & & & r & & & $\mathrm{Y}$ & & & & & & & & & & & 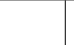 & \\
\hline & & REP GRID & & & & & & $\mathrm{Y}$ & & $\mathrm{Y}$ & $\mathrm{r}$ & $\mathrm{y}$ & $\mathrm{Y}$ & & & & & & & & & $\mathrm{Y}$ & & & $\mathrm{Y}$ & \\
\hline & NM & SEMI-STRUCT & & & & & & & & & . & & & & & & & & & & & & & & & \\
\hline & & INCID. DOCS & & $\mathrm{Y}$ & & & & & & & $\mathrm{Y}$ & & & & & & & & & $\mathrm{Y}$ & & & & & & \\
\hline & & REP GRID & $\mathrm{Y}$ & & & & & $\mathrm{Y}$ & & & $\mathrm{Y}$ & & $\mathrm{Y}$ & & & & & & & & $\mathrm{Y}$ & & $\mathrm{Y}$ & & $\mathrm{Y}$ & \\
\hline & PI & SEMI-STRUCT & & & & & & & & & & & & & & & & & & & & & & & & \\
\hline & & INCID. DOCS & & & & & & $\mathrm{Y}$ & & & . & & & $\mathrm{Y}$ & & & & & & & & & & & & \\
\hline \multirow{9}{*}{ SITES } & & REP GRID & $\bar{Y}$ & & & & & $\bar{Y}$ & $\bar{Y}$ & & $\mathrm{Y}$ & & & & & & & & & & $\bar{Y}$ & $\mathrm{Y}$ & $\mathrm{Y}$ & & $\overline{\mathrm{Y}}$ & \\
\hline & A & SEMI-STRUCT & & & & Y & & Y & & & & & & & & & & & & & & & $\mathrm{Y}$ & & . & \\
\hline & & INCID. DOCS & y & $\mathrm{Y}$ & Y & & & Y & & & Y & & & & & & & & & y & & & . & & y & \\
\hline & & REP GRID & $\mathrm{Y}$ & & & & & $\mathrm{Y}$ & & $\mathrm{Y}$ & $\mathrm{Y}$ & $\mathrm{Y}$ & $\mathrm{Y}$ & & & & & & & & $\mathrm{Y}$ & & $\mathrm{Y}$ & $\mathrm{Y}$ & $\mathrm{Y}$ & \\
\hline & в & SEMI-STRUCT & & & & & & & & & . & & & & $\mathrm{Y}$ & & & & & & & & $\mathrm{Y}$ & & & \\
\hline & & INCID. DOCS & $\mathrm{Y}$ & $\mathrm{Y}$ & Y & & y & $\mathrm{Y}$ & & & Y & & & $\mathrm{Y}$ & & & & & & $\mathrm{Y}$ & & & 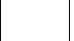 & & & \\
\hline & & REP GRID & & & & & & & & & & $\mathrm{y}$ & & $\mathrm{y}$ & & & & & & & $\mathrm{y}$ & $\mathrm{Y}$ & $\mathrm{Y}$ & $\mathrm{Y}$ & & \\
\hline & C & SEMI-STRUCT & & & & $\mathrm{y}$ & y & & & & $\mathrm{y}$ & & & & $\mathrm{y}$ & Y & $\mathrm{Y}$ & $\mathrm{y}$ & $\mathrm{Y}$ & & & & $\mathrm{Y}$ & & & y \\
\hline & & INCID. DOCS & $\mathrm{Y}$ & $\mathrm{Y}$ & $\mathrm{Y}$ & $\mathrm{Y}$ & Y & $\mathrm{Y}$ & & & $\mathrm{Y}$ & & & $\mathrm{Y}$ & & & & & & $\mathrm{Y}$ & & & & & & \\
\hline
\end{tabular}


Charles Cowley is a post-doctoral researcher at Cranfield School of Management with particular interest in safety leadership of operating high hazard technology. After a career in industry he now advises on operational and process safety, and on project management. Charles is a Chartered Engineer and Fellow of the Institute of Leadership and Management.

David Denyer is a leading authority on organizational resilience, leadership and change. He is Professor of Leadership and Organizational Change at Cranfield School of Management and leads the Cranfield University multi-disciplinary Resilience Grand Challenge. David is Fellow of the Academy of Social Sciences and Fellow of the British Academy of Management.

Elmar Kutsch is an Associate Professor in Risk Management at Cranfield University. He engages widely with industry and advocates of risk management and organisational resilience, and his current research interest lies in the area of dualisms and dualities of resilient organising.

Kim Turnbull James is Professor of Leadership and Executive Learning at Cranfield School of Management. She focuses on leadership and complexity, and creating the capacity for rethinking leadership practices. As a Chartered Psychologist she works with the political and emotional dynamics that impact strategic change, drawing on systems psychodynamic thinking. 


\section{Constructing safety: Reconciling Error Prevention and Error Management in Oil \& Gas and Petrochemicals Operations}

\section{SUPPLEMENT}

Charles Cowley

David Denyer

Elmar Kutsch

Kim Turnbull James
Cranfield University School of Management

College Road, Cranfield MK43 0AL, Bedfordshire

United Kingdom

Tel: $+44(0) 1234751122$

Fax: +44 (0)1234 751806

charles.cowley@cranfield.ac.uk / charlescowley51@gmail.com

Cranfield University School of Management

david.denyer@cranfield.ac.uk

Cranfield University School of Management

elmar.kutsch@Cranfield.ac.uk

Cranfield University School of Management

k.james@cranfield.ac.uk

\section{Acknowledgement}

The authors are grateful for the sponsorship of the Energy Institute who gave financial support and practical help in gaining access to carry out the fieldwork. 
CONTENT

A) ADDITIONAL INFORMATION ON METHODS

Data Collection

Three fieldwork sites

Types of Incident

Repertory Grid Interview Technique

B) ADDITIONAL TABLES

Table SUP-1 Summary profiles of the three sites

Table SUP-2 Consequence Severity Scale

Table SUP-3 Illustrative Quotes \& Categorisation of Factors from Semi-Structured Interviews

Table SUP-4a Illustrative Quotes \& Categorisation of Causal Factors from Incident Documents

Table SUP-4b Illustrative Quotes \& Categorisation of Recommendations from Incident Documents

Table SUP-5 Differentiation between EP and EM

C) ADDITIONAL FIGURES

Figure SUP-1 Bow Tie hazard management diagram

Figure SUP-2 Extract from Reliability Matrix

Figure SUP-3 Data Saturation Graph - Repertory Grid

Figure SUP-4 Data Saturation Graph - Semi-Structure Interviews

Figure SUP-5 Data Saturation Graph - Incident Documents 


\section{Data Collection}

\section{A) ADDITIONAL INFORMATION ON METHODS}

Three fieldwork sites

Site A was a large petrochemicals complex in the Middle East that had been started up only a few years earlier. The site operated continuously with a typical $24 \mathrm{~h}$ shift pattern, supervised from a state-of-the-art central control room in radio communication with field operators monitoring the physical plant. The organization was fairly hierarchical, emphasising the importance of compliance with procedures. The operations and maintenance organizations were populated largely with ex-patriot workers of numerous different nationalities, predominantly Asian, and also many from Europe, Australasia and North America. The organization was still in transition from project-based to operations-based, with a number of modification projects in process. The site received significant specialist support from the parent organization in engineering and other fields. Although it had had a good safety record during construction, the site had suffered a number of significant process safety incidents in the early years of operation, including some fatalities.

Site B was an oil and gas onshore production operation in the Asia-Pacific region with a large number of geographically dispersed fields feeding a single large treatment and export plant. Many of the production units were in locations remote from support infrastructure and only visited periodically by technical personnel. The number of production units had been growing rapidly over the previous decade, and the older units had been designed and built to lower standards than the more modern ones. The organization was very much in the stage of developing and maturing, having been rapidly expanding for some years, drawing operator/technicians from the local population and providing extensive training, while maintaining a fairly flat hierarchy. The operation was in the process of adopting and implementing a new set of parent organization engineering and operating standards, for which the parent organization was providing some specialist support. There was significant concern to improve the process safety record, the site having suffered a number of significant incidents, including some high potential consequence nearmisses and potential incidents.

Site $\mathbf{C}$ was an offshore oil and gas production operation in Europe, with a large offshore platform that had been in operation for over 20 years, supported by a team of engineering and operations support personnel located in a nearby onshore office. It was a mature organization that had evolved to be a fairly small stable team of people with considerable experience and a marked culture of mutual respect, open to much discussion up and down the fairly flat hierarchy; many people had worked together for some years and had rotated through a range of different roles. The organization was largely self-sufficient in terms of operational and technical expertise with good support from the parent organization as needed. The perceived safety performance was above average; it had recently been given a major award for its process safety performance.

Site characteristics are summarised in Table SUP-1 


\section{Types of Incident}

The incidents of interest to this research were process safety incidents, that is, those that can occur as a result of the high hazards of the oil and gas and chemical industry, typically fire, explosions and releases of toxic material, that can lead to major consequences such as deaths, serious injuries, major environmental effects and major financial losses. Our research was primarily concerned with incidents that had or could have had consequences of 3 to 5 on the consequence scale shown in Table SUP- 2 drawing on Summers, Vogtmann and Smolen (2011).

\section{REFER TO TABLE SUP-2}

The definitions we used are:

Actual incident: real incident that happened (energy or hazardous material was released) and had significant actual consequences (Consequence level 3 to 5)

Near-miss incident: real incident that happened (energy or hazardous material was released) without significant consequences - but could have had level 3 to 5 consequences

Potential incident - unsafe act or condition that could have led to an incident (Consequence level 3 to 5) but was stopped from developing into a real incident, without release of energy or hazardous material.

The three types of incident examined in this study, Actual Incident (AI) Near Miss (NM) and Potential Incident (PI) are understood more completely with reference to the 'bow tie' hazard management diagram (ICI, 1979) an example of which is shown in Figure SUP-1.

\section{REFER TO FIGURE SUP-1}

A bow tie diagram portrays, for a particular hazard such as 'pressurised flammable gas contained in a pipe', a number of possible incident causation pathways. It also shows the progression of an incident from left to right through several stages of incubation (Turner and Pidgeon, 1997). The left-hand side shows the mechanisms by which the hazard could be released, such as for an underground pipeline: corrosion, fatigue or excavator damage. These mechanisms are shown as 'threat lines', along which are placed 'barriers' designed to prevent the threats from releasing the hazard. Examples of such 'prevention' barriers are a steel containment envelope (the pipe), a process alarm with operator response, and an automatic shut-down system (CCPS and Energy Institute, 2018). Each such 'threat line' can be seen as a partial Swiss Cheese model (Reason, 1990a) (Hudson and Hudson, 2015). If the barriers (slices of Swiss Cheese) designed to contain the hazard from being released by a specific threat were all to fail simultaneously (the 'holes' in the slices of cheese all lining up) then a 'top event' would occur. In the process industries a typical 'top event' is a release of flammable gas. The hazard could also be released by a previously unknown mechanism or one considered so unlikely as not to warrant preventative controls, a socalled 'Black Swan' (Taleb, 2007). On the right-hand side of the diagram, the known possible pathways that could lead to consequences are shown as continuations of the Swiss Cheese diagram. Along these pathways, 'mitigation' barriers are shown that are designed to reduce potential consequences such as injuries or damage from an incident such as explosion, fire or plume of toxic gas. Examples of mitigation barriers are an automatic firefighting system, evacuation by lifeboat and use of an escape respirator. 
In Figure SUP-1 an 'Actual Incident' (shown within the outer (red) box) is an event in which the hazard is released (a 'top event' occurs) and the hazard goes on to result in significant consequences (such as deaths, injuries or damage to plant and equipment due to fire or explosion).

A 'Near Miss' is shown as the release of the hazard (again, a 'top event' occurs) that could have resulted in significant consequences but in fact for some reason did not (Reason, 1997: 118); this is shown as an event within the middle (orange) box. Finally, in contrast to both an Actual Incident and a Near Miss, a system weakness that is detected before it could result in the release of the hazard (no 'top event' occurs) is known as a 'Potential Incident' and is shown within the inner (green) box. Evidently in the case of an Actual Incident, all of the prevention barriers on at least one threat line proved ineffective, allowing the hazard to be released (for example creating a cloud of flammable gas) and unfortunately the mitigation barriers (for example gas detection system, remotely operated shutoff valve, water deluge system) were unable to stop the hazard from leading to significant consequences (in this example, the gas cloud being ignited with ensuing explosion and fire). A Near Miss starts in a similar way to an Actual Incident, with release of the hazard, so evidently, as for an Actual Incident, all of the prevention barriers on at least one threat pathway proved ineffective. However, in a Near Miss, although the hazard is released, there are no significant consequences. This might be because of the effective operation of one or more designed mitigation barriers (such as the examples given above for Actual Incidents) or just by luck, such as a gas cloud dispersing before reaching a source of ignition. Another more potentially interesting mechanism that leads to a Near Miss rather than an Actual Incident is a successful improvised intervention. An example of this could be a vigilant operator correctly diagnosing an unexpected build-up of pressure and opening a valve to release the pressure, performing a non-standard but effective action. If such improvisations were frequently involved in the Near Miss incidents occurring in a particular organization that may be an indicator of the organization explicitly or tacitly supporting more adaptive, EM, practices than otherwise.

It is Potential Incidents that are perhaps of most interest for this research. These are the 'latent conditions' and 'active failures' that are represented as holes in the 'Swiss Cheese' slices (Reason, 1990a, 2016, 1997). If such a system weakness is detected before it has the opportunity to incubate into a release of the hazard, it is termed a 'Potential Incident'. In the traditional view, such a system weakness could be a degraded or failed barrier, or it may be a 'resident pathogen' (Reason, 1990a: 29) such as an ambiguous procedure, loss of currency in a technical skill, a maintenance backlog or an unclear critical communication. In the 'Safety II' view, a Potential Incident can also manifest as a degradation of mindfulness and expert improvisation that may normally be operating to maintain safety despite imperfect equipment or system design (Hollnagel, 2014). A system weakness representing a Potential Incident may be detected by luck, from a chance observation. Or it may be detected by the effective working of routine testing or inspection process that was designed specifically to detect such weaknesses. Or a Potential Incident may be detected by a vigilant human operator, technician or engineer discovering some anomaly, perhaps by a diligent, thorough analysis of an unusual indication in the control room.

These latter two mechanisms are of most interest for this research. The identification of a Potential Incident provides the opportunity for an organization to learn about a system weakness and correct or mitigate it before it can incubate into either an Actual Incident or a Near Miss. An organization's ability to identify Potential Incidents may therefore be a useful indicator of its safety. 


\section{Repertory Grid Interview Technique}

We asked each participant to come to the interview prepared to discuss six incidents, two of each type (actual incident, near miss and potential incident) with which they were personally familiar, and in order to focus on significant incidents, that had or could have had consequences of level 3 to 5 inclusive on a scale of severity (see Table SUP - 2). We did not discuss incidents resulting from highly unpredictable events, so-called 'Black Swans' (Taleb, 2007) as these would be less likely to provide insights into action errors.

To help participants prepare, we sent them a pre-interview briefing note (see below) that included definitions of the three different incident types. At the beginning of each interview we also checked the participant's understanding, using a visual portrayal of the three incident types shown on the bow tie model diagram (CCPS and Energy Institute, 2018) (see Figure SUP - 1). Although the bow tie model represents a typically EP view of how hazards are controlled, each incident pathway shown on the bow tie also represents a 'Swiss Cheese' model (Reason, 1990a) 'undoubtedly the most popular accident causation model' (Underwood and Waterson, 2014: 76) which can also encompass an EM view, in that the independence of the cheese slices, commonly interpreted as 'defences in depth', can become degraded in common failure modes that require an EM approach to identify and mitigate (Hudson and Hudson, 2015). Both models were familiar to all participants.

Having agreed with the participant the 'topic' of averting and mitigating process safety incidents, and the 'elements' as the six incidents chosen by the participant, the researcher conducted the interview using the following process:

After asking the participant to describe briefly how each incident unfolded, and noting each one on a card pre-printed with the relevant incident type definition, the researcher selected three, laying the cards in front of the participant, and asked the standard question: "Considering these three incidents, please think about how two of these were similar, and thereby different from the third one?". While the participant reflected on this the researcher occasionally moved the cards around and prompted "In what sense are they similar and different?".

Picking out a key word or phrase the participant used in responding, the researcher then asked the interviewee to describe the two extremes of that idea. The construct and its polar opposite or 'pole' were then summarised into short phrases describing these two extremes. After the interviewee had confirmed their agreement to the wording, the researcher wrote down these phrases at each end of the first line on a prepared repertory grid sheet and asked the participant to clarify the meaning of construct with the question: "In what way is [Construct] important to you in regard to describing these incidents?".

The participant's response to this was captured in the interview recording and later used to contextualise the construct, to help with categorisation as part of the data analysis. Next, the interviewee was asked to score the three events on a scale from 1 to 4 , with 4 representing the extreme of the construct and 1 representing the extreme of the pole. Finally, the interviewee was asked to score the remaining events on the same scale, thus creating the first line of the repertory grid. 
Further different combinations of three incidents ('triads') were then used to elicit other constructs. The triads were presented in a pre-determined sequence designed so that as far as practically each incident type was represented equally. With each triad, a new construct was sought; no repeat constructs were allowed, so the interviewee was encouraged to think more deeply about the incidents as the interview progressed. This process continued until the interviewee could think of no new constructs; the result of the interview was the participant's repertory grid summarising their personal views about the incidents.

\section{PRE-INTERVIEW BRIEFING NOTE (email sent to each interviewee before interview)}

\section{Dear (INSERT NAME)}

Thank you very much for agreeing to be interviewed about process safety incidents. The purpose of this research is to examine what operational and technical people see as the important factors that influence process safety. I would like to emphasise that this is voluntary you are free to leave the interview at any time. In addition, the contents of the interview will remain confidential and anonymous. With your permission, the interview will be recorded.

I would emphasise that the subject of this research is process safety - meaning basically avoiding explosions, fires and toxic releases - the sort of incidents that can result from the nature of the plant and the materials it contains. These incidents can lead to multiple fatalities and serious injuries as well as major environmental impact and asset damage.

In the interview I would like to ask you about a number of process safety-related occurrences that you know about, to get your personal interpretation of the circumstances and factors affecting them. Before the interview, please choose two examples of each of the following types of occurrence:

Actual incident: real incident that happened (energy or hazardous material was released) and had significant actual consequences (Consequence level 3 to 5)

Near-miss incident: real incident that happened (energy or hazardous material was released) without significant consequences - but could have had level 3 to 5 consequences

Potential incident - unsafe act or condition that could have led to an incident (Consequence level 3 to 5) but was stopped from developing into a real incident, without release of energy or hazardous material.

Please come to the interview ready to talk about each of them, i.e. a total of six occurrences. Please also bring with you basic documentation about each one: incident report, database reference etc.

The objective is to get your personal views about each one: What happened, how it occurred, and the things that were happening during and in the lead-up to the incident that may have influenced the people involved to act as they did. During the interview I will ask you about how they compare and contrast, following a straightforward process. The interview should take 1 to $1 \frac{1}{2}$ hours maximum.

Thank you once again for your help with this research. I look forward very much to meeting and working with you.

Best wishes 


\section{B) ADDITIONAL TABLES}

Table SUP-1 Summary profiles of the three sites

\begin{tabular}{|c|c|c|c|}
\hline & Site A & Site B & Site C \\
\hline Overview & $\begin{array}{l}\text { Very large single site } \\
\text { Petrochemicals } \\
\text { complex }\end{array}$ & $\begin{array}{l}\text { Onshore Oil \& Gas } \\
\text { production, Large number of } \\
\text { remote production units } \\
\text { dispersed geographically; } \\
\text { single large treatment and } \\
\text { export plant }\end{array}$ & $\begin{array}{l}\text { Offshore Oil \& Gas } \\
\text { production, single platform; } \\
\text { onshore technical and } \\
\text { operations support }\end{array}$ \\
\hline Location & Middle East & Asia Pacific & Europe \\
\hline Organization form & Strong hierarchy & Hierarchy / open culture & Weak hierarchy / open culture \\
\hline Personnel & Largely ex-patriot & Largely local & Largely local \\
\hline No. of people & $2000+$ & $4000+$ & $200+$ \\
\hline $\begin{array}{l}\text { Organizational } \\
\text { Maturity }\end{array}$ & $\begin{array}{l}\text { In transition from very } \\
\text { large Project to } \\
\text { Operations }\end{array}$ & $\begin{array}{l}\text { Mixed; rapidly growing } \\
\text { number of physical assets }\end{array}$ & Stable; very mature \\
\hline Years of operation & $5+$ & $10+$ & $20+$ \\
\hline $\begin{array}{l}\text { Relation with } \\
\text { Parent Org }\end{array}$ & $\begin{array}{l}\text { Significant specialist } \\
\text { support }\end{array}$ & $\begin{array}{l}\text { In process of adopting Parent } \\
\text { Org technical standards }\end{array}$ & $\begin{array}{l}\text { Fairly independent; supported } \\
\text { as needed }\end{array}$ \\
\hline $\begin{array}{l}\text { Perceived Safety } \\
\text { Performance }\end{array}$ & Mixed & Below average & Above average \\
\hline
\end{tabular}

Table SUP-2 Consequence Severity Scale Reference: (Summers, Vogtmann and Smolen, 2011)

\begin{tabular}{|c|c|c|c|}
\hline & People & Environmental damage & Asset loss / Operation impact \\
\hline 5 & Multiple fatalities & Catastrophic off-site damage & $>\$ 10 \mathrm{M}$ and substantial offsite damage \\
\hline 4 & 1 or more fatalities & Significant off-site damage & $\$ 1 \mathrm{M}-\$ 10 \mathrm{M}$ and severe impact \\
\hline 3 & Hospitalization injury & On-site or offsite release with damage & $\$ 100 \mathrm{~K}-\$ 1 \mathrm{M}$ and significant impact \\
\hline 2 & Lost workday injury & On-site or offsite release without damage & $\$ 10-\$ 100 \mathrm{~K}$ and some impact \\
\hline 1 & Recordable injury & On-site release & $<\$ 10 \mathrm{~K}$ and minor impact \\
\hline
\end{tabular}


Table SUP-3 Illustrative Quotes \& Categorisation of Factors from Semi-Structured Interviews

\begin{tabular}{|c|c|c|c|}
\hline Theor. Cat. & Site & Illustrative Quote from Semi-Structured Interviews & EP / EM Cat. \\
\hline \multirow{3}{*}{$\begin{array}{l}\text { Risk } \\
\text { Management }\end{array}$} & A & $\begin{array}{l}\text { The permit applicant goes in the morning and applies for a permit. Then he is taking about half an hour or } 45 \\
\text { minutes, then he will go to the field to meet the field operator...Then he will give a toolbox talk... then there's a } \\
\text { last-minute risk assessment. So I think people arriving to the site, for example, at six o'clock in the morning start } \\
\text { work at eight o'clock. These two hours... demotivates the people, making mistakes to happen. }\end{array}$ & \multirow{12}{*}{$\begin{array}{l}\text { EP } \\
\text { Organization } \\
\text { Practices }\end{array}$} \\
\hline & B & $\begin{array}{l}\text { When something is a barrier impact, it might be the level of SCE fail or something. It might be something } \\
\text { reported in the field but it is still just a manual entry and risk assessment into the barrier model. }\end{array}$ & \\
\hline & $\mathbf{C}$ & $\begin{array}{l}\text { Okay we have risk matrices, risk meetings....My team has meetings with } C \text { and } D \text { to discuss safety issues and I } \\
\text { attend an Ops team meeting where we discuss the issues... They have morning meetings offshore, onshore every } \\
\text { day at nine o'clock. There's a structure in place so that the entire organization is on the same page }\end{array}$ & \\
\hline \multirow{3}{*}{$\begin{array}{l}\text { Planning and } \\
\text { resourcing }\end{array}$} & A & $\begin{array}{l}\text { when you think about technical authority and the clarity of the technical authority and roles and responsibilities. } \\
\text { It is there, but it is effective or not? I am neutral, I don't think we are there yet. }\end{array}$ & \\
\hline & B & $\begin{array}{l}\text { There's definitely a genuine interest in some of those key things such as asset integrity, process safety review } \\
\text { meeting, the incident review panel, and the MOC meeting. That's key. The safety guys often ran those things. } \\
\text { Now, the new leadership is, "no, I will chair that" }\end{array}$ & \\
\hline & $\mathbf{C}$ & $\begin{array}{l}\text { We do regular surveillance, the team do surveillance before the morning meeting, and also after. It's not only a } \\
\text { red and green. It's a bit richer than that, Yes. Because you need to both understand, is it trending upwards or } \\
\text { downwards? Is it stable? Can we do better? }\end{array}$ & \\
\hline \multirow{3}{*}{ Competence } & A & $\begin{array}{l}\text { So the guy goes into the field, opens the valve - which he shouldn't open. With the best intent. Experienced } \\
\text { operator with the best intent, but there's more around does this guy understand our process safety mindset, our } \\
\text { process safety behaviours? Does he understand you don't open a drain valve on a running line at } 3.5 \text { bar? }\end{array}$ & \\
\hline & B & $\begin{array}{l}\text { They've never been educated around process safety risks... Having to move from a mindset where blow-torching } \\
\text { the pig launchers to get the paint off was an operational task on a live plant, no permit required... to the point } \\
\text { where you're purging and leak testing for every service that you complete, is quite a mindset change }\end{array}$ & \\
\hline & $\mathbf{C}$ & I think it's very experienced personnel in the control room. The operators, they know the hazards very good. & \\
\hline \multirow{3}{*}{ Procedures } & A & $\begin{array}{l}\text { We create a lot of paperwork; we do create a lot of paperwork versus other sites where I've worked where } \\
\text { there's a lot less paperwork. I think this is an interesting one in that if you create a new organization, and you're } \\
\text { bringing people in from all over the place ... you tend to therefore document things very rigidly... }\end{array}$ & \\
\hline & B & $\begin{array}{l}\text {...we're a long way from where we need to be. The procedures that we've got in the business are one task fits all. } \\
\text { If I pull out the procedures now it will say this is what the plant operator does, this is what the control room } \\
\text { contributes into it, this is what the next person will do. It...becomes very disjointed. }\end{array}$ & \\
\hline & $\mathbf{C}$ & $\begin{array}{l}\text { I think that we have quite good systems that should we have the FSR reports and show that. We have this -- } \\
\text { When we have a deviation it is quite a good group of people sitting together in discussion, and challenging each } \\
\text { other and have mitigation. We also have several systems that should cover all these issues }\end{array}$ & \\
\hline
\end{tabular}




\begin{tabular}{|c|c|c|c|}
\hline Theor. Cat. & Site & Illustrative Quote from Semi-Structured Interviews & EP / EM Cat. \\
\hline \multirow{3}{*}{$\begin{array}{l}\text { Embedding } \\
\text { improvements }\end{array}$} & $\mathbf{A}$ & $\begin{array}{l}\text { So very interactive session, about two hours, we do it every quarter on a couple of processes. And that gives two } \\
\text { ways. That gives them the way of our assurance on how healthy we are in execution, but it also gives the } \\
\text { opportunity to feedback what we think can be better in the procedures. }\end{array}$ & \multirow{3}{*}{$\begin{array}{l}\text { EP } \\
\text { Organization } \\
\text { Practices }\end{array}$} \\
\hline & B & $\begin{array}{l}\text { I think the way that I do it is I engage the technicians in doing all of the red lining and reviewing of } \\
\text { procedures... typically use night shift. To walk and red line the procedures. Is this currently what we do? }\end{array}$ & \\
\hline & $\mathbf{C}$ & $\begin{array}{l}\text { They have found several errors between the control room master } P \& I D \text { and on the site. They have then now } \\
\text { suggested to actually elevate this as a bigger project... I know that when they raise that to their leadership, they } \\
\text { will get support of doing that. }\end{array}$ & \\
\hline \multirow{3}{*}{ Compliance } & $\mathbf{A}$ & $\begin{array}{l}\text { But always the issue is the implementation. For example, when you see the documentation, and the rules and } \\
\text { procedures, everything is there, but who is going to implement it. So the leaders are giving the coaching, } \\
\text { showing the way, the direction, the guidance, everything, but always the problem is with the implementation. }\end{array}$ & \multirow{3}{*}{$\begin{array}{l}\quad \text { EP } \\
\text { Working } \\
\text { Practices }\end{array}$} \\
\hline & B & $\begin{array}{l}\text { If you feel the procedure is not working, the procedure is not letting you to get to the desired objective, stop it, } \\
\text { come to us. That is the expectation we have given. }\end{array}$ & \\
\hline & $\mathbf{C}$ & $\begin{array}{l}\text { We have a tendency to write too many procedures and not respect the craftsmanship...I think this is a very nice } \\
\text { balance because I don't expect people to follow procedure if they certainly see that the procedure is wrong. I will } \\
\text { not challenge them a lot on the way they will do the task but I will challenge them to document the difference }\end{array}$ & \\
\hline \multirow{3}{*}{$\begin{array}{l}\text { Supporting } \\
\text { individuals \& } \\
\text { networks }\end{array}$} & $\mathbf{A}$ & $\begin{array}{l}\text { I've seen that at A just by giving the right steer, the right expectations to guys. Don't distract them with all kind } \\
\text { of other shit, just let the guys focus on what they need to deliver and need to do and give them the few of the right } \\
\text { tools and steers to them, makes a hell of a difference. }\end{array}$ & \multirow{6}{*}{$\begin{array}{l}\text { EM } \\
\text { Organization } \\
\text { Practices }\end{array}$} \\
\hline & B & $\begin{array}{l}\text { I think we've got potentially some strengthening of network and networks... Yes, that's where I'd like to see this } \\
\text { get to but where we're at the moment is probably reliant on ...communications and networks at the field manager } \\
\text { / superintendent level. }\end{array}$ & \\
\hline & $\mathbf{C}$ & $\begin{array}{l}\text { If you've got a problem, you know who to contact to talk about that problem. It's not that you go outside and } \\
\text { shout to the moon. [laughter] You know who to contact ... you know who they are, most of them. }\end{array}$ & \\
\hline \multirow{3}{*}{$\begin{array}{l}\text { Enabling } \\
\text { Ambidexterity }\end{array}$} & $\mathbf{A}$ & $\begin{array}{l}\text { We used to crack open the bypass and then things are getting managed. But then it was challenged by the } \\
\text { technologists; how do your operators bypass this? But this should not come after bypass opening, this should } \\
\text { have come before bypass opening. If you can't open the bypass, we should have not designed the bypass. }\end{array}$ & \\
\hline & B & $\begin{array}{l}\text { You're going to leave it a little bit loose, the micro-manager will want to check everyone's activity... You have } \\
\text { that. You also have a person who completely trusts his people, which does the opposite extreme and can result in } \\
\text { people pushing themselves outside where...their confidence level goes above where their actual competency is. } \\
\text { It's finding that balancing point between the competency and the confidence to allow people to use that }\end{array}$ & \\
\hline & $\mathbf{C}$ & $\begin{array}{l}\text { I think this is a very nice balance because I don't expect people to follow procedure if they certainly see that the } \\
\text { procedure is wrong. I will not challenge them a lot on the way they, in fact, will do the task but I will challenge } \\
\text { them to document the difference }\end{array}$ & \\
\hline
\end{tabular}




\begin{tabular}{|c|c|c|c|}
\hline Theor. Cat. & Site & Illustrative Quote from Semi-Structured Interviews & EP / EM Cat. \\
\hline \multirow{3}{*}{$\begin{array}{l}\text { Encouraging } \\
\text { improvement }\end{array}$} & A & $\begin{array}{l}\text { We are reasonably well engaged in the two-way, then ideas, suggestions do get raised from the ground floor } \\
\text { and find a way, not every idea gets through but at least people feel that they can raise ideas... }\end{array}$ & \multirow{9}{*}{$\begin{array}{l}\text { EM } \\
\text { Organization } \\
\text { Practices }\end{array}$} \\
\hline & B & $\begin{array}{l}\text { We have some KPIs in people's goals around identifying a better way of work or coming up with a business } \\
\text { improvement...things like that. I don't think we're as focused on to this as we could be. }\end{array}$ & \\
\hline & $\mathbf{C}$ & $\begin{array}{l}\text { Then we give feedback to the person that's raised the question and it's open for everyone to go in and see. We } \\
\text { also have to put good feedback if we decide not to do it, but actually we do. I think we try to do about } 70,75 \% \\
\text { of it. Since we started this, I would think we have } 50 \text { - } 60 \text { the last year. }\end{array}$ & \\
\hline \multirow{3}{*}{$\begin{array}{l}\text { Encouraging } \\
\text { teamwork }\end{array}$} & $\mathbf{A}$ & $\begin{array}{l}\text { We have a multi-cultural environment. We have people working from different countries...It's advantageous } \\
\text { because people have worked in different environments and they have a different mindset to work. }\end{array}$ & \\
\hline & B & $\begin{array}{l}\text {...if this role says in our daily meeting, "I need a hand," it's now actually my job to go and find the engineer } \\
\text { and go and chase... You need something, you're going to work it all out. }\end{array}$ & \\
\hline & $\mathbf{C}$ & $\begin{array}{l}\text { More systematic. Better instruction and procedure. The people, our leaders, make this procedure and } \\
\text { instruction. They are not: "our leadership is making the procedure and instruction, and here we are"... but the } \\
\text { team are doing it together. }\end{array}$ & \\
\hline \multirow{3}{*}{$\begin{array}{l}\text { Emergent } \\
\text { leadership }\end{array}$} & $\mathbf{A}$ & $\begin{array}{l}\text { Give the work back to the people and be very clear, all leaders, about what you expect of people. I say that to } \\
\text { my Board, it's such a danger so I've been focussing on process safety for the past year. We didn't have any } \\
\text { process safety incidents, hardly any weak signals. We really stepped up tremendously. I've shown it now for a } \\
\text { year, how do I make sure that next year I will show that same rigour on this subject? }\end{array}$ & \\
\hline & B & $\begin{array}{l}\text { Managers come in bringing new ideas, but also get trained in what the safety culture is of the business by the } \\
\text { people at the lower level now. I'm actually seeing that leadership transitioning from the managers that brought } \\
\text { them in in the first place, down to people on the ground actively leading in on the safety culture }\end{array}$ & \\
\hline & $\mathbf{C}$ & $\begin{array}{l}\text { If you are putting three or four people together in a working group, it's normal that one of them taking the lead } \\
\text { in the group because he might have some more experience on the working and mostly what they're going to do. } \\
\text { Also, the foreman tried to put people together, so we always have one that's very experienced }\end{array}$ & \\
\hline \multirow{3}{*}{$\begin{array}{l}\text { Sensemaking / } \\
\text { sensegiving \& } \\
\text { challenging }\end{array}$} & $\mathbf{A}$ & $\begin{array}{l}\text { If you then ask all of them there, they will tell you this, this guy always ask the question because I told him sir. I } \\
\text { need to ask you because something when wrong and I did not ask you maybe I will do something foolish there, so } \\
\text { I need come up to you ask you again. }\end{array}$ & \multirow{3}{*}{$\begin{array}{l}\text { EM } \\
\text { Working } \\
\text { Practices }\end{array}$} \\
\hline & B & $\begin{array}{l}\text { It's no good bringing something out and saying you're doing this. First, they've got to convince me that whilst I'm } \\
\text { no expert on any one subject, if I can see it, if I feel it's okay, then I've got half a chance of convincing the team } \\
\text { as okay, and not just following the direction because it's a piece of paper. }\end{array}$ & \\
\hline & C & $\begin{array}{l}\text { We have worked a lot to connect individuals with the strategy, so you see how you contribute. What's my purpose } \\
\text { in this organization? Everyone here should be able to answer that question }\end{array}$ & \\
\hline
\end{tabular}




\begin{tabular}{|c|c|c|c|}
\hline Theor. Cat. & Site & Illustrative Quote from Semi-Structured Interviews & EP / EM Cat. \\
\hline \multirow{3}{*}{$\begin{array}{l}\text { Preoccupation } \\
\text { with Failure }\end{array}$} & A & $\begin{array}{l}\text { One of our guys who put test packs together, he noticed on our relief valve that an impulse tube was } \\
\text { disconnected...luckily this lad knew what he was looking at, realised the consequences and stepped in } \\
\text { immediately. He was recognised for the P [Production Safety] award. }\end{array}$ & \multirow{15}{*}{$\begin{array}{c}\text { EM } \\
\text { Working } \\
\text { Practices }\end{array}$} \\
\hline & B & $\begin{array}{l}\text { There's very active asset integrity inspection programs, testing programs, maintenance programs. There's all } \\
\text { systemized methods of doing that. There's also encouragement of hazard reporting across most of the business }\end{array}$ & \\
\hline & $\mathbf{C}$ & $\begin{array}{l}\text { I think we're fairly good, we have very few actual incidents. We have quite a lot of potential incidents, and I } \\
\text { think that's a good thing, because potential incidents tells me as a leader that we actually notice it. }\end{array}$ & \\
\hline \multirow{3}{*}{$\begin{array}{l}\text { Reluctance to } \\
\text { Simplify }\end{array}$} & A & $\begin{array}{l}\text { I think we're learning how to use incidents as weak signals and I think when you do that, if you jump on } \\
\text { everything you create also a lot of unrest in the organization. }\end{array}$ & \\
\hline & B & $\begin{array}{l}\text { It's definitely changed now, though commissioning was definitely production based: Let's get it finished and get } \\
\text { it online. But now it's a lot more... stop and think a lot more }\end{array}$ & \\
\hline & $\mathbf{C}$ & $\begin{array}{l}\text { Yes, you trust your good experience and your competence that even though it's in a procedure, well maybe this } \\
\text { that or maybe you can't follow it like that. It's not that difficult to get something changing the procedure. }\end{array}$ & \\
\hline \multirow{3}{*}{$\begin{array}{l}\text { Sensitivity to } \\
\text { Operations }\end{array}$} & A & $\begin{array}{l}\text { Ownership in shifts is always difficult... So there is someone in day shift, in the operations management space, } \\
\text { who we've put in the driving seat to make the calls on the higher risk activities }\end{array}$ & \\
\hline & B & $\begin{array}{l}\text { If a couple descriptions weren't right on a work order, if we don't know 100\%, we just revert it all back and } \\
\text { make sure we get exactly the information that we require. }\end{array}$ & \\
\hline & $\mathbf{C}$ & $\begin{array}{l}\text { We also have introduction of situation-based information on those big screens. I take it on the big screen and } \\
\text { show the shift going off goes through the logbook and say what they have done, and...then the day man, when } \\
\text { they finish here, going in the coffee bar, and then they are going talking back-to-back. }\end{array}$ & \\
\hline \multirow{3}{*}{$\begin{array}{l}\text { Commitment } \\
\text { to Resilience }\end{array}$} & A & $\begin{array}{l}\text { You see those teams maturing at the moment, but the intervention we needed to make was we believe those } \\
\text { teams are at the moment not... mature enough to make the calls on whether or not we are good enough to go... }\end{array}$ & \\
\hline & B & So I try to get them thinking about barriers. The Swiss Cheese model and the outcomes if you don't. & \\
\hline & $\mathbf{C}$ & $\begin{array}{l}\text { We don't know everything and so we have to be aware and do a lot of campaigns. So now when we have these } \\
\text { findings, we do a lot of more inspections in same systems }\end{array}$ & \\
\hline \multirow{3}{*}{$\begin{array}{l}\text { Deference to } \\
\text { Expertise }\end{array}$} & A & $\begin{array}{l}\text { If it was a safety threat, myself, my panel operators and my field operators are all empowered to take a decision } \\
\text { of shut down or isolating or making the plant safe if it feels to be unsafe. }\end{array}$ & \\
\hline & B & ...if something's urgent, at my technician level, they can deal with certain things, then they can escalate & \\
\hline & $\mathbf{C}$ & $\begin{array}{l}\text { That respect for what level of organization is doing what and accept that you can't know everything at any time. } \\
\text { That means a lot to me, that my boss appreciate that I tell him, "I don't know... The only thing I know, I have } \\
\text { good people on it, and I will tell you when we have more information." }\end{array}$ & \\
\hline
\end{tabular}




\begin{tabular}{|c|c|c|c|}
\hline Theor. Cat. & Site & Illustrative Quote from Semi-Structured Interviews & EP / EM Cat. \\
\hline \multirow{3}{*}{ Culture } & $\mathbf{A}$ & $\begin{array}{l}\text { The best way is to just whatever happens, you just come out and tell exactly what happened, just be frank so } \\
\text { that people can learn okay this happened so we should just avoid. But suppose if I say like this, then there will } \\
\text { be a lot of finger pointing, then we end up missing actually what caused this one. }\end{array}$ & \multirow{6}{*}{$\begin{array}{l}\text { Contextual } \\
\text { Conditions }\end{array}$} \\
\hline & B & $\begin{array}{l}\text { I would say the reporting culture in itself is excellent within the company. I do believe it's certainly one of the } \\
\text { best I've seen. However, in terms of investigation and action on low level near misses I would say we are poor. }\end{array}$ & \\
\hline & $\mathbf{C}$ & $\begin{array}{l}\text { I also think that you are allowed to speak up. Also the management actually expects you to speak up. By having } \\
\text { this open dialogue and also that extra dare to speak up and also have that ownership. }\end{array}$ & \\
\hline \multirow{3}{*}{$\begin{array}{l}\text { Structure \& } \\
\text { Maturity }\end{array}$} & A & $\begin{array}{l}\text { We went into operating mode without considering what the right organization needs to be. So now we're at a } \\
\text { point where we are in an operating phase and mature enough where we can start to say what activities do we } \\
\text { have? How are we going to execute those activities? And then how much resources ...? }\end{array}$ & \\
\hline & $\mathbf{B}$ & $\begin{array}{l}\text { I've been in B now for six years. It's only really been the last } 18 \text { months or so that I would say it feels like an } \\
\text { operating company. Before that, it felt like a projects company but that will be in operation. Then suddenly we } \\
\text { had all this stuff built and handed over. }\end{array}$ & \\
\hline & $\mathbf{C}$ & $\begin{array}{l}\text { Tomorrow we're doing this monthly, it's an integrity, safety and reliability meeting. Then we go through all the } \\
\text { safety critical elements and issues.. The whole management team knows what's going on. Most of them, they } \\
\text { have been manager at } C \text {-- they know the equipment, they understand what's going on }\end{array}$ & \\
\hline
\end{tabular}


Table SUP-4a Illustrative Quotes \& Categorisation of Causal Factors from Incident Documents

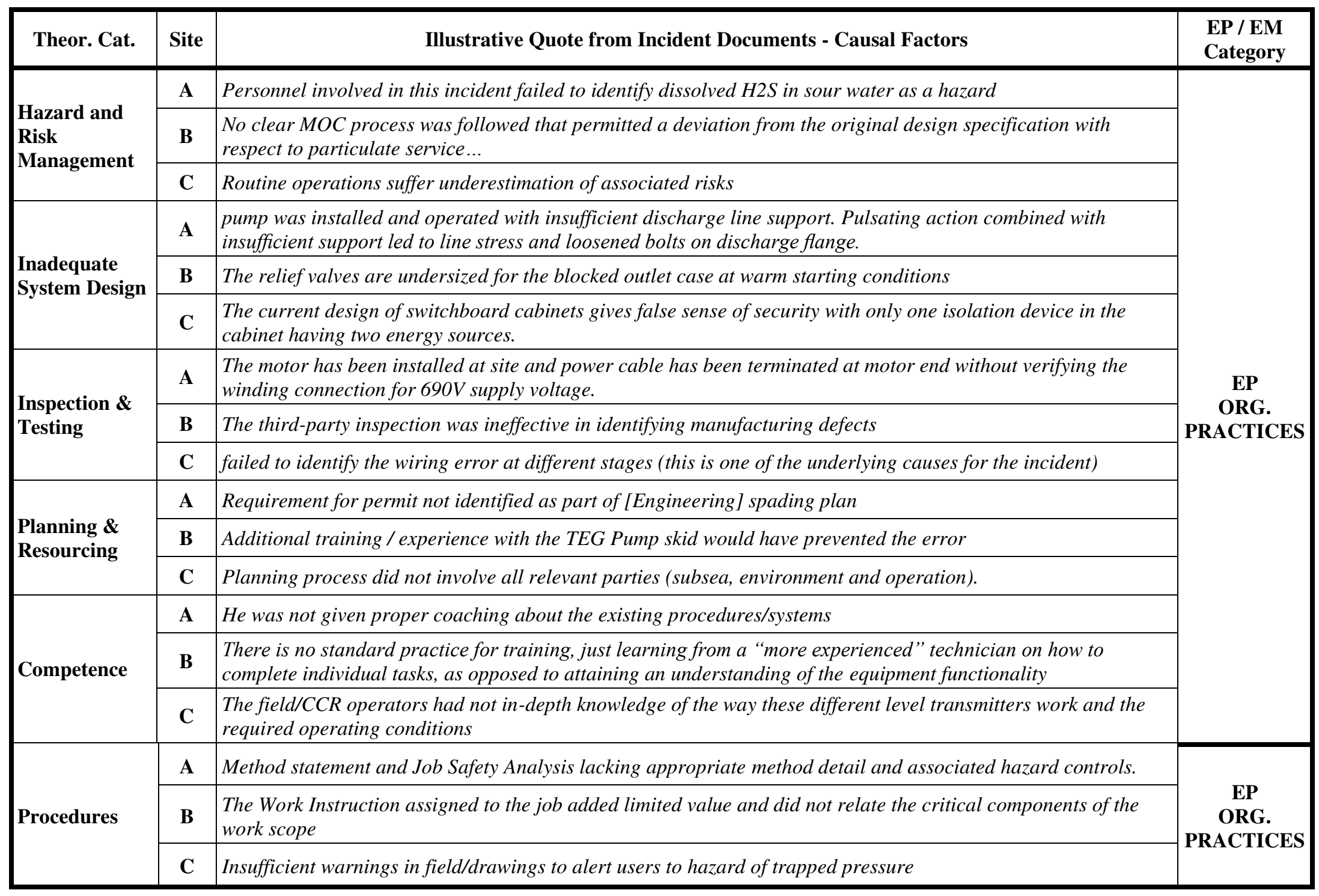




\begin{tabular}{|c|c|c|c|}
\hline Theor. Cat. & Site & Illustrative Quote from Incident Documents - Causal Factors & $\begin{array}{l}\text { EP / EM } \\
\text { Category }\end{array}$ \\
\hline \multirow{3}{*}{ Compliance } & $\mathbf{A}$ & $\begin{array}{l}\text { Coordinator and System Owner left the work location and supervision of Operation Support personnel was left to } \\
\text { Area } 1 \text { mech execution lead }\end{array}$ & \multirow{3}{*}{$\begin{array}{l}\text { EP } \\
\text { WORKING } \\
\text { PRACTICES }\end{array}$} \\
\hline & B & The Isolation Authority did not cross-check with P\&ID to identify the correct vessel & \\
\hline & $\mathbf{C}$ & Several isolations plans set in the same area created confusion and conflicts & \\
\hline \multirow{3}{*}{$\begin{array}{l}\text { Emergency } \\
\text { Response }\end{array}$} & A & None & \multirow{9}{*}{$\begin{array}{l}\text { EM } \\
\text { ORG. } \\
\text { PRACTICES }\end{array}$} \\
\hline & B & Delay in mobilising Emergency Response Team to incident. & \\
\hline & $\mathbf{C}$ & $\begin{array}{l}\text { Emergency Coordinator did not log manually the communication (process will be automatic if Crisis Manager } \\
\text { portal was used, but they did not log into system) }\end{array}$ & \\
\hline \multirow{3}{*}{ Empowerment } & A & Lack of empowerment \& ownership & \\
\hline & B & None & \\
\hline & $\mathbf{C}$ & None & \\
\hline \multirow{3}{*}{$\begin{array}{l}\text { Organizational } \\
\text { Learning }\end{array}$} & A & $\begin{array}{l}\text { This was a repeat incident, The previous investigation of a small acid leak at the same location did not identify } \\
\text { the correct root cause, therefore the weak signal was not followed through. }\end{array}$ & \\
\hline & B & $\begin{array}{l}\text { Of significant concern is that as there has been at least three similar incidents have occurred at [Site B] in the } \\
\text { past five year, it is clear that with regard to this issue that organisation learning has not happened }\end{array}$ & \\
\hline & $\mathbf{C}$ & Knowledge of similar incidents was not sufficiently taken into account in planning process. & \\
\hline \multirow{3}{*}{$\begin{array}{l}\text { Non-Technical } \\
\text { Skills }\end{array}$} & A & Over confidence because of this job was carried out several time in past. & \multirow{3}{*}{$\begin{array}{l}\text { EM } \\
\text { WORKING } \\
\text { PRACTICES }\end{array}$} \\
\hline & B & $\begin{array}{l}\text { Risk identified during turn around, partial isolation applied by one shift though removed by the following shift } \\
\text { due to confusion of the intention of the isolation \& believing it was not required }\end{array}$ & \\
\hline & C & $\begin{array}{l}\text { The 'organizational memory' had a negative impact this time, since the assumption that one of the instruments } \\
\text { did not work due to methanol in the mixture. 'Organizational memory' determined the opening earlier, since the } \\
\text { operators might want to avoid overfilling the separator, as it happened during start-up after SD } 2009\end{array}$ & \\
\hline \multirow{3}{*}{$\begin{array}{l}\text { Blame \& } \\
\text { Pressure }\end{array}$} & A & $\begin{array}{l}\text { Time pressure resulted in Area } 1 \text { mech supervisor executing the work himself instead of searching for different } \\
\text { support personnel }\end{array}$ & \multirow{3}{*}{ CONTEXT } \\
\hline & B & $\begin{array}{l}\text { more focussed with production / cost saving initiatives than asset integrity. Concern was explicitly voiced that } \\
\text { these fires are continually occurring. }\end{array}$ & \\
\hline & C & $\begin{array}{l}\text { Operator stressed to complete job within the night shift and stressed by weather conditions (heavy rains, papers } \\
\text { wet), which caused the decision to break the isolation plan }\end{array}$ & \\
\hline
\end{tabular}


Table SUP-4b Illustrative Quotes \& Categorisation of Recommendations from Incident Documents

\begin{tabular}{|c|c|c|c|}
\hline Theor. Cat. & Site & Illustrative Quote from Incident Documents - Recommendations & EP / EM Cat. \\
\hline \multirow{3}{*}{$\begin{array}{l}\text { Hazard and } \\
\text { Risk } \\
\text { Management }\end{array}$} & $\mathbf{A}$ & $\begin{array}{l}\text { Operations personnel involved in this incident to develop a safety briefing highlighting exactly what went } \\
\text { wrong and the potential consequences }\end{array}$ & \multirow{18}{*}{$\begin{array}{c}\text { EP } \\
\text { ORG. } \\
\text { PRACTICES }\end{array}$} \\
\hline & B & $\begin{array}{l}\text { Develop communication to staff to clarify use of electrical and non-intrinsically safe equipment inside the } \\
\text { plant. }\end{array}$ & \\
\hline & $\mathbf{C}$ & $\begin{array}{l}\text { Communicate to all relevant parties the incident learnings and how to work safely on live systems with } \\
\text { compression fittings. }\end{array}$ & \\
\hline \multirow{3}{*}{$\begin{array}{l}\text { Equipment or } \\
\text { System Design }\end{array}$} & A & Design and install permanent heat tracing for the external balance line at first opportunity & \\
\hline & B & $\begin{array}{l}\text { Revise interlock logic sequencing of XV-1234 to ensure that secondary interlock activates regardless of } \\
\text { whether } X V \text {-1234 finishes closing }\end{array}$ & \\
\hline & $\mathbf{C}$ & $\begin{array}{l}\text { CCTV surveillance inside the hood against leak critical components and areas in turbine must be } \\
\text { prioritized and put into action }\end{array}$ & \\
\hline \multirow{3}{*}{$\begin{array}{l}\text { Inspection \& } \\
\text { Testing }\end{array}$} & A & Trace material certificates of valve stem to check for sub-standard part & \\
\hline & B & $\begin{array}{l}\text { Implement revised Maintenance strategy to overhauls of drive head motors and ensure associated QA/QC } \\
\text { \& testing meets strategy requirements }\end{array}$ & \\
\hline & $\mathbf{C}$ & $\begin{array}{l}\text { Good practice is to double check all links when one considers the job as done, preferably by one } \\
\text { colleague if you work more together }\end{array}$ & \\
\hline \multirow{3}{*}{$\begin{array}{l}\text { Planning \& } \\
\text { Resourcing }\end{array}$} & A & Maintenance team to review current JHA with update to include hazard of xxx services & \\
\hline & B & Define well integrity work programme and establish whether resourcing levels are adequate & \\
\hline & $\mathbf{C}$ & The matrix for start-up should be reviewed & \\
\hline \multirow{3}{*}{ Competence } & A & $\begin{array}{l}\text { Job Safety Analysis (JSA) standard/training/authorisation/auditing procedure required. Action PTW Lead } \\
\text { by end Q3 }\end{array}$ & \\
\hline & B & $\begin{array}{l}\text { Develop and implement a skills maintenance program for all activities. Reinforce proper operations } \\
\text { practices via recurring training program }\end{array}$ & \\
\hline & $\mathbf{C}$ & $\begin{array}{l}\text { Train operators, technicians and supervision in the new hydraulic systems. Include field time in this } \\
\text { training. }\end{array}$ & \\
\hline \multirow{3}{*}{ Procedures } & $\mathbf{A}$ & $\begin{array}{l}\text { add new step in maintenance procedure: to stroke test valves in the field after installation to confirm } \\
\text { actuator is moving freely }\end{array}$ & \\
\hline & B & $\begin{array}{l}\text { New procedure to facilitate the depressurizing of the Piping ex. the discharge XV's to fin fan rack after } \\
\text { N2 purging of the respective compressors }\end{array}$ & \\
\hline & $\mathbf{C}$ & $\begin{array}{l}\text { Update current PTW procedure to clarify roles and responsibilities for small repairs activities on the } \\
\text { handed over equipment }\end{array}$ & \\
\hline
\end{tabular}




\begin{tabular}{|c|c|c|c|}
\hline Theor. Cat. & Site & Illustrative Quote from Incident Documents - Recommendations & EP / EM Cat. \\
\hline \multirow{3}{*}{ Compliance } & $\mathbf{A}$ & $\begin{array}{l}\text { Assign a PPE focal point as per the PPE Procedure, and complete an audit and feedback regarding the } \\
\text { use and effectiveness of various PPE }\end{array}$ & \multirow{3}{*}{$\begin{array}{c}\text { EP } \\
\text { WORKING } \\
\text { PRACTICES }\end{array}$} \\
\hline & B & Review expectations and roles of performing authorities in relation to performing and supervising work. & \\
\hline & $\mathbf{C}$ & $\begin{array}{l}\text { A matrix on the difference between normal operation functions and the SD functions regarding roles and } \\
\text { responsibilities should be implemented }\end{array}$ & \\
\hline \multirow{3}{*}{$\begin{array}{l}\text { Emergency } \\
\text { Response }\end{array}$} & A & None & \multirow{9}{*}{$\begin{array}{c}\text { EM } \\
\text { ORG. } \\
\text { PRACTICE }\end{array}$} \\
\hline & B & $\begin{array}{l}\text { Establish clear expectation about the required wellsite emergency response by staff in case of gas release } \\
\text { at wellsite. }\end{array}$ & \\
\hline & $\mathbf{C}$ & Conduct a separate review of the emergency response activities carried out after the incident & \\
\hline \multirow{3}{*}{$\begin{array}{l}\text { Recognition and } \\
\text { Support }\end{array}$} & A & Appreciation to be given to the Area 1 FO (Field Operator) & \\
\hline & B & None & \\
\hline & $\mathbf{C}$ & $\begin{array}{l}\text { Update the Duty Manager responsibilities to include ensuring that all persons involved in an incident } \\
\text { have been spoken to by their line manager and have received appropriate support. }\end{array}$ & \\
\hline \multirow{3}{*}{$\begin{array}{l}\text { Organizational } \\
\text { Learning }\end{array}$} & A & $\begin{array}{l}\text { Share Investigation results with other areas to create awareness where XYZ pumps or temporary } \\
\text { equipment is used }\end{array}$ & \\
\hline & B & $\begin{array}{l}\text { Review PSV dossier for all other similar PSV on other facilities to determine if there is any evidence of an } \\
\text { installed failure }\end{array}$ & \\
\hline & $\mathbf{C}$ & $\begin{array}{l}\text { Giving a problem statement, a solution or an action will probably not shift your belief. Giving you } \\
\text { insights and understanding on what caused the problem will }\end{array}$ & \\
\hline \multirow{3}{*}{$\begin{array}{l}\text { Non-Technical } \\
\text { Skills }\end{array}$} & A & $\begin{array}{l}\text { Any sudden change in Flow other than normal to be communicated by [Plant] PO to [Facilities] PO } \\
\text { (Panel Operators) }\end{array}$ & \multirow{3}{*}{$\begin{array}{c}\text { EM } \\
\text { WORKING } \\
\text { PRACTICES }\end{array}$} \\
\hline & B & staff to avoid (perception of) informal instruction and multiple accountable persons & \\
\hline & $\mathbf{C}$ & $\begin{array}{l}\text { To avoid future similar incidents Projects /Asset to share practices between Platform and Onshore plant } \\
\text { and possibly agree one leading practice }\end{array}$ & \\
\hline \multirow{3}{*}{$\begin{array}{l}\text { Safety } \\
\text { Messaging }\end{array}$} & $\mathbf{A}$ & Safety stand down conducted to communicate incident & \multirow{3}{*}{ CONTEXT } \\
\hline & B & $\begin{array}{l}\text { In light of lessons learnt from incident, senior management team to address shutdown safety village to } \\
\text { provide message on the importance of safety above all else }\end{array}$ & \\
\hline & $\mathbf{C}$ & $\begin{array}{l}\text { Stand-down with all shifts. Emphasize respect for isolation plans: set isolation plans shall not be broken } \\
\text { for any reason. }\end{array}$ & \\
\hline
\end{tabular}


Table SUP-5 Differentiation between EP and EM

\begin{tabular}{|c|c|}
\hline EP Paradigm & EM Paradigm \\
\hline $\begin{array}{l}\text { Basic assumption: Error prevention is necessary and } \\
\text { sufficient for avoidance of negative outcomes }\end{array}$ & $\begin{array}{l}\text { Basic assumption: Errors cannot be completely } \\
\text { prevented and are opportunities for learning }\end{array}$ \\
\hline Basic strategy: eliminate error precursors & Basic strategy: detect, mitigate and learn from errors \\
\hline Tactics: & Tactics: \\
\hline Identification of potential errors \& precursors: & Error detection: \\
\hline Analysis of hazards and risks / Risk Management & $\begin{array}{l}\text { 'Preoccupation with failure' } \\
\text { (suspicion of errors; standard checks and tests) }\end{array}$ \\
\hline \multirow[t]{4}{*}{$\begin{array}{l}\text { 'Fail-safe' \& ergonomic design of systems and } \\
\text { equipment }\end{array}$} & $\begin{array}{l}\text { 'Situation awareness' } \\
\text { (Vigilance / Sensemaking / Anticipation) }\end{array}$ \\
\hline & Communication \\
\hline & 'Psychological safety' for speaking up \\
\hline & Error management training \\
\hline Elimination of potential errors $\&$ precursors: & Error mitigation: \\
\hline Systems and equipment inspection \& maintenance & $\begin{array}{l}\text { Interventions by others } \\
\text { (Teamwork; Emergent Leadership) }\end{array}$ \\
\hline Planning \& Resourcing & Avoidance of error cascades \\
\hline Competence assurance & Collaborative problem-solving / Deference to expertise \\
\hline Formal work procedures & Emergency Response \\
\hline \multicolumn{2}{|l|}{ Compliance enforcement } \\
\hline \multicolumn{2}{|l|}{ Avoidance of distractions } \\
\hline \multicolumn{2}{|l|}{ Supervision } \\
\hline \multicolumn{2}{|l|}{ Command and control / Escalation to hierarchy } \\
\hline Improvement: & Learning from errors: \\
\hline \multirow[t]{4}{*}{$\begin{array}{l}\text { Embedding improvements by the operation of a } \\
\text { Plan-Do-Check-Act management system }\end{array}$} & $\begin{array}{l}\text { Incident Investigation \& Analysis } \\
\text { (including near miss and potential incidents) }\end{array}$ \\
\hline & Secondary error prevention (reducing recurrence) \\
\hline & Improved understanding of the system \\
\hline & Improved safety climate and culture \\
\hline Characteristics of organizations espousing only EP & $\begin{array}{l}\text { Characteristics of organizations adopting EM as } \\
\text { well as EP }\end{array}$ \\
\hline 'Zero-tolerance' mindset and climate & Culture of no blame / acceptance of errors \\
\hline Blame culture & Open communication about errors \\
\hline Reluctance to report errors & $\begin{array}{l}\text { Ambidexterity } \\
\text { / Collaborative competent improvisation }\end{array}$ \\
\hline Performance improvement limited by above & Long term performance improvement \\
\hline
\end{tabular}

NOTE: This table has been synthesised from the existing literature (Van Dyck et al., 2005; Frese and Keith, 2015; Frese and Zapf, 1994; Goodman et al., 2011; Hofmann and Frese, 2011; Lei, Naveh and Novikov, 2016; Reason, 1990a; Zapf, Prumper and Frese, 1992). 


\section{C) ADDITIONAL FIGURES}

Figure SUP-1 Bow Tie hazard management diagram

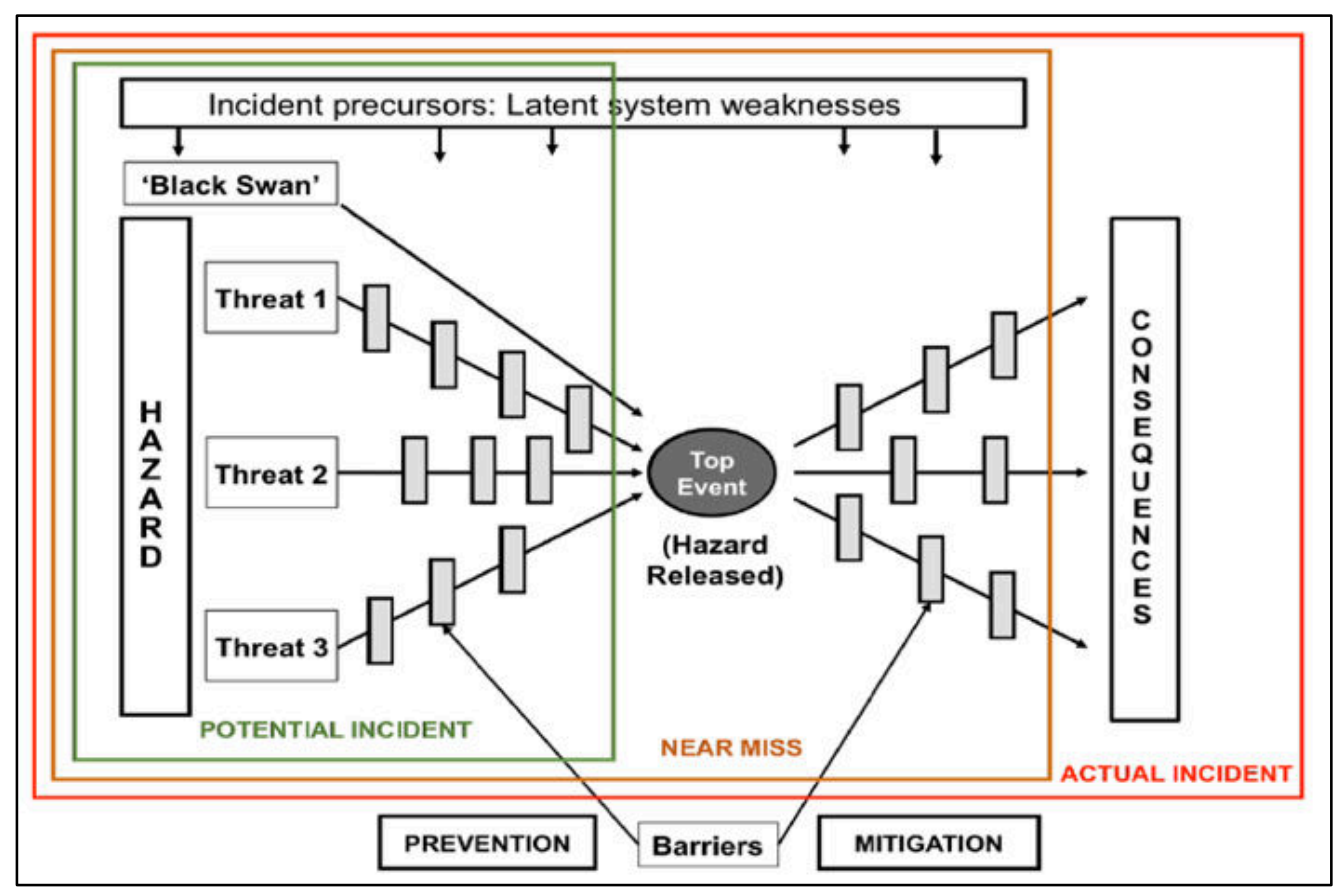


Fig SUP-2 Extract from Reliability Matrix

\begin{tabular}{|c|c|c|c|c|c|c|c|}
\hline REF & & & & 1 & 2 & 3 & 4 \\
\hline & Team DN & Team EC & & WORK PRESSURE & PROCEDURES & COMMUNICATION & COMPLIANCE \\
\hline & & COUNT & & 7 & 13 & 3 & 9 \\
\hline & & & & $\begin{array}{l}1.1 .1 \\
1.10 .4 \\
1.14 .2 \\
1.20 .1 \\
2.4 .4 \\
2.5 .2 \\
2.24 .2\end{array}$ & $\begin{array}{l}1.1 .2^{*} \\
1.3 .2 \\
1.4 .3 \\
1.7 .2 \\
1.11 .3 \\
1.17 .2 \\
1.19 .2 \\
2.1 .3 \\
2.53 \\
2.10 .1 \\
2.16 .3 \\
2.19 .2 \\
2.19 .5\end{array}$ & $\begin{array}{l}1.1 .3 \\
1.3 .1 \\
1.11 .2\end{array}$ & $\begin{array}{l}1.1 .4 \\
1.2 .1 \\
1.5 .2 \\
2.1 .1^{*} \\
2.1 .2 \\
2.4 .3 \\
2.9 .5 \\
2.24 .3 \\
2.26 .1\end{array}$ \\
\hline 1 & WORK PRESSURE & 6 & $\begin{array}{l}1.1 .1 \\
1.10 .4 \\
1.14 .2 \\
1.20 .1 \\
2.4 .4 \\
2.24 .2\end{array}$ & $\begin{array}{l}1.1 .1 \\
1.10 .4 \\
1.14 .2 \\
1.20 .1 \\
2.4 .4 \\
2.24 .2\end{array}$ & & & \\
\hline 2 & PROCEDURES & 11 & $\begin{array}{l}1.3 .2 \\
1.4 .3 \\
1.7 .2 \\
1.11 .3 \\
1.17 .2 \\
1.19 .2 \\
2.1 .1^{*} \\
2.5 .3 \\
2.6 .2 \\
2.10 .1 \\
2.16 .3\end{array}$ & & $\begin{array}{l}1.1 .2 * \\
1.3 .2 \\
1.4 .3 \\
1.7 .2 \\
1.11 .3 \\
1.17 .2 \\
1.19 .2 \\
2.1 .1^{*} \\
2.5 .3 \\
2.10 .1 \\
2.16 .3\end{array}$ & & \\
\hline 3 & COMMUNICATION & 3 & $\begin{array}{l}1.1 .3 \\
1.3 .1 \\
1.11 .2\end{array}$ & & & $\begin{array}{l}1.1 .3 \\
1.3 .1 \\
1.11 .2\end{array}$ & \\
\hline 4 & COMPLIANCE & 10 & $\begin{array}{l}1.1 .2^{*} \\
1.1 .4 \\
1.2 .1 \\
1.5 .2 \\
2.1 .2 \\
2.4 .3 \\
2.9 .5 \\
2.24 .3 \\
2.26 .1 \\
2.26 .2\end{array}$ & & & & $\begin{array}{l}1.1 .2^{*} \\
1.1 .4 \\
1.2 .1 \\
1.5 .2 \\
2.1 .1^{\star} \\
2.1 .2 \\
2.4 .3 \\
2.9 .5 \\
2.24 .3 \\
2.26 .1\end{array}$ \\
\hline
\end{tabular}

The axes of the reliability matrix are formed of the construct categories established separately by each researcher team, together with the reference numbers of the individual constructs the teams allocated to each category. Individual constructs that were categorised differently from the other team are shown in red. The intersecting cells in the matrix, shaded grey, contain the individual constructs allocated by both teams to the same category. Constructs agreed by both teams as fitting into two categories are shown in bold and marked with an asterisk. 
Figure SUP-3 Data Saturation Graph - Repertory Grid

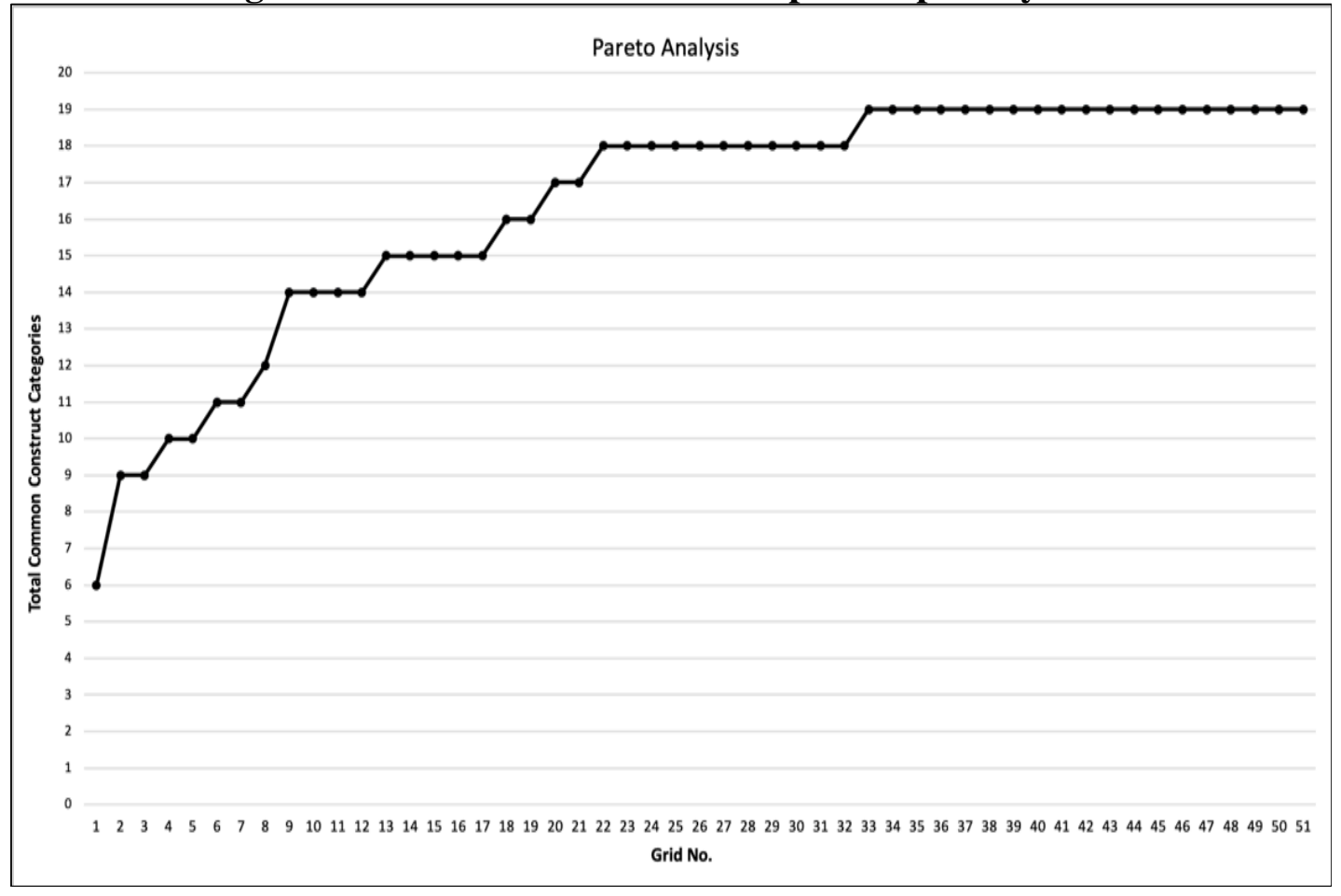

Figure SUP-4 Data Saturation Graph - Semi-Structure Interviews

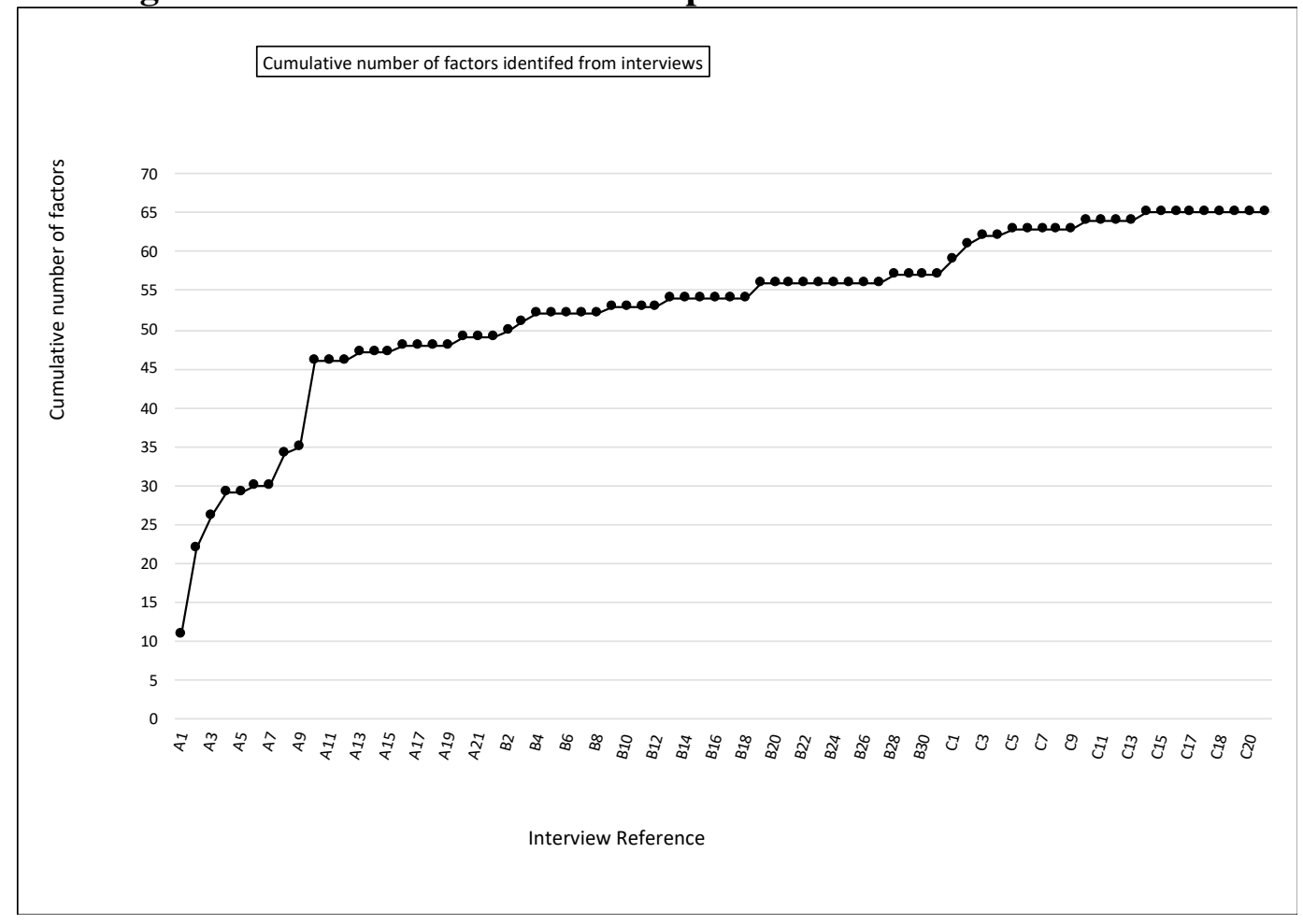


Figure SUP-5 Data Saturation Graph - Incident Documents

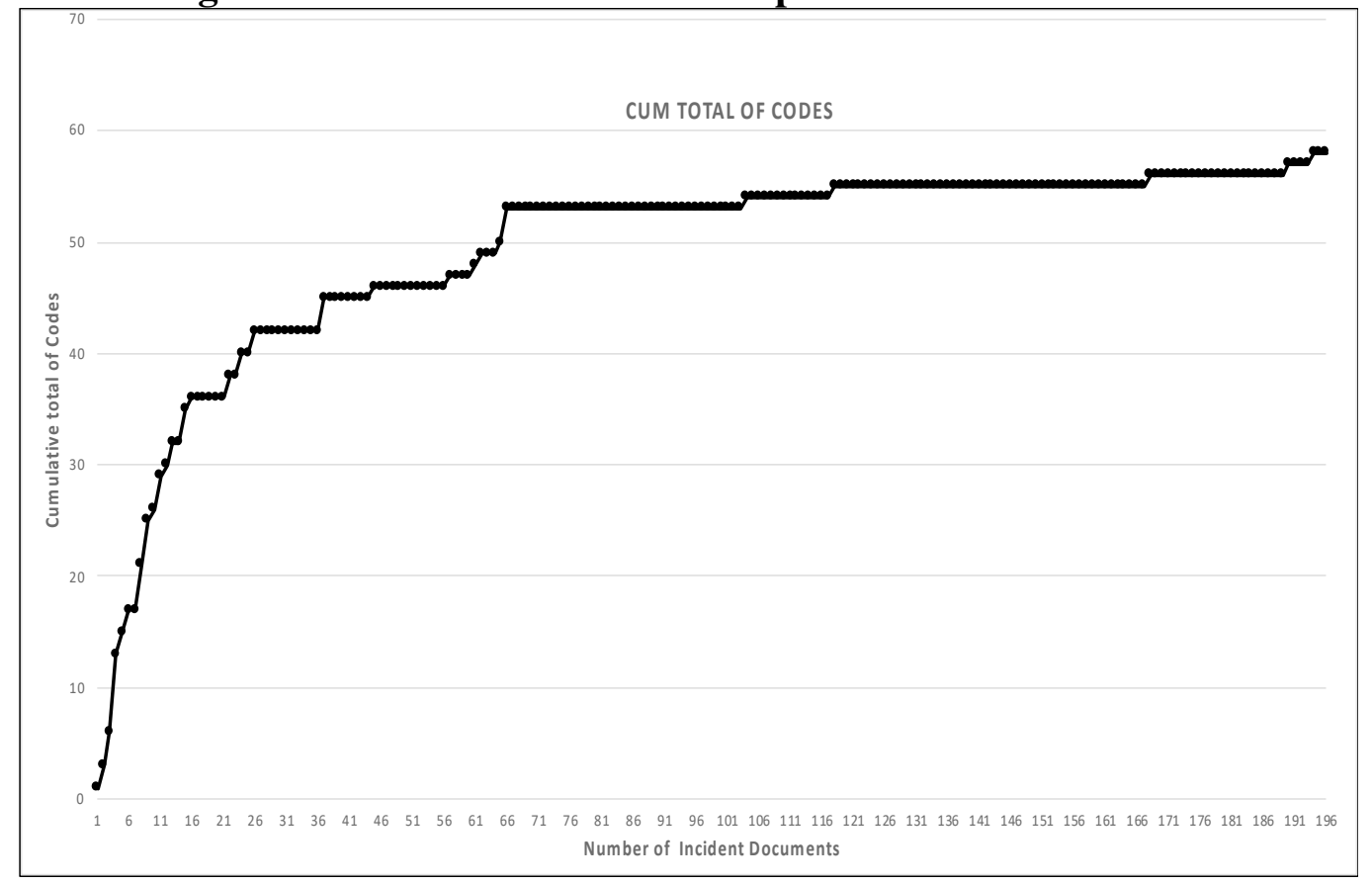

\section{REFERENCES}

CCPS and Energy Institute (2018) Bow Ties in Risk Management. Hoboken, NJ, USA: Wiley. Van Dyck, C., Baer, M., Frese, M. and Sonnentag, S. (2005) 'Organizational error management culture and its impact on performance: A two-study replication', Journal of Applied Psychology, 90(6), pp. 1228-1240.

Frese, M. and Keith, N. (2015) 'Action Errors, Error Management, and Learning in Organizations', Annual Review of Psychology, 66(1), pp. 661-687.

Frese, M. and Zapf, D. (1994) 'Action as the core of work psychology: A German approach', in Triandis, H. C., Dunnette, M. D. and Hough, L. M. (eds.) Handbook of Industrial and Organizational Psychology. Consulting Psychologists Press, pp. 271-340.

Goodman, P.S., Ramanujam, R., Carroll, J.S., Edmondson, A.C., Hofmann, D.A. and Sutcliffe, K.M. (2011) 'Organizational errors: Directions for future research', Research in Organizational Behavior, 31, pp. 151-176.

Hofmann, D.A. and Frese, M. (2011) Errors in Organizations. New York: Routledge/Taylor \& Francis Group.

Hollnagel, E. (2014) Safety-I and Safety-II. Aldershot: Ashgate Publishing Limited.

Hudson, P.T.W. and Hudson, T. (2015) 'Integrating Cultural and Regulatory Factors in the Bowtie: Moving from Hand-Waving to Rigor', in Ibrahamapour, V. and Yacout, S. (eds.)

Ontology Modeling in Physical Asset Integrity Management. Springer, pp. 1-264.

ICI (1979) Hazard Analysis Course Notes - University of Queensland.

Lei, Z., Naveh, E. and Novikov, Z. (2016) 'Errors in Organizations: An Integrative Review via Level of Analysis, Temporal Dynamism, and Priority Lenses', Journal of Management, 42(5), pp. 1315-1343.

Reason, J. (1990a) Human Error. Cambridge: Cambridge University Press. 
Reason, J. (2016) Organizational Accidents Revisited. Farnham: Ashgate Publishing Limited. Reason, J. (1990b) 'The Contribution of Latent Human Failures', Philosophical Transactions of the Royal Society of London, 327, pp. 475-484.

Reason, J.T. (1997) Managing the risks of organizational accidents. Farnham: Ashgate.

Summers, A., Vogtmann, W. and Smolen, S. (2011) 'Improving PHA/LOPA by consistent consequence severity estimation', Journal of Loss Prevention in the Process Industries, 24(6) Elsevier Ltd, pp. 879-885.

Taleb, N.N. (2007) 'Black Swans and the domains of statistics', American Statistician, 61(3), pp. 198-200.

Turner, B.A. and Pidgeon, N.F. (1997) Man-Made Disasters.2nd Editio. Oxford: Butterworth/ Heinemann.

Underwood, P. and Waterson, P. (2014) 'Systems thinking, the Swiss Cheese Model and accident analysis: A comparative systemic analysis of the Grayrigg train derailment using the ATSB, AcciMap and STAMP models', Accident Analysis and Prevention, 68 Elsevier Ltd, pp. 75-94.

Zapf, D., Prumper, J. and Frese, M. (1992) 'Errors in Working with Office Computers: A First Validation of a Taxonomy for Observed Errors in a Field Setting', International Journal of Human-Computer Interaction, 4(4), pp. 311-339. 